


\section{Methodology to simulate the impact of a large deployment of a residential energy management system in the electricity grid}

Submitted to the Faculty of Sciences and Technology of the University of Coimbra in partial fulfillment of the requirements for the degree of Doctor of Philosophy in Sustainable Energy Systems.

\section{Author}

\section{Pedro Carvalho Miguel}

\section{Supervisors}

\section{António Manuel de Oliveira Gomes Martins}

Department of Electrical Engineering and Computers of the Faculty of Sciences and Technology of the University of Coimbra

\section{Luís Miguel Pires Neves}

School of Technology and Management of the Polytechnic Institute of Leiria

Institutional collaboration

$$
\begin{array}{ll}
\text { MIT Portugal } & \begin{array}{l}
\text { Massachusetts Institute } \\
\text { of Technology - Portugal } \\
\text { Program }
\end{array}
\end{array}
$$

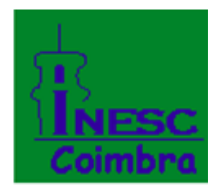

Institute for Systems

Engineering and

Computers of Coimbra

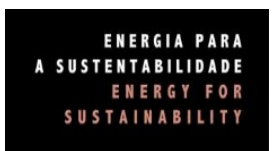

Energy for Sustainability

Initiative of the

University of Coimbra

\section{Funding}

This work has been framed under the Energy for Sustainability Initiative of the University of Coimbra and supported by the Energy and Mobility for Sustainable Regions Project CENTRO-07-0224-FEDER-002004, co-funded by the European Regional Development Fund (ERDF) through the «Programa Operacional Regional do Centro 2007 - 2013 (PORC)», in the framework of the "Sistema de Apoio a Entidades do Sistema Científico e Tecnológico Nacional», and by the "Fundação para a Ciência e Tecnologia». The work was also funded by the "Fundação para a Ciência e Tecnologia» under PEstOE/EEI/UI0308/2014 and under project grant UID/MULTI/00308/2013. 



\section{Abstract}

This work proposes a methodology to evaluate the energy and power resources that can be made available through the deployment and use of a residential energy management system, as the Energy Box (EB) proposed by Livengood \& Larson (2009). The impact on the electricity distribution system of such technology will result of changes in the electricity usage by end-use customers in response to stimuli like real-time changes in the electricity price, corresponding to the widely known demand response (DR). However, due to the dispersed and uncontrolled nature of the management of end-use appliances, estimating the energy and power output of the aggregation of a high number of EB's requires a specific approach which can take into account the random nature of load response.

The approach that was followed simulated a certain universe of consumers from one particular city, using information regarding total electricity consumption as well as the segregated consumption per main appliance. The proposed methodology makes use of queried data regarding the willingness of consumers to postpone the start of appliances, as well as prototypes of hourly price diagrams. These prototypes were obtained through a data clustering exercise that was also proposed as part of the methodology. The possible environmental impact of the aggregated use of EB's was also estimated.

The output of the methodology includes the range of released network capacity as well as load rebound, both caused by the aggregated EB response. In particular, load rebound is a relevant phenomenon that presents new challenges to the management of the grid, and for which some preventive measures are suggested.

The analysis of the environmental significance of the aggregated EB resource shows that $\mathrm{DR}$ is not per se a tool to reduce $\mathrm{CO}_{2}$ emissions, being strongly dependent of the generation technologies that are used to compensate demand variations.

Future work is also proposed including new load research for existing and for new types of loads, as well as for control techniques not considered. This extended view seeks to provide a wider image of the increasing potential of energy management systems such as the Energy Box.

Keywords: Load Simulation, Smart Grid, Demand Response, Energy Box, Household Energy Management, Distribution System Operator. 


\section{Resumo}

Este trabalho propõe uma metodologia para avaliar os recursos de energia e de potência que podem ser disponibilizados através da disseminação e utilização de um sistema de gestão de energia no sector residencial, como a Energy Box (EB) proposta por Livengood \& Larson (2009). O impacto de tal tecnologia sobre o sistema de distribuição de energia elétrica irá resultar de mudanças no uso da eletricidade por utilização final de clientes em resposta a estímulos como mudanças em tempo real no preço da electricidade, correspondendo ao amplamente conhecido conceito de gestão da procura (DR). No entanto, a natureza dispersa e não controlada da gestão destas cargas exige uma abordagem que tenha em conta o caráter aleatório do comportamento desta procura para efetuar uma estimativa agregada do consumo de energia e da potência causados por um elevado número de dispositivos EB.

A abordagem que foi seguida exigiu a simulação de um determinado universo de consumidores de uma determinada cidade, utilizando informações sobre o consumo total de energia eléctrica, bem como o consumo por eletrodoméstico. A metodologia proposta faz uso de dados consultados sobre a disponibilidade dos consumidores para adiar o início da operação dos seus aparelhos, bem como de protótipos horários de diagramas de preços. Esses protótipos foram obtidos através de um exercício de agrupamento de dados que também foi proposto como parte da metodologia. O possível impacto ambiental da utilização agregada das EB também foi estimado.

Os resultados da metodologia fornecem a gama de energia libertada e da potência adicional requerida como resultado agregado das EB, sendo o último um fenómeno relevante que apresenta novos desafios para a gestão da rede, e para o qual foram sugeridas algumas medidas preventivas.

$A$ análise ambiental do recurso EB agregada mostra que a $D R$ não é por si só uma ferramenta para reduzir as emissões de $\mathrm{CO}_{2}$, sendo fortemente dependente das tecnologias de geração que são utilizadas para compensar as variações de procura.

O trabalho futuro sugere investigação para atuais e para novos tipos de cargas, bem como o estudo para as técnicas de controlo não consideradas. Esta visão alargada irá fornecer uma imagem mais ampla do potencial crescente para os sistemas de gestão de energia, como a Energy Box.

Palavras-chave: Simulação de Cargas Elétricas, Rede elétrica inteligente, Gestão da procura, Energy Box, Gestão de Energia no setor residencial, Operador da rede de distribuição. 


\section{Acknowledgments}

It is the fundamental duty of an engineer to be prepared to carry out its work with competence and to contribute to the progress of engineering and to its better application in the service of Mankind ${ }^{1}$.

An engineer that chooses to pursue a PhD knows that the road ahead will be full of obstacles and difficulties. This is the reason why it is so important to recognize that, without the help of so many people it would be impossible to conclude with success such hard to obtain degree.

I specially recognize the indispensable knowledge, the guidance, the advices, the help and the experience of my supervisors, namely, Doctor António Gomes Martins and Doctor Luís Neves. With their help I was not only able to develop this work, but also to improve so many relevant aspects in the way I work.

I am also thankful to Professor João Sousa, from the School of Technology and Management of the Polytechnic Institute of Leiria, for extremely helpful comments and suggestions. I would also like to thank Dr. Júlia Boucinha and Engineer Paulo Pereira from EDP the Portuguese electric utility for providing part of the information that enabled this study going forward and the important feedback that was provided.

I also need to thank all the incredible people that I met in the MIT Portugal Program, with a very special tribute to all members and colleagues of the Energy for Sustainability Initiative of the University of Coimbra and of the Institute for Systems Engineering and Computers at Coimbra. In this part, I need to highlight my longtime friend and colleague, José Gonçalves, the other member of the "Electrical Team", as well as Joana Bastos, Gabriela Oliveira, Nuno Figueiredo, Ana Soares, Marta Lopes Andreia Carreiro and Professor Pedro Moura, all from the University of Coimbra.

Last but not the least, I thank my parents who always believed in me, that always helped me and that continue to help me in every moment of my life.

To all, my deep, grateful and sincere, thank you.

\footnotetext{
${ }^{1}$ In article 86, Chapter 3 of the "Estatuto da Ordem dos Engenheiros", approved by the Portuguese decree law $119 / 92$ of June $30^{\text {th }}$.
} 


\section{Index}

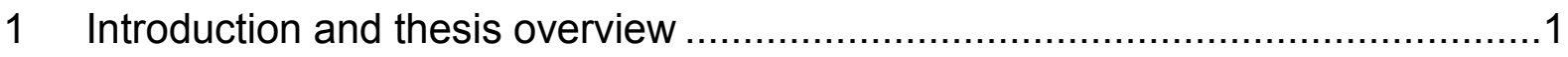

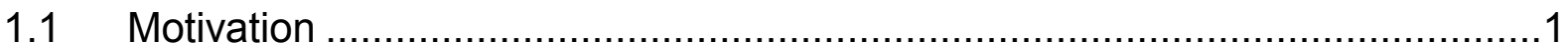

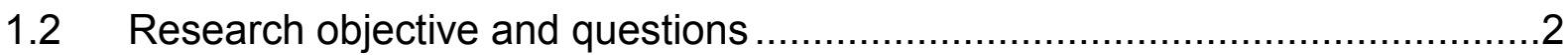

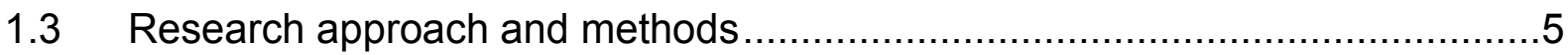

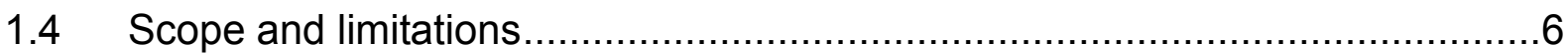

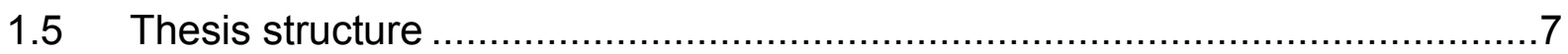

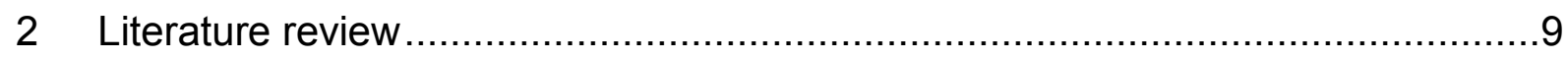

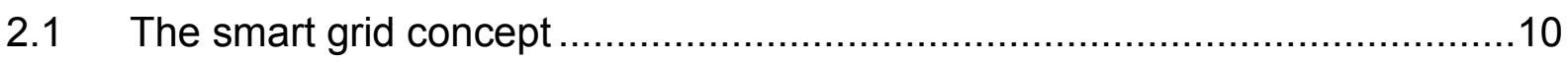

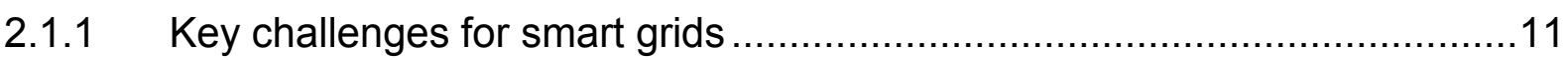

2.1.2 Energy efficiency in the smart grid concept..................................13

2.1.3 Smart grid and market transformation ........................................ 17

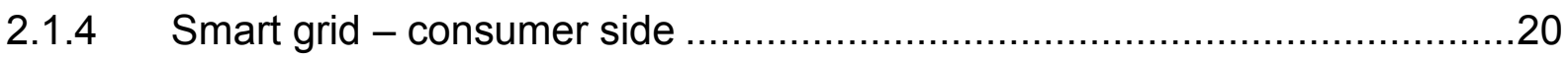

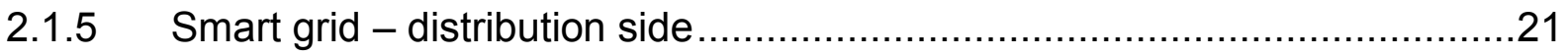

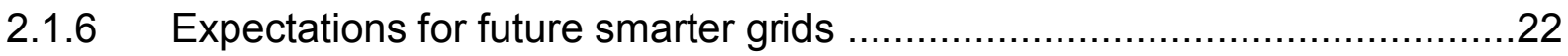

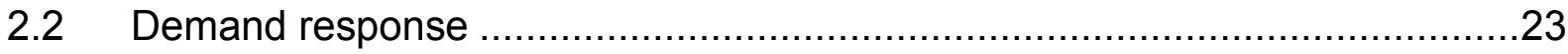

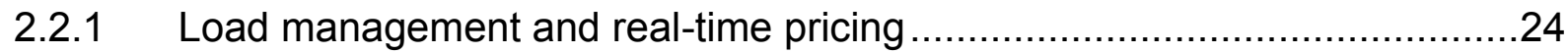

2.2.2 New possibilities in the internet age: REMS ....................................

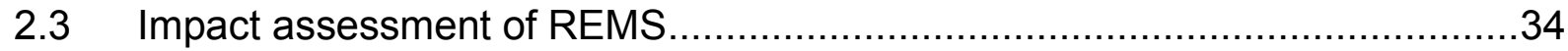

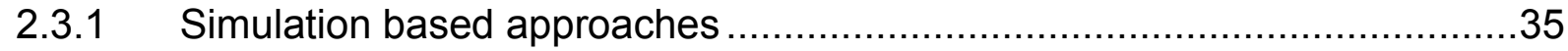

2.3.2 Forecasting based approaches ....................................................41

$2.4 \quad$ The Portuguese power system ............................................................. 43

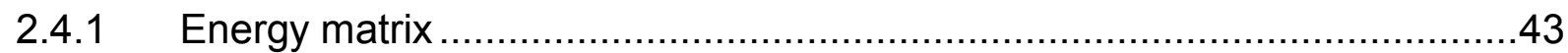

2.4.2 Environmental impact of producing electricity ..................................44

2.4.3 Load research studies in Portugal ...............................................45

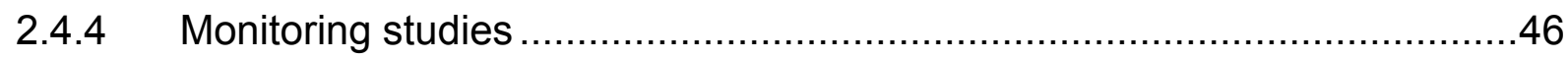


2.4.5 Statistical studies and surveys ……............................................... 48

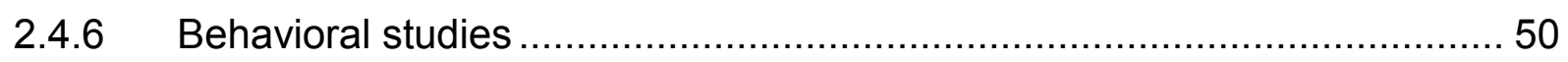

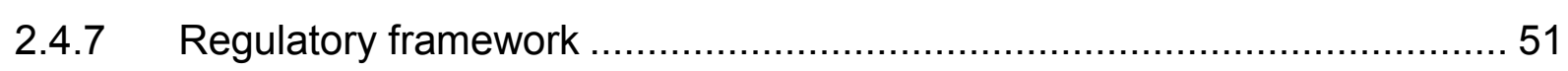

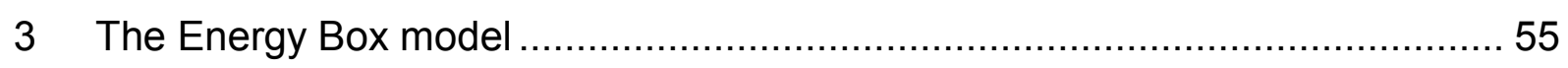

3.1 Estimating the average load diagram of a city …...................................... 55

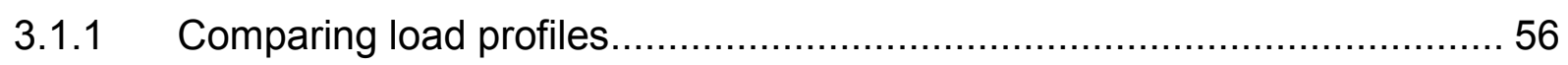

3.1.2 Estimating an average load profile for Demand Response simulation .......60 60

3.2 Simulating the household energy usage in the city of Coimbra...................... 64

3.3 Selecting appliances for DR actions - Possible control over S\&I loads .......... 65

3.4 Simulating schedulable \& interruptible (S\&I) loads ..................................... 72

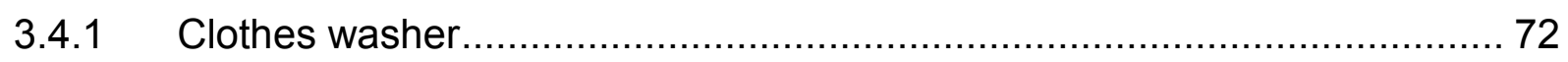

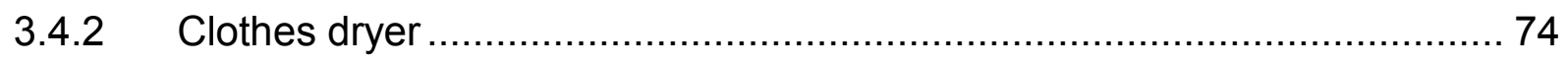

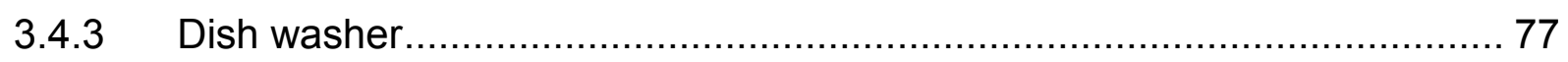

3.5 Simulation scenarios for the smart grid .................................................... 78

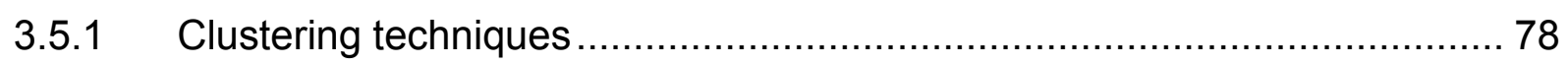

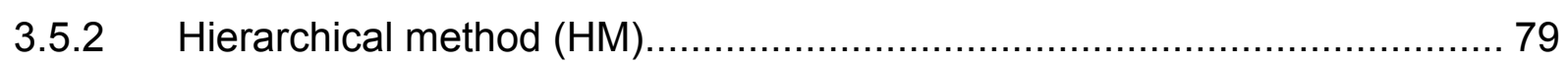

3.5.3 Artificial neural networks (ANN) method .............................................. 81

3.6 Methodology to simulate demand response actions ................................... 84

3.7 Methodology to assess the environmental impact of demand response ........ 87

3.7.1 Assessing the environmental impact of demand response ....................... 88

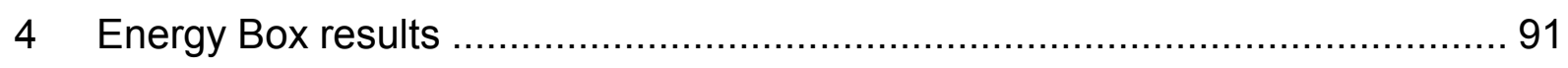

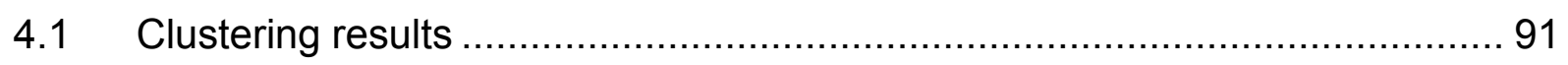

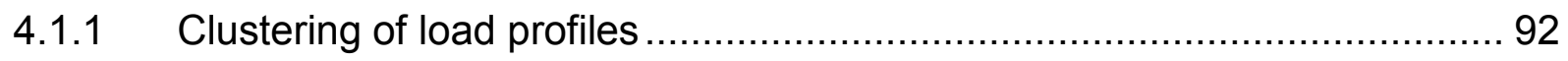

4.1.2 Clustering of gross market price profiles ............................................. 95

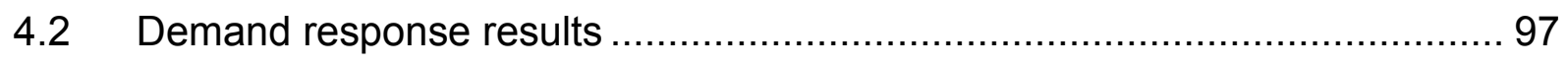

4.2.1 Simulation based on the average 2012 day prices .................................. 98 
4.2.2 Simulation based on price clusters - $20 \%$ deployment of the Energy Box 100

4.2.3 Simulation based on price clusters - comparing deployments................105

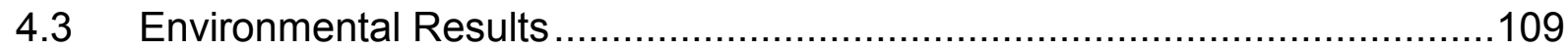

4.3.1 Reference of the environmental impact of Demand Response ...............109

4.3.2 Case 1 - Using gas as the target for actions of the Energy Box ..............110

4.3.3 Case 2 - Using coal and gas as the target of the Energy Box actions.......112

4.3.4 Case 3 - Using hydro-dam as the target of the Energy Box actions ..........114

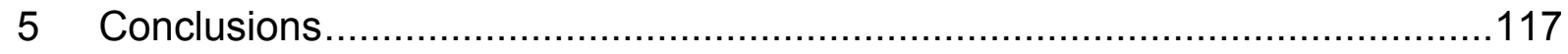

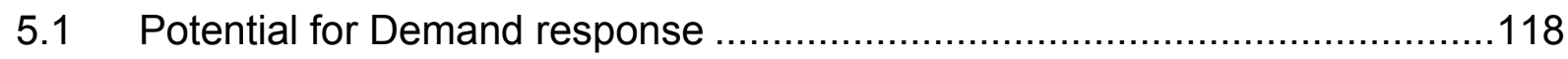

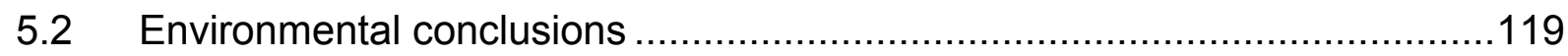

5.3 Analysis of the electricity price profiles obtained through clustering ............120

5.4 Advantages and disadvantages of the developed methodology ................121

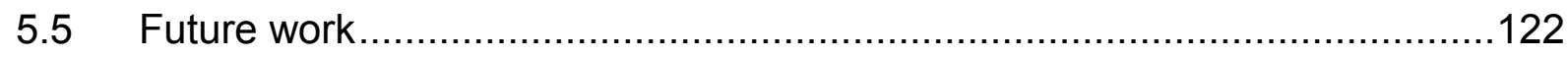

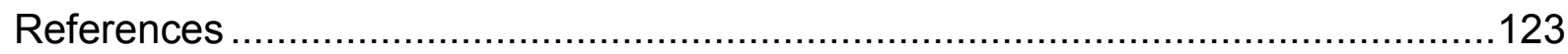




\section{Figure Index}

Figure 1 - Technical Potential for $\mathrm{CO}_{2}$ reductions in the US Electric Sector (EPRI, 2008).

Figure 2 - Smart grid goals concerning energy savings and reducing carbon (EPRI, 2008).

Figure 3 - Load control strategies (Gellings \& Chamberlin, 1993) .25

Figure 4 - Load shape objectives (Kostková, Omelina, Kyčina, \& Jamrich, 2013) ....26

Figure 5 - Categorization of load management approaches (Kostková, Omelina, Kyčina, \& Jamrich, 2013).

Figure 6 - Categorization of communication technologies (Kostková, Omelina,

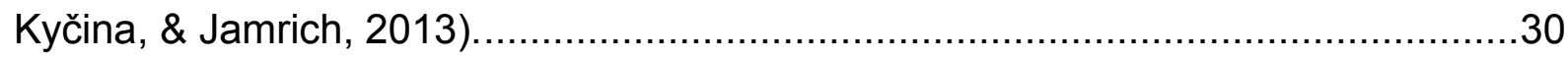

Figure 7 - Energy Box Illustration. .32

Figure 8 - Evolution of the contribution of each generation technology to the Portuguese demand during an average day of 2013. .44

Figure 9 - Greenhouse gas emissions, base year 1990 (Eurostat, 2014). 45

Figure 10 - Contribution to the household energy usage understanding. .46

Figure 11 - Fitting operation flowchart for the profile comparison. .56

Figure 12 - Methodology for obtaining daily average load diagrams segregated per end-use for a city or a region. 56

Figure 13 - Comparison between type C average ERSE and REN profiles. .58

Figure 14 - Comparison between type C average ERSE for 2012 and the EEESECR2004 original profiles. .59

Figure 15 - Comparison between type C average ERSE for 2012 and the EEESECR2004 updated profiles. .59

Figure 16 - Comparison between type C average ERSE for 2012 and the REMODECE2008 profiles. 60 
Figure 17 - Estimation of the distribution of electrical energy for the average day for the city of Coimbra with loads represented by decreasing regularity of the standard deviation (Miguel P. , Neves, Martins, \& Sousa, 2013)....................................... 61

Figure 18 - Methodology to determine the Energy Box value in 5 stages................ 63

Figure 19 - Energy Box operating conditions, based on (Livengood \& Larson, 2009).

Figure 20 - Developed Methodology for determining the value of the Energy Box (redefined).

Figure 21 - Clothes Washer: Acceptance of Smart Operation, based on Smart-A (Mert, 2008). 68

Figure 22 - Clothes Dryer: Acceptance of Smart Operation, based on Smart-A (Mert, 2008).

Figure 23 - Dish Washer: Acceptance of Smart Operation, based on Smart-A (Mert, 2008). 69

Figure 24 -Scenario 1 consumer tolerance for postponing start based on (Mert, 2008). .70

Figure 25 - Scenario 2 - Smart - A probabilities without the possibility of postponing $24 \mathrm{~h}$. 70

Figure 26 - Scenario 3, Adapted probabilities from (Jamasb \& Pollitt, 2011). .71

Figure 27 - Willingness to postpone start [\%] for the considered appliances. 71

Figure 28 - General Pattern of a Power Demand Curve of a clothes washing machine cycle in 1/4 hour steps (Stamminger, 2008). 72

Figure 29 - Probability of energy consumption and number of cycles for the average day for clothes washing in the City of Coimbra (Miguel, Neves, \& Martins, 2014)... 73 Figure 30 -Simulating the average consumption of clothes washing at Coimbra in Matlab (Miguel, Neves, \& Martins, 2014). 74

Figure 31 - General Pattern of a Power Demand Curve of a clothes dryer cycle in 1/4 hour steps (Stamminger, 2008). 75 
Figure 32 - Probability of energy consumption and number of cycles for the average day for clothes drying in the City of Coimbra (Miguel, Neves, \& Martins, 2014)........76

Figure 33 - Simulating the average consumption of clothes drying at Coimbra in Matlab (Miguel, Neves, \& Martins, 2014)...

Figure 34 - General Pattern of a Power Demand Curve of a dish washer cycle in 1/4 hour steps (Stamminger, 2008).

Figure 35 - Probability of energy consumption and number of cycles for the average day for dish washing in the City of Coimbra (Miguel, Neves, \& Martins, 2014). .77

Figure 36 - Simulating the average consumption of dish washing at Coimbra in Matlab (Miguel, Neves, \& Martins, 2014). .78

Figure 37 - Methodology for profile cluster prototypes of price, residential electricity consumption and renewable generation.

Figure 38 - Structure of the developed simulation routine. .86

Figure 39 -Average load diagram of the city of Coimbra, with the quarter-hour contribution of each energy source. .89

Figure 40 - Method for assessing the energy transfer and $\mathrm{CO}_{2}$ changes due to demand response actions. . .90

Figure 41 - Relation between the number of clusters and the distance between centers of clusters for the normalized LV load demand in 2012-2013. .91

Figure 42 - HM 2012-2013 cluster prototypes for the residential load profiles. .93

Figure 43 - ANN method 2012-2013 cluster prototypes for the residential load profiles. .94

Figure 44 - Clustering evaluation of household load demand for the 2012-2013 cluster profiles.

Figure 45 - Range of variation of household load demand for the 2012-2013 cluster profiles (around the average profile). .95

Figure 46 - Clustering price prototypes for the HM and the ANN method, for the 2008 year. .95 
Figure 47 - Clustering price prototypes for the HM and the ANN method, for the 2012 year.

Figure 48 - Prototypes price range variation, for the year of 2008. 96

Figure 49 - Prototypes price range variation, from October 2012 to September 2013.

Figure 50 - City of Coimbra, simulation results for $20 \%$ deployment of the Energy Box (100 runs). 98

Figure 51 - Range of the power delivery and rebound for a $20 \%$ deployment of the Energy Box in the city of Coimbra. 99

Figure 52 - Range of rebound and power delivery for all simulations concerning a $20 \%$ deployment, for scenario 1. 101

Figure 53 - Range of rebound and power delivery for all simulations concerning a $20 \%$ deployment, for scenario 2 . 102

Figure 54 - Range of rebound and power delivery for all simulations concerning a $20 \%$ deployment, for scenario 3 . 102

Figure 55 - Min and Max of all simulations concerning the deployment of the Energy Box, for a $20 \%$ deployment. 103

Figure 56 - Max. rebound and power delivery for all simulations concerning a $20 \%$ deployment. 103

Figure 57 - Range of rebound and power delivery for scenario 1 simulations (100 runs each). 106

Figure 58 - Range of rebound and power delivery for scenario 2 simulations (100 runs each). 106

Figure 59 - Range of rebound and power delivery for scenario 3 simulations (100 runs each). 107

Figure 60 - Number of hits for actions of DR for Scenario 1, for all deployments. .. 108 Figure 61 - Number of hits for actions of DR for Scenario 2, for all deployments. .. 108 Figure 62 - Number of hits for actions of DR for Scenario 3, for all deployments. .. 109 


\section{Table Index}

Table 1 - Strategies for Balancing Electricity Supply and Demand (Livengood D. J., 2011).

Table 2 - Comparison between the current grid and a smart grid ( Prabhudesai , Hazare, Patil , Parab , \& Tawade, 2011).

Table 3 - Key challenges for smart grids (European Union Advisory Council, 2010).12

Table 4 - Smart grid energy savings and avoided $\mathrm{CO}_{2}$ emissions summary in the US Electric Grid (EPRI, 2008).

Table 5 - Potential annual reductions in electricity and $\mathrm{CO}_{2}$ Emissions in 2030 attributable to the use of smart grid technologies in the electricity power grid (PNNL, 2010). 15

Table 6 - Classification of DR Programs (Albadi \& El-Saadany, 2008).

Table 7 - Review of studies regarding electrical energy usage/influence for the Portuguese household sector.

Table 8 - Comparison between end-use weights in the average consumption of reference studies. .57

Table 9 - Summary table of the differences between profiles. 60

Table 10 - Type of load by possibility of control (Miguel P. , Neves, Martins, \& Sousa, Review of load research studies applied to the Portuguese household sector, 2013).

Table 11 - Electric domestic consumption in the City of Coimbra for the year of 2010 (Miguel, Neves, \& Martins, 2014).

Table 12 - Description of the initial idea for the developed methodology and status.

Table 13 - Advantages and disadvantages for different operation modes in appliances, based on Smart-A project (Mert, 2008). .66

Table 14 - Appliances information from (Jamasb \& Pollitt, 2011). 70

Table 15 - Data regarding the penetration of the clothes washer in the city of Coimbra (INE, I.P. \& DGEG, 2011) and (PORDATA, 2013). 
Table 16 - Descriptive Statistics for the clothes washer.

Table 17 - Data regarding the penetration of the clothes dryer in the city of Coimbra.

Table 18 - Descriptive Statistics for the clothes dryer (Miguel, Neves, \& Martins, 2014). 76

Table 19 - Data regarding the penetration of the dish washers in the city of Coimbra (INE, I.P. \& DGEG, 2011) and (PORDATA, 2013).

Table 20 - Descriptive Statistics for the dish washer (Miguel, Neves, \& Martins, 2014).

Table 21 - Data allocation for 2008 electricity prices using the hierarchical method.92 Table 22 - Data allocation for 2008 electricity prices using the artificial neural networks method.

Table 23 - Data allocation for 2012-2013 LV load demand performed in the hierarchical method.

Table 24 - Data allocation for 2012-2013 LV load demand performed in the artificial neural networks method. 93

Table 25 - Generation of electricity in Portugal.

Table 26 - Energy average day simulation results in MWh for the household sector in the City of Coimbra. 98

Table 27 - Maximum and minimum power verified in the load diagrams at a certain time. 100

Table 28 - Energy day simulation results in MWh for the household sector in the City, for a $20 \%$ deployment of the Energy Box. 100

Table 29 - Demand Response actions verified for simulations of a $20 \%$ deployment of the Energy Box. 104

Table 30 - Estimation of the contribution of each electricity generation technology for the average day of the city of Coimbra in the original simulated scenario (without DR) in [GJ/day]. 109 
Table $31-\mathrm{CO}_{2}$ emissions for the original simulated scenario.

Table 32 - Statistical results of energy supply contributions for simulations of Demand Response for the city of Coimbra with gas generation technology used to compensate power demand fluctuations.

Table 33 - Statistical results of equivalent $\mathrm{CO}_{2}$ emissions for simulations of Demand Response actions for the city of Coimbra, using gas generation technology to compensate power demand fluctuations

Table 34 - Case 1, generation technology shares, in \%.

Table 35 - Statistical results of energy supply contributions of Demand Response for the city of Coimbra, with coal and gas generation technologies used to compensate power demand fluctuations.

Table 36 - Statistical results of equivalent $\mathrm{CO}_{2}$ emissions simulations of Demand Response actions for the city of Coimbra, with coal and gas generation technologies used to compensate power demand fluctuations.

Table 37 - Case 2, generation technology shares, in \%.

Table 38 - Statistical results of energy supply contributions for simulations of Demand Response for the city of Coimbra, with hydro-dam generation technology used to compensate power demand fluctuations.

Table 39 - Statistical results of equivalent $\mathrm{CO}_{2}$ emissions of Demand Response actions for the city of Coimbra, with hydro-dam generation technology used to compensate power demand fluctuations 115

Table 40 - Case 3, generation technology shares, in $\%$. 115 


\section{Glossary of frequently used acronyms}

AMR - Automated Meter Reading

ANN - Artificial Neural Networks

AV - average variation

CCGT - Combined Cycle Gas Turbine

$\mathrm{CO}_{2}$ - carbon dioxide

CPP - Critical Peak Pricing

DG - distributed generation

DR - Demand Response

DSM - Demand Side Management

DSO - Distribution System Operator

EB - Energy Box

EC - European Commission

EDP - the Portuguese electric utility

ERSE - Portuguese regulator of energy services

ESCO - Energy Service Company

ESD - Energy Services Directive

EU - European Union

GHG - greenhouse gas emissions

HM - Hierarchical method

HTML - hypertext markup language

HV - high voltage

HVAC - heating, ventilation and air conditioning

IBP - Incentive Based Programs

ICT - information and communication technologies

LM - Load Management 
LV - Low Voltage

$M \& V$ - measurement and verification

MAPE - mean absolute percentage error

MIBEL - The Iberian Energy Derivatives Market Exchange

MNHV - maximum negative hourly variation

MPHV - maximum positive hourly variation

PBP - Price Based Programs

PHEV - plug-in hybrid electric vehicles

$\mathrm{RE}$ - renewable energies

REMS - Residential Energy Management Systems

REN - Portuguese Transmission System Operator

RMSE - root mean square error

$\mathrm{RRC}$ - regulation of commercial relations

RTP - Real-time pricing

SRP - Special Regime Producers

T\&D - transmission and distribution

TOU - Time of Use

TSO - Transmission System Operator

USA - United States of America 


\section{Introduction and thesis overview}

\subsection{Motivation}

Operation and planning of electrical power systems, especially at the distribution level, are influenced by a set of conditions which can be divided in two main categories: naturally occurring and those dependent on the applicable regulatory framework.

Natural occurring issues are related with the growth of demand and extreme climatic changes, while regulatory/framework issues are associated with the trend of power markets, the change in the concept of electricity as a commodity, the increasing environmental constraints and the integration of new energy sources, energy storage systems and disperse generation (Figueiredo, Rodrigues, \& Vale, 2005).

In this context, the management of electricity consumption is an important tool to balance demand and supply. Instead of strongly investing in new network infrastructures and installing more generators to operate during peak demand periods, with low load factors (Borenstein, Jaske, \& Rosenfeld, 2002) (Wilson, Rassenti, \& Smith, 2003) (Guo, Zeman, \& Li, 2009), it is possible to manage energy use in households, through the so called Demand Response (DR $)^{2}$ strategies (Albadi \& El-Saadany, 2008) (Livengood \& Larson, 2009).

In the smart grid context, new devices have been proposed to modernize Electrical Power Systems, combining features of smart metering with Residential Energy Management Systems (REMS). According to Roe, Meliopoulos, Entriken, \& Chhaya (2011) REMS is a combination of hardware and software that conducts monitoring, planning and control functions of energy uses within a home. However, having such a resource requires an investment by the Distribution System

\footnotetext{
${ }^{2}$ Demand Response (DR) - is a term used for programs designed to encourage end-users to make short-term reductions in energy demand in response to a price signal from the electricity hourly market, or to a trigger initiated by the electricity grid operator due to some operational problem (Albadi \& El-Saadany, 2008) (Renner, et al., 2011).
} 
Operator (DSO), the utility company and/or by the energy consumer. Therefore, an analysis of the consequences of a large scale application of REMS in households is fundamental to give a broader view of the resource potential for consumers, for utility companies and for the Distribution System Operator (DSO).

The overall purpose of this research consists of analyzing the impact of a large scale deployment of residential energy management systems in the Portuguese electricity grid, namely the Energy Box ${ }^{3}$ (Livengood \& Larson, 2009). This will be an original perspective to analyze REMS because it must consider the uncertainty associated to consumer and utility adoption as well as the randomness of loads use. Although DR and REMS are being actively studied and developed, to the best of the author's knowledge, there is no known methodology to evaluate the energy and power resources that can be released by the deployment of Energy Boxes, in order to justify the possible investment in this technology. Based on, consumer preferences, information related to which loads can be controlled and other constraints related to the load control, it is possible to simulate scenarios for estimating the network impact of the large deployment of the Energy Box. Such impact was determined under different conditions, e.g., penetration, resource use and significance, type of consumers, and electricity price.

The development of this work intends to provide new information, offering the DSO a methodology to assess the advantages and disadvantages of a wide use of the Energy Box.

\subsection{Research objective and questions}

In order to increase security of energy supply and to reduce greenhouse gas emissions (GHG), Europe made a strong effort to integrate renewable energies $(\mathrm{RE})$ in the electricity grid. Several reasons could be pointed out for the European Commission and European Countries to define concrete objectives for the expansion and integration of RE in the electricity grid, namely, the necessity of having a diversified energy mix, RE potential and several technological breakthroughs (European Parliament and European Council, 2009).

\footnotetext{
3 INESC-C R\&D Project in http://www.uc.pt/en/org/inescc
} 
Of the available renewable energy sources, the most likely to be used at a larger scale are solar and wind, both of which are non-dispatchable, irregular and difficult to forecast. Using current tools to manage load and supply fluctuations, it is possible to deal with the variability of renewable energy sources at low levels of implementation. However, an increase in penetration of RE of $10-30 \%$ of the power supply capacity requires new resources to make the fluctuating supply match the also fluctuating load (Kempton \& Tomic, 2005).

Another reason for the study of new tools to balance supply and demand is that transmission networks in Europe, due to new market mechanisms, are becoming a platform to increasing energy flows (UCTE, 2007) (Zeilinger, 2011).

In addition to this burden, technological advances require more energy to supply new appliances. Thus, the gap between electrical supply and demand is increasing in many countries (D.O.E, March 2002) (Guo, Li, \& James, 2005).

Conventional approaches to solve the above referred problems are based on the expansion of the supply-side resources, even to serve only as idle backup power. These are usually high-investment solutions which are expected to operate for a very small fraction of time. An alternative approach is then to manage the energy consumption, in order to compensate fluctuations, avoiding the need of new, most of the times stranded, supply capacity (Borenstein, Jaske, \& Rosenfeld, 2002) (Wilson, Rassenti, \& Smith, 2003) (Guo, Zeman, \& Li, 2009).

Managing the consumption instead of controlling the energy production allows relieving the transmission systems and helps the implementation of decentralized structures with small and autonomous energy systems. The opportunities of loadside control interventions in households through Demand Response will therefore be discussed further in this work.

The overall purpose of this research consisted in determining the range of values of energy and power that result from a large integration in the Portuguese electricity grid of residential energy management systems or REMS, namely the Energy Box (Livengood \& Larson, 2009). The present study considered the use of the Energy Box, as a permanent managing equipment for the electrical energy resources (loads) of Portuguese households. 
According to Livengood \& Larson (2009) the Energy Box is operated best in an environment of demand-sensitive real-time pricing. The automatic decision capacity of the Energy Box will enable minute-by-minute decisions over the course of the day. The possibility to act on the load diagram is also an advantage and an old ambition, performing peak clipping, valley filling and load shifting, thereby reducing the need for capacity expansion in electrical power generation and distribution. The Energy Box can also manage on-site energy generation, storage and sale of electricity back to the grid. The use of the Energy Box should result in reduced electrical energy costs to the electric energy consumer.

It is therefore relevant in a smart grid context to evaluate the Energy Box resource as a way to determine the degree of motivation of the DSO to encourage or stimulate its installation. An innovative perspective could be brought to REMS usage by a analyzing the set of resources available in households, combining consumer preferences and restrictions related to load control and simulating different scenarios to analyze the Energy Box resource according, e.g., to the resource deployment status and the availability of consumers.

The developed methodology was implemented and validated using data on global electrical energy consumption of Portuguese households, data which is available from national and European household characterization campaigns and also information provided by EDP, the main Portuguese electric utility.

Research questions were formulated as a consequence of the previous assumptions and reflexions, as follows:

- What potential for demand flexibility is available in a defined household area?

- What is the reasonable expected potential of REMS?

- What are the consequences of a wide integration of the Energy Box in Portuguese households for the DSO management operations?

- Are the results expected to be attractive enough for the DSO to demand/suggest the deployment of this type of equipment or stimulate its use? 


\subsection{Research approach and methods}

The initial task consisted of identifying and characterizing the energy usage in households, by gathering and analyzing existent information from surveys and campaigns. This initial research provided fundamental information on the composition of typical electrical equipment, the ownership rate of appliances, types of loads and the use of controllable resources. Such information, combined with existent load profiles, allowed estimating, at a city scale, the daily usage pattern of the different energy services.

For identifying whose load patterns consumers would more easily accept to change, it was necessary to deal with the identification of possible DR actions to be applied in the Portuguese household sector. In a Real-time pricing (RTP) framework these strategies are used to reshape the load diagram, according to the specificity and possibility of each resource: which operations may be shifted to other time periods, loads whose operation may be programmed by the user, loads that can be interrupted a certain number of times and non-controllable loads (Soares, 2011). In order to develop load control strategies aiming at modifying load diagrams, it was useful to choose DR strategies and actions (Albadi \& ElSaadany, 2008) (Chardon, Almén, Lewis, Stromback, \& Château, 2008) (Stromback, Dromacque, \& Yassin, 2011) (Mert, 2008) (Lopes, Peixoto, Antunes, \& Martins, 2014) that match the purpose of this research, regarding the use of an enabling technology such as the EB (Livengood D. J., 2011), while attempting to balance Demand and Supply, as shown in Table 1 .

\begin{tabular}{llll}
\hline & Peak management & Days, Hours and Minutes & Seconds \\
\hline Demand $\rightarrow$ Supply & Direct load control; & Time-varying, demand- & FAPERs; \\
& $\begin{array}{l}\text { Energy efficiency programs; } \\
\text { Load dispatch (e.g. } \\
\text { sensitive pricing. }\end{array}$ & Grid-friendly Appliances ${ }^{\mathrm{TM} .}$ \\
& EnerNOC). & & \\
\hline Supply $\rightarrow$ Demand & Build new power plants & & $\begin{array}{l}\text { Automatic Generation } \\
\text { Control (AGC) }\end{array}$ \\
\hline
\end{tabular}

Table 1 - Strategies for Balancing Electricity Supply and Demand (Livengood D. J., 2011).

The research work that was conducted identified two main inputs for evaluating DR actions, namely, the willingness of consumers to accept the EB operation and the energy price. The types of loads selected for the simulation were the clothes washer, the clothes dryer and the dish washer. All the selected loads are schedulable and interruptible. 
The information gathered allowed the development of a simulation tool running on the Matlab software. This tool allows performing simulations that enable the evaluation of the impact, at the grid level, of postponing the starting time of appliances, using the case-study of the city of Coimbra, in Portugal. To better understand such impact, it was decided to develop figures that exhibit the range of the power relief and rebound for the different deployment shares of the EB, per scenario (framework) and deployment share ranging from $20 \%$ to $100 \%$.

A data clustering analysis of electricity prices was also carried out. The purpose of this task consisted in identifying and studying possible typical daily price patterns from the Iberian Energy Derivatives Exchange database (OMIP, 2013). The identification of the relations between the established clusters of price with, e.g., season of the year and type of day (weekday, weekend), was attempted. The data clustering exercise was also expanded to assess the range of variation of the average residential load demand profile, making use of data provided by EDP.

Additionally, a methodology that uses several demand response scenarios is also presented, for different penetration levels of advanced smart meters combined with time series data of the electricity generation system. Several consequences are assessed, such as changes on the hourly contribution of each generation technology to balance demand, as well as the corresponding changes of $\mathrm{CO}_{2}$ emissions, for an average day.

\subsection{Scope and limitations}

The model that was developed to simulate an aggregate of Energy Boxes and its impact, critically assesses the electrical deployment and the environmental outcome for the selected simulation framework that will be further described in section 3.6.

The present subsection intends to present the reader with the scope of the work that was developed and with its limitations.

Scope:

- Determine the range of energy and power resources made available by the deployment of the EB; 
- Determine a set of household load demand profiles and its variation range;

- Determine price profiles for electrical energy and its variation range;

- Determine the environmental impact of DR due to EB actions.

Limitations (what the tool does not account for):

- The EB impact due to actions on other loads is not accounted, e.g., electric vehicles, water heaters, among others;

- There is no feature allowing the interruption of operation due to some sort of emergency signal;

- The possibility to evaluate/simulate the EB range of values of energy and power for each of the established day clusters. This limitation was due to the lack of information on how appliances are used outside the average day.

\subsection{Thesis structure}

This thesis is organized in five chapters, each one describing the different stages of the work. In this first chapter the motivation and the work environment are described, as well as the objectives and the proposed methodological approach.

The remaining chapters are organized as follows:

- Chapter 2 discusses three major topics, namely, the smart grid concept, demand response and the Portuguese power system. The first topic deals with literature on smart grids, e.g., key aspects on smart grids, key challenges, the possible role that smart grids may have on improving the efficiency of energy use, the perspective of such infrastructure from the consumer side and from the distribution side. The second topic, demand response, addresses the perspective of load management and real time pricing, concluding with a brief review on methodologies to assess its impacts on the management of the grid. The third section focuses on the specific characterization of the Portuguese power system framework. This particular context is justified by the fact that a specific Portuguese city is used in the thesis as a case-study. A brief description of European commitments related to greenhouse gas emissions is provided and the 
current national status of such commitments is also illustrated, allowing the establishment of a connection between demand response actions in the future and the evaluation of possible carbon dioxide emission changes. A review concerning the current state of the art of Portuguese studies is also provided, focusing on load research, monitoring, statistics and surveys, and behavior, on the residential sector. Finally, the regulatory framework is presented, specifically referring the definition and use of standard load profiles.

- Chapter 3 presents the methodologies that were developed to assess possible impacts of a large scale deployment of the Energy Box. Initially, it was demonstrated how an hourly based average diagram depicting household consumption was put together. Such data allowed the development of a scenario oriented computer simulation tool based on previously selected appliances and DR actions that used data clustering techniques. Finally, a methodology to assess the environmental impact of demand response is presented.

- Chapter 4 presents the results of the simulation exercises, focusing on all three essential aspects: clustering, demand response and environmental impact.

- Chapter 5 presents the main conclusions of the thesis and suggestions for future work to be developed. 


\section{Literature review}

The electricity grid is one of the most significant technological achievements of the twentieth century and is considered by many the most complex system ever built. This remarkable infrastructure carries electricity, which flows at the speed of light in order to enable services now considered essential for living (EPRI, 2008). Since electricity can't be stored, there is a need to continuously balance supply and demand throughout the day in real time.

Over the years, utilities have made various cost-effective improvements to the generation and dispatch of electricity to maintain reasonably reliable and affordable service to evolving electricity demands. Yet, today's grid still largely resembles the fundamental structure of its early days, with central generating stations and electromechanical power delivery systems operated from control centers.

Today, utility companies must also address new societal and regulatory obligations - mitigating emissions of greenhouse gases, especially carbon dioxide $\left(\mathrm{CO}_{2}\right)$ in their energy generating facilities, combining these traditional energy generation processes with dispersed generation, renewable energies and energy efficiency measures/requirements.

Renewable energy sources and energy efficiency related measures, e.g. demand response, must be integrated both into the network and in the market. Often the solution to the integration strategies has to take into account mutual influence, eventual mutual exclusions and eventual complementarity between the components. In short, presently the debate mixes power and market issues, frequently requiring a precise clarification of concepts and the identification of scopes (Bundesnetzagentur, 2011).

The future of both the electricity grid and the market needs the coordinated actions of competing players - producers, suppliers, customers, prosumers (consumers that also produce and/or commercialize and/or store energy) and energy service providers (IEA, 2011). Therefore, the path to the future of energy infrastructures must have more room for innovation (Bundesnetzagentur, 2011). 


\subsection{The smart grid concept}

A Smart grid employs innovative products and services together with intelligent monitoring, control, communication, and self-healing technologies to better facilitate the connection and operation of generators of all sizes and technologies, allow consumers to play a part in optimizing the operation of the system, provide consumers with greater information and choice of supply, significantly reduce the environmental impact of the whole electricity supply system and deliver enhanced levels of reliability and security of supply.

EPRI (2006) presented the concept of smart grids as constituted by a set of 4 building blocks:

- Communications infrastructure to allow bi-directional flow of information between electricity suppliers and consumers;

- Innovative rates and regulation to provide adequate incentives to energy efficiency investments for electricity suppliers and consumers. This can drive the implementation of innovative retail rate design structures such as time-of-use or dynamic pricing, which provide electricity customers with rates that closely follow wholesale market prices. It also includes regulatory instruments that encourage utilities to pursue energy efficiency;

- Smart end-use devices that are energy-efficient and able to receive and respond to real- time control signals;

- Innovative markets to ensure that energy efficiency measures promoted by regulation become self-sustaining. This can encompass the launching of progressive energy efficiency programs - implemented by utilities, state agencies, or other entities - and codes and standards that transform the market for energy efficient products and services.

While the establishment of innovative rates, regulations and markets, and the development of smart and efficient end-use devices, are all key pillars of energy efficiency, the development of a smart grid communications infrastructure has the potential to increase energy savings beyond what is achievable through conventional piecemeal deployments of energy efficiency, and also to allow 
demand response implementation. A smart grid, in essence, can make the energy efficiency benefits of the whole, greater than the sum of its parts (EPRI, 2006).

\subsubsection{Key challenges for smart grids}

It is stated by the European Union Advisory Council (2010) that European electricity networks of the future will have to integrate all low carbon electricity generation technologies as well as to stimulate the role of demand side management and demand response, e.g., the appearance of residential energy management systems (Livengood \& Larson, 2009) with the capacity to manage all energy resources in households including micro generation on a large scale stimulating distributed generation (DG). Other technological solutions and tools must be used to allow smart grids to help mitigate carbon emissions and provide energy savings, while ensuring energy security and environmental sustainability, within an appropriate regulatory and legislative framework.

\begin{tabular}{|c|c|}
\hline Current Grid & Future Grid (The Smart One) \\
\hline Analogue/Electromechanical & Digital/microprocessor \\
\hline Centralized (generators) & Decentralized (generation) \& Green \\
\hline Reactive (prone to failures \& & Proactive \\
\hline blackouts) & \\
\hline Manual (field restoration) & Semi/Full Automated (self-healing) \\
\hline One price & Real Time Pricing \\
\hline No/limited consumer choice & Multiple consumer products \\
\hline One-way communication (if any) & Two-way communication \\
\hline Few sensors & Ubiquitous monitors, sensors \\
\hline Hardly Equipment reporting & Condition-/performance-based \\
\hline Limited control over power flows & Pervasive control systems \\
\hline Estimated reliability & Predictive reliability \\
\hline
\end{tabular}

Table 2 - Comparison between the current grid and a smart grid ( Prabhudesai , Hazare,

$$
\text { Patil , Parab , \& Tawade, 2011). }
$$

There are multiple challenges for the transformation of the electric grid into a smart grid. Table 2 compares the features of the current electricity grid and the expected features of a smart grid ( Prabhudesai , Hazare, Patil , Parab , \& Tawade, 2011).

In Table 3, key challenges are identified with high impact on the European targets for renewable energy, energy efficiency and carbon emission reduction by 2020 and 2050. These European objectives/policies were defined considering that in the future one common managed European electricity market will exist, therefore reducing energy imports and maintaining the security of supply at the lowest cost in the European continent. 
The key challenges for smart grids

Strengthening the grid - ensuring that there is sufficient transmission capacity to interconnect energy resources, especially renewable resources, across Europe;

Moving offshore - developing the most efficient connections for offshore wind farms and for other marine technologies;

Developing decentralized architectures - enabling smaller scale electricity supply systems to operate harmoniously with the total system;

Communications- delivering the communications infrastructure to allow potentially millions of parties to operate and trade in the single market;

Active demand side - enabling all consumers, with or without their own generation, to play an active role in the operation of the system;

Integrating intermittent generation - finding the best ways of integrating intermittent generation including residential microgeneration;

Enhanced intelligence of generation, demand and grid management;

Capturing the benefits of DG and storage;

Preparing for electric vehicles - whereas smart grids must accommodate the needs of all consumers, electric vehicles are particularly emphasized due to their mobile and highly dispersed character and possible massive deployment in the next years, what would yield a major challenge for the future electricity networks.

Table 3 - Key challenges for smart grids (European Union Advisory Council, 2010).

Since every national European electricity system has a unique starting point, the progressive implementation of smart grids in the several countries will face different challenges and requirements. This framework stimulated the European Union Advisory Council (2010) to present a road map for orientation and initial information for each member state. The European Union Advisory Council has identified six deployment stages for smart grid implementation in Europe. These deployment stages consider the 2020 and 2050 targets set by European policies, defining the following main milestones:

- DP\#1 - optimizing grid operation and structure, 2014;

- DP\#2 - optimizing grid infrastructure, beyond 2020;

- DP\#3 - integrating large scale intermittent generation, beyond 2020;

- DP\#4 - Information and Communication technology, 2018;

- DP\#5 - Active distribution networks, beyond 2020;

- DP\#6 - New markets, users, efficiency, beyond 2020. 


\subsubsection{Energy efficiency in the smart grid concept}

According to EPRI (2008) the electrical sector will need to diversify the usage of tools in order to meet future carbon reduction goals, namely, through energy efficiency measures, use of renewables and distributed energy sources, nuclear energy, advanced coal, carbon capture and storage, and plug-in hybrid electric vehicles (PHEV).

Most industry experts agree that energy efficiency is the most technically and economically viable near-term option for reducing the carbon footprint of the electric power industry (EPRI, 2008).

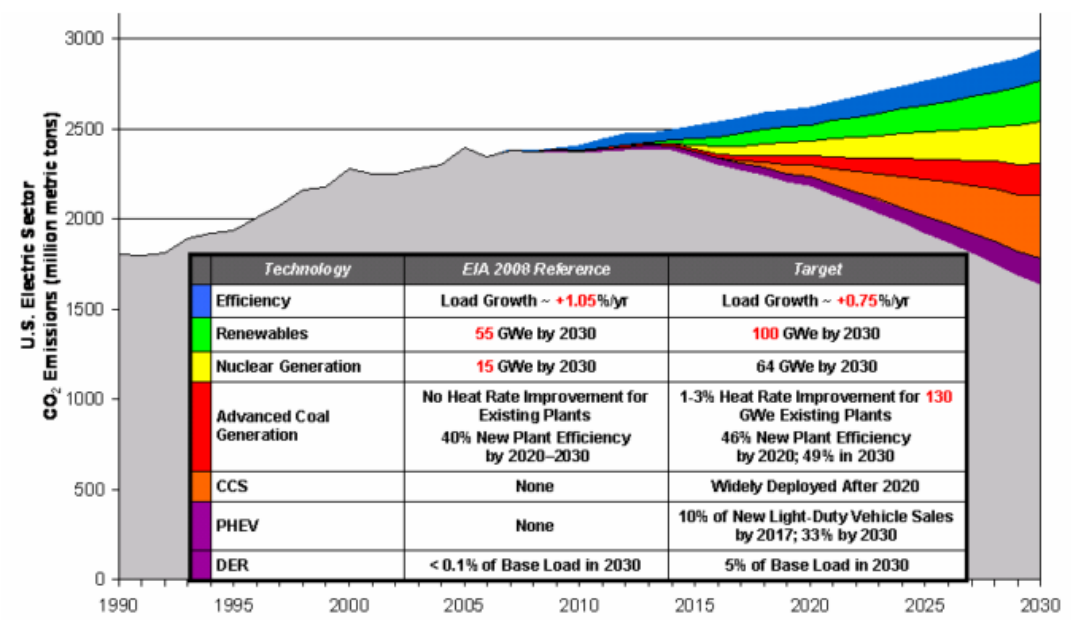

Figure 1 - Technical Potential for $\mathrm{CO}_{2}$ reductions in the US Electric Sector (EPRI, 2008).

According to EPRI (2008), the seven instruments used to enable $\mathrm{CO}_{2}$ emissions reductions in the United States of America are represented in Figure 1. Energy Efficiency measures comprise continuous commissioning of buildings, reduced transmission and distribution (T\&D) line losses, direct feedback to customers, more effective and reliable demand response and load control, enhanced measurement and verification (M\&V) capabilities. The measures regarding energy efficiency depicted in the EPRI study are represented in Figure 2. 


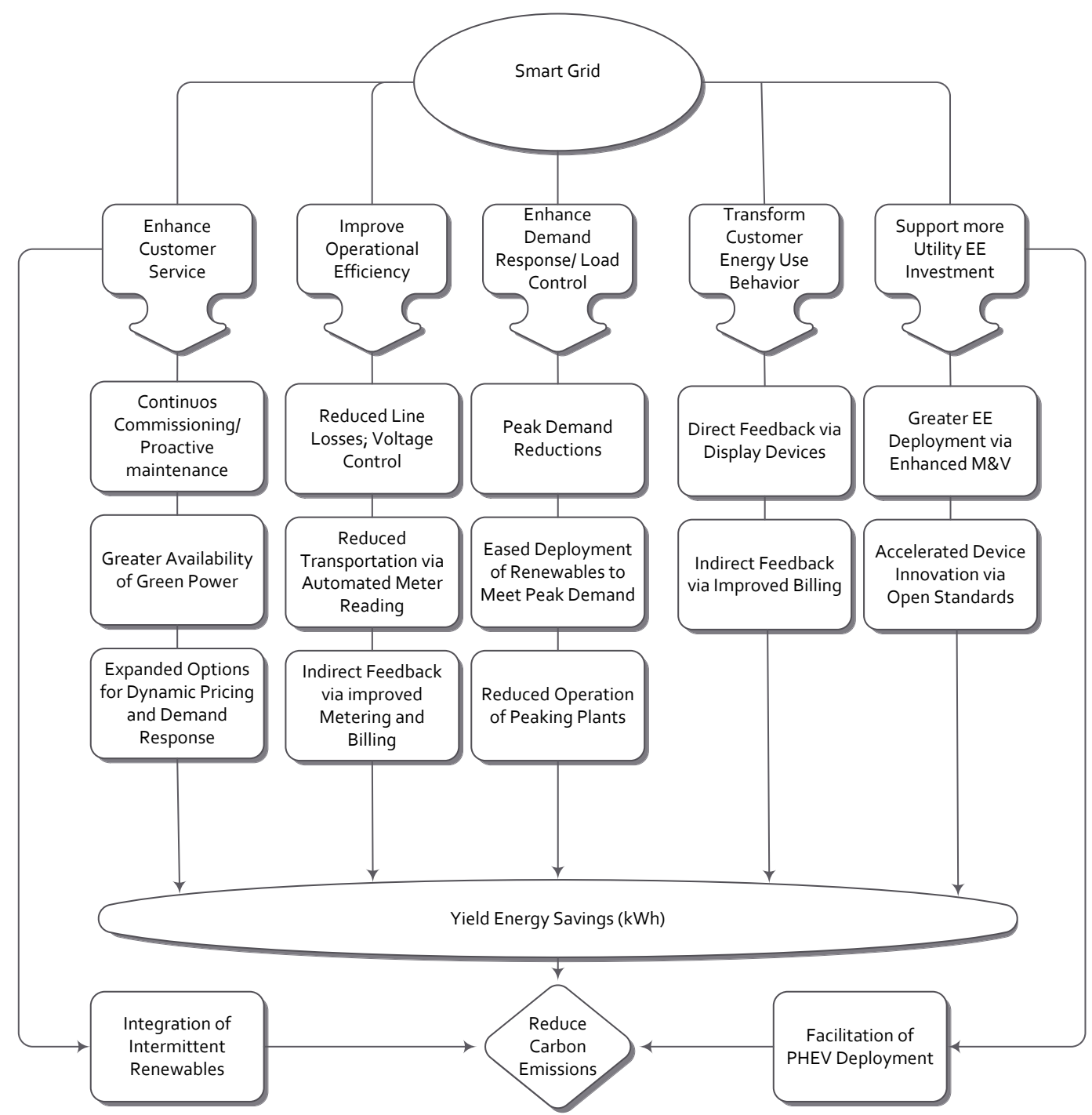

Figure 2 - Smart grid goals concerning energy savings and reducing carbon (EPRI, 2008).

The combined mechanisms of Table 4 have the potential to yield energy savings of 56-203 billion kWh and to reduce annual carbon emissions by 60-211 million metric tons $\left(\mathrm{Tg}^{4}\right) \mathrm{CO}_{2}$ by 2030 (EPRI, 2008). On this basis, the environmental value of a U.S. Smart grid is equivalent to converting 14 to 50 million cars into zero-emission vehicles each year (EPRI, 2008). However, it is also stated by the authors that further research is needed to narrow conclusions regarding the energy efficiency results.

${ }^{4} \mathrm{Tg} \mathrm{CO}_{2}$ Eq stands for teragrams of carbon dioxide equivalent, instead of million metric tonnes of carbon equivalent (MMTCE). Tg are the units used by the EPA to report U.S. greenhouse gas emissions, source: http://www.odlt.org/dcd/ballast/tg co2 eq.html. 


\begin{tabular}{|c|c|c|c|c|c|}
\hline \multicolumn{2}{|c|}{$\begin{array}{l}\text { Emissions-Reduction Mechanism } \\
\text { Enabled by Smart Grid }\end{array}$} & \multicolumn{2}{|c|}{ Energy Savings, 2030 (billion kWh) } & \multicolumn{2}{|c|}{$\begin{array}{l}\text { Avoided } \mathrm{CO}_{2} \text { emissions, } 2030(\mathrm{Tg} \\
\left.\mathrm{CO}_{2}\right)\end{array}$} \\
\hline \multirow[b]{2}{*}{1} & & Low & High & Low & High \\
\hline & $\begin{array}{l}\text { Continuous Commissioning of } \\
\text { Large Commercial Buildings }\end{array}$ & 2 & 9 & 1 & 5 \\
\hline 2 & $\begin{array}{l}\text { Reduced Line Losses (Voltage } \\
\text { Control) }\end{array}$ & 4 & 28 & 2 & 16 \\
\hline 3 & $\begin{array}{l}\text { Energy Savings Corresponding } \\
\text { to Peak Load Management }\end{array}$ & 0 & 4 & 0 & 2 \\
\hline 4 & $\begin{array}{l}\text { Direct Feedback on Energy } \\
\text { Usage }\end{array}$ & 40 & 121 & 22 & 68 \\
\hline 5 & $\begin{array}{l}\text { Accelerated Deployment of } \\
\text { Energy Efficiency Programs }\end{array}$ & 10 & 41 & 6 & 23 \\
\hline 6 & $\begin{array}{l}\text { Greater Integration of } \\
\text { Renewables }\end{array}$ & - & - & 19 & 37 \\
\hline 7 & $\begin{array}{l}\text { Facilitation of Plug-in Hybrid } \\
\text { Electric Vehicles (PHEVs) }\end{array}$ & & & 10 & 60 \\
\hline & & 56 & 203 & 60 & 211 \\
\hline
\end{tabular}

Table 4 - Smart grid energy savings and avoided $\mathrm{CO}_{2}$ emissions summary in the US Electric Grid (EPRI, 2008).

PNNL (2010) analyzed the direct and indirect impact of eight mechanisms that may provide energy savings and enable the reduction of $\mathrm{CO}_{2}$ emissions, considering a $100 \%$ adoption of smart technologies by 2030 in the USA.

\begin{tabular}{llc}
\hline Mechanism & \multicolumn{2}{c}{$\begin{array}{l}\text { Reductions in Electricity Sector } \\
\text { Energy and } \mathbf{C O}_{2} \text { Emissions }\end{array}$} \\
\cline { 2 - 3 } & Direct (\%) & Indirect (\%) \\
\hline Conservation Effect of Consumer Information and Feedback Systems & 3 & - \\
\hline Joint Marketing of Energy Efficiency and Demand Response Programs & - & 0 \\
\hline $\begin{array}{l}\text { Deployment of Diagnostics in Residential and Small/Medium Commercial } \\
\text { Buildings }\end{array}$ & 3 & - \\
\hline Measurement \& Verification (M\&V) for Energy Efficiency Programs & 1 & 0.5 \\
\hline Shifting Load to More Efficient Generation & $<0.1$ & - \\
\hline Support Additional Electric Vehicles and Plug-In Hybrid Electric Vehicles & 3 & - \\
\hline Conservation Voltage Reduction and Advanced Voltage Control & 2 & - \\
\hline $\begin{array}{l}\text { Support Penetration of Renewable Wind and Solar Generation (25\% renewable } \\
\text { portfolio standard [RPS]) }\end{array}$ & $<0.1$ & 5 \\
\hline $\begin{array}{l}\text { Total Reduction } \\
\text { (a) Assumes 100\% penetration of smart grid technologies }\end{array}$ & 12 & 6 \\
\hline
\end{tabular}

Table 5 - Potential annual reductions in electricity and $\mathrm{CO}_{2}$ Emissions in 2030 attributable to the use of smart grid technologies in the electricity power grid (PNNL, 2010).

According to PNNL (2010) the importance of these reduction estimates is in their combined effect. As observable in Table 5, several mechanisms are estimated to have very small or even negligible impacts while five of them can potentially provide reductions above $1 \%$. The combined effect of direct mechanisms is $12 \%$ whereas the indirect mechanisms account for $6 \%$ of energy and carbon emission reductions. At a broader national scale the savings represent $5 \%$ of the total 
energy consumption and $2 \%$ of the total carbon emissions of all sectors in the USA.

According to the previously presented studies (EPRI, 2008) (PNNL, 2010) it is perceivable that a smart grid is not the primary mechanism for setting big national goals for energy and carbon savings. However, through smart grids, a substantial contribution is given to the electricity sector goals of reducing carbon emissions and promoting energy efficiency, as well as, regarding the integration of distributed micro generation.

Also, both studies present the same conclusion, stating that due to the diversity and specificity of the tools used, it is necessary to assess the environmental and energy related impact of smart grid technologies thoroughly, in order to prioritize the use and the development of equipment. Key research in technologies and innovative methodologies for addressing the challenges of the future, and the response of the smart grid, are therefore needed. Future research will have to analyze the integration of renewable energy sources with shares above $20 \%$, DR and storage technologies, and electric vehicles, maintaining an adequate voltage control and reduced transmission and distribution losses. Customer feedback is also considered an important issue for maximizing energy efficiency and demand response management programs attractiveness, as well as, reducing the uncertainty associated with consumer behavior.

As for Europe, the European Union Advisory Council (2010) referred that national states will have to accept the functionalities provided by the deployment of smart grids. For this to happen, smart grid technologies will have to demonstrate costeffectiveness as replacement technologies for traditional grid infrastructures, providing the same or superior levels of power quality and reliability. However, the transition to a decentralized system will have to involve regulatory and business changes, e.g. planning, monetary, risk and incentives (PNNL, 2010). Due to the required investment for the transition process, a quantitative method to quantify the investment in the grid will have to be appropriately defined. 


\subsubsection{Smart grid and market transformation}

A publication from the German Federal Agency Bundesnetzagentur (2011) refers the need to distinguish issues that should be dealt with on the market or on the grid. This agency makes a distinction between the concepts of smart grid and smart market, based mainly on the question of whether the issue being treated is related to grid capacity (power sphere) or energy trade (market sphere). All those who use or provide energy are participants in the market sphere. Efficiency services can be implemented with variable electricity tariffs which aim to cause a change on energy consumption reflecting the variability of the cost of energy supply translated to a correspondingly variable price signal. This price signal, as mentioned earlier, will have to involve operational but also environmental concerns regarding carbon reductions and a path to energy efficiency, therefore leading the way to market transformation. A more general concept could even include the payment for local electricity generation which would correspond to a variable negative price.

\subsubsection{Guiding principles}

In the near future, the share of renewable energy in the energy supply is expected to grow. At the same time, the development of technology allows a dynamic management of the grid, facilitating the inescapable need to match a continuously changing demand to a now also continuously changing supply. A new type of player in the energy market is also to be accounted for, as energy consumers may become energy producers during part of the day, becoming "prosumers", the implications of this being more than just market-based as energy flows may be reversed during these periods.

The European vision towards a common energy market with different production priorities, demand, and generation technologies, including transport requirements over certain distances, has an impact on the required network capacity in terms of flexibility (on the side of the market) and capacity (on the network side).

The technological breakthroughs in information and communication technologies (ICT) in the past two decades, highlighting computer and internet development, can be used to optimize the energy sector. These technologies can be used to 
mitigate costs in energy transactions allowing automated interactions at reduced costs.

In the present context of the liberalized market, the competition is present in the generation and in retail, since network services are considered universal and are universally paid. This means that the introduction of a mechanism or a technology that clearly brings a benefit for the network and not so much for the remaining players, needs an innovative and sophisticated way of implementation.

As an example, in the so called E-Energy ${ }^{5}$ regions in Germany, both energy and services can be traded/negotiated for grid stabilization purposes.

This gives Demand Side Management and Demand Response practical applications, pointing to a transition in the market, and therefore controlling consumption trough price signals. This transition, through smart grids, is moving from the sphere of power to the sphere of market.

Energy policy is generally focused on mitigating the environmental impact through the maximization of the integration of renewable energies and on maximizing the efficiency in electricity consumption. Nevertheless, energy policies need to ensure the security of supply, namely through the use of local generation (or equivalent) resources to decrease using imported primary energy sources.

\subsubsection{Barriers to energy efficiency the smart grid can address}

Smart Grid Australia (2010) state that energy efficiency opportunities are not being accessed, despite their economic attractiveness, due to the existence of market barriers.

One known barrier is the lack of information on energy usage and potential savings. This barrier prevents consumers to make cost-effective energy efficiency investments or to change behavior.

In household budgets or business investments the competition for capital prevents consumers of choosing energy efficiency measures over other investments which allow an accurate calculation of the return of investment.

\footnotetext{
${ }^{5}$ E-Energy Smart Grids made in Germany in http://www.e-energy.de/en/ .
} 
Smart grids can also address information asymmetries through a better energy pricing system, providing both consumers and utility companies with accurate information, and enabling them to make informed decisions and have unprecedented control over energy usage, production and storage.

The existence of this bi-directional flow of information can lead, on a broader scale, to overcome the barrier of access to capital. Energy Service Companies ${ }^{6}$ can particularly help the commercial building sector through commissioning under innovative financial agreements.

The appearance of ICT and automatic energy management technologies distributed in the low voltage infrastructure can therefore help aggregate energy efficiency savings under circumstances which otherwise would not be possible due to consumer indifference or to transaction costs.

\subsubsection{Barriers concerning the implementation of smart grids}

Several reasons have been pointed out for smart grids not being implemented.

The costs of grid modernization are not negligible in spite of the short-term return of the investment (smartgridnews.com, 2010). This reason associated with the global recession is helping to delay the "start" of smart grids. Other known barriers are related with regulatory issues. Since the electricity market is generally regulated, most of the policies are outdated because they were originally developed during the great depression of the 1930's (smartgridnews.com, 2010) ( Prabhudesai , Hazare, Patil, Parab , \& Tawade, 2011). Another reason, in the European case, is that each member state has its own rates and policies, creating jurisdictional barriers for utility companies whose territories cross countries borders. This barrier can slow projects for months or years.

The lack of standards (smartgridnews.com, 2010) or technological options (Smart Grid Australia, 2010) is another type of barrier. Like the Internet would not be possible without its protocols, the smart grid needs consistent standards to its deployment. These standards must also ensure secure connections and data

\footnotetext{
${ }^{6}$ Energy Service Companies or ESCOs are suppliers of energy services and / or energy efficiency which use their own or a third party's financial resources to support the necessary investments.
} 
privacy issues ( Prabhudesai, Hazare, Patil, Parab , \& Tawade, 2011). This barrier is also due to the fact that smart grid technologies are at various stages of development and commercialization (Smart Grid Australia, 2010).

According to the same report (Smart Grid Australia, 2010), there is little incentive for investment and innovation from distributors (on the grid-side) and energy retailers (on the consumer-side) due to the existence of applications that offer significant societal benefits but minimal or negative returns for the investor. This leads to smart grid pre-deployment problems in which the potential benefits and penalties are misaligned.

It is therefore necessary, as recognized by the European Union Advisory Council (2010), to analyze in detail the need for smart grids and the benefits smart grids provide, evaluate deployment barriers and choose the tools to address these barriers. It is expected that smart grids will play a major role in energy security policies and sustainability targets mandated by the European Commission for 2020 and 2050.

\subsubsection{Smart grid - consumer side}

The energy savings that consumers may obtain from smart grid technologies should be taken into consideration for the development of policies.

In some regions, e.g. Baltimore in the USA, there has been a certain opposition of consumer and public entities to the deployment of smart meters (Simchak \& Ungar, 2011) due to privacy issues. This opposition can also be explained by the majority of financial risk being placed on consumers without the offering of attractive benefits in return. Additionally, this resistance may be attributable to the lack of consumers awareness of some important reasons for the widespread use of smart meters, e.g., maintaining grid stability and reducing blackouts, integration of renewable energy sources and distributed generation.

Because a smart grid can lead to market transformation and the generation of savings to consumers, it is relevant to discuss how consumers deal with the benefits of smart metering and how the metered data will be managed (Simchak \& Ungar, 2011). 
Smart metering programs will have to provide information to consumers regarding their energy usage on a regular and frequent basis, in an easy to understand form, accessible and continuously appealing. However, solely based on these requirements, smart metering by itself will be insufficient to provide market transformation or to cause energy savings. An evolution is required towards systems that take automatic decisions under a defined regulatory framework, otherwise there is a risk of consumers increasing their consumption. An example is provided by Simchak, Ungar (2011) who carried out a study that analyzed consumer response to data display systems, and concluded that consumers tend to increase consumption when they realize that certain equipment consume less than others, leading to greater energy use, a reaction known as the direct rebound effect of energy efficiency improvement.

The future of smart grids is still uncertain as well as unavoidable. While consumers are concerned with the privacy and access to information, utilities are concerned with data accuracy, availability, security and associated costs, leading to the need of a third kind of player which is emerging in the energy markets. This third party sees a potential market in assisting consumers in dealing with the information provided by smart metering, in providing aggregate demand response and also in implementing energy efficiency measures.

It is therefore necessary to define who will pay for the introduction of smart grid technologies and which new energy services will be provided to consumers.

\subsubsection{Smart grid - distribution side}

Smart grids can be used to promote the reduction of losses in generation, transmission and distribution of electricity.

Smart grids are expected to bring more efficiency and quick responsiveness to the management of the power system. As an example, an improved energy voltage regulation as result of the smart grid operation is estimated to increase the energy savings range by reducing line losses from 3.5 to 28 billion kWh in 2030 (EPRI, 2006) (EPRI, 2008). 
Smart grid technologies can also play an important role in managing potential problems that may come from the increased demand caused by electric vehicles and the integration of non-dispatchable energy sources in the electric grid.

In the case of integrating and managing electric vehicles, smart grid technologies can provide a way to improve transportation efficiency through the optimal scheduling of charging periods, maintaining the stability of the grid. According to the report of McKinsey \& Company (2009), existing off-peak capacity could accommodate $73 \%$ market penetration of plug-in hybrid and battery electric vehicles in the US electric grid. The financial incentives for consumers, manufacturers and utilities should be adequate to guarantee that electric vehicles stabilize the grid instead of crippling it, through real time pricing for example.

Electric vehicles batteries or other means of electric energy storage can also be used to store energy from non-dispatchable energy sources creating an additional spinning reserve and backup generation, therefore matching loads to renewable supply and ensuring grid reliability.

\subsubsection{Expectations for future smarter grids}

Electrical power systems in their traditional form will face significant changes in a near future. A larger deployment and need for integration of renewable energy sources in the electric grid will lead to a necessary restructuring of the supply system in order to attain desired technical, societal and economic benefits for all participants, providing a more efficient use of energy and consequent environmental benefits.

McKinsey \& Company (2009) concluded that a smart grid is not the primary mechanism for setting big national goals for energy and carbon savings. However, through smart grids, a substantial contribution may be given to the electricity sector goals of reducing carbon emissions and improving energy efficiency, as well as to integrate distributed micro generation to a minimum share of $20 \%$, while offering significant benefits to consumers, grid operators and to countries, always considering the environmental contribution of these technologies. 
Power generation at the demand side is one essential element of smart grids, helping to reduce line losses and occasional "bottlenecks". This relief in the transmission system requires however a more complex network control.

Information barriers concerning the implementation of smart grids need to be addressed, providing real information for consumers and utilities of the consequences of the technological upgrade. Smart grids adoption is only justifiable when its recognized value exceeds its implementation cost. Among the benefits that add value to smart grids are, e.g., the improvement of grid reliability, energy savings and other savings resulting from more flexible management.

\subsection{Demand response}

As mentioned in section $1.1, \mathrm{DR}$ is a designation used for programs that seek to take profit of price elasticity of demand to get short-term load reactions to price signals or to signals related to some kind of operational grid constraint (Albadi \& El-Saadany, 2008) (Renner, et al., 2011).

In order to allow decision makers to select local, regional or national end-use energy efficiency policies it is necessary to assess the technical, economic, environmental and societal effect of replacing a given equipment or technology, or of adopting a given measure.

The deployment of Demand-Response programs and the recent trend towards combining the use of advanced smart meters require the assessment of their possible aggregated impact, and for that purpose, the knowledge of the household consumption pattern and its composition in terms of the individual end-uses is fundamental.

Demand response is based upon the assumption that the several elements of the electric grid can communicate with each other, their response to comply with the needs of the grid operation. Possible examples are: managing demand to deal with grid events, switching off appliances temporarily in order to cope with peak load situations, shifting loads in order to reduce losses and take more advantage of available renewable generation. If no doubts exist that demand response can help optimize system operation it is unclear if it effectively reduces energy use from consumers, bringing energy savings and environmental benefits. Some 
demand response activities may provide net energy savings while others do not. In an emergency situation, dimming lights in an installation during the required time will not mean they will consume more energy afterwards, but for other equipment as, e.g. air conditioning, switching it off during a system event can lead to an increase in consumption after the event is over.

Nevertheless, even when DR does not reduce energy usage it can help reduce energy losses in the grid.

\subsubsection{Load management and real-time pricing}

In order to increase security in the energy supply and to reduce greenhouse gas emissions ( $\mathrm{GHG})$, Europe made a strong effort to integrate renewable energies $(\mathrm{RE})$ in the electric grid. Several reasons could be pointed out for the European Commission and European Countries to devise concrete objectives for the expansion and integration of RE in the electric grid, namely, the need for a diversified energy mix and for the exploitation of the endogenous RE potential or the promotion of technology development.

An important share of the available renewable energy sources, namely solar and wind, are mostly non-dispatchable and suffer fluctuations, according to the weather conditions. Using current tools to manage load and supply fluctuations it is possible to deal with the lack of regularity of renewable energy sources at low levels of implementation. However, an increase in penetration of RE of $10-30 \%$ of the whole power supply requires new resources to counterpart the fluctuating supply to the also fluctuating load (Kempton \& Tomic, 2005).

Another reason for the study of new tools to balance supply and demand is that transmission networks in Europe, due to new market mechanisms, are becoming a platform to increasing energy flows (UCTE, 2007) (Zeilinger, 2011) (Gyamfi \& Krumdieck, 2012) (Gorria, Jimeno, Laresgoiti, Lezaun, \& Ruiz, 2013).

In addition to this burden, technological advances require more energy to supply new appliances. Thus, the gap between electrical supply and demand is increasing in many countries (Guo, Li, \& James, 2005) (D.O.E, March 2002).

Conventional approaches to solve the above referred problems are based on the expansion of the supply resources, even to serve only as idle backup power. 
These are usually high-investment solutions, forced by the context to work for a very small fraction of the time. An alternative approach is then to manage energy consumption, in order to compensate fluctuations, avoiding the need of high levels of reserve supply capacity (Borenstein, Jaske, \& Rosenfeld, 2002) (Wilson, Rassenti, \& Smith, 2003). Managing the consumption instead of controlling energy production allows relieving the transmission systems and helps the implementation of decentralized structures with small and autonomous energy systems.

Figure 3 presents the main load control strategies that are used to balance load and demand in the demand-side management (DSM) perspective as presented by Gellings \& Chamberlin (1993).
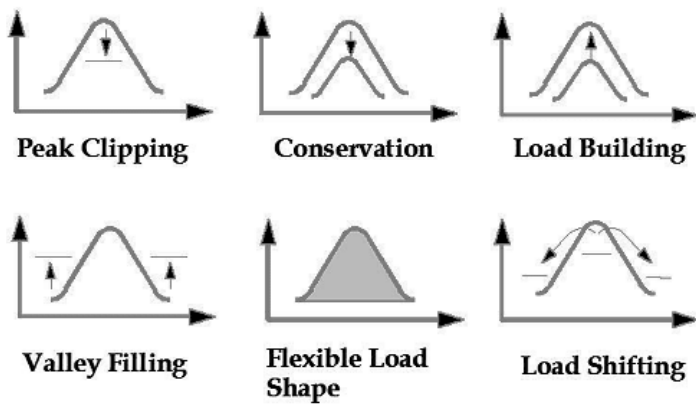

Figure 3 - Load control strategies (Gellings \& Chamberlin, 1993) .

A brief description of such load control objectives as referred by Gellings \& Chamberlin (1993) is as follows:

- Peak clipping consists in reducing peak demand. It can be implemented by means of direct load management, power limiters and applying specific programs or tariffs;

- Load shifting aims at moving demand from peak periods to valley periods. This objective can be reached by providing some sort of economic incentives to consumers;

- Load building and Conservation address strategic actions on loads that focus on the improvement of energy efficiency;

- Valley filling intends to increase overall energy consumption during low demand periods. Valley filling can be stimulated by means of tariff stimuli; 
- Flexible load shape has to do with the DSO need to obtain a short-term response of consumers that may lead to a balanced grid operation, namely by using interruptible tariff options.

\subsubsection{Theory of load management}

Kostková, Omelina, Kyčina, \& Jamrich (2013) provide an extensive review of load management methods, techniques and programs, theoretically described or practically used in developed and developing countries, schematically represented in Figure 4.

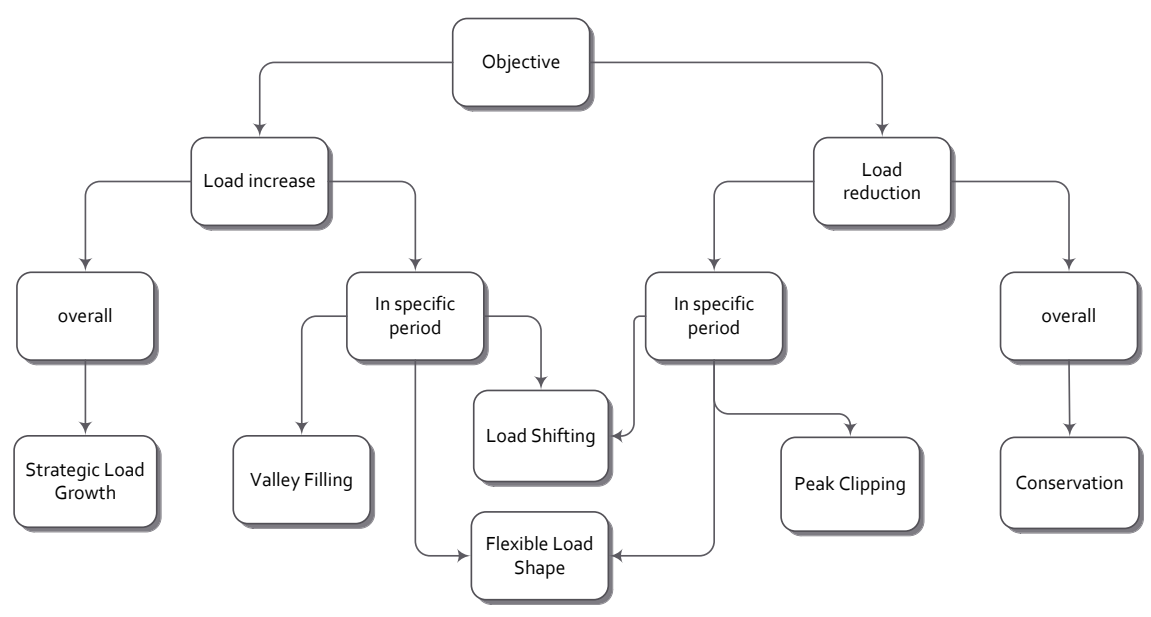

Figure 4 - Load shape objectives (Kostková, Omelina, Kyčina, \& Jamrich, 2013) .

According to these authors there is no straight border between LM, DSM and DR, stating that such terms overlap and their meaning depend on the point of view. An attempt to provide a narrower distinction between such terms was also performed by the authors. It is stated that LM and its actions can be implemented, both on the supply side and on the demand. LM in the supply side include building new power plants and energy storage technologies. DSM includes planning the activities that affect the consumer's behavior with the objective of changing the shape of the load curve. In brief, DR is a term used for programs designed to encourage end-users to make short-term reductions in energy demand in response to a price signal from the electricity hourly market, or a trigger initiated by the electricity grid operator (Albadi \& El-Saadany, 2008) (Renner, et al., 2011).

Figure 5 presents a graphical visualization of the categorization of load management approaches described by Kostková, Omelina, Kyčina, \& Jamrich 
(2013). According to the same authors, such programs can be divided in two streams: direct load management programs and indirect load management programs.

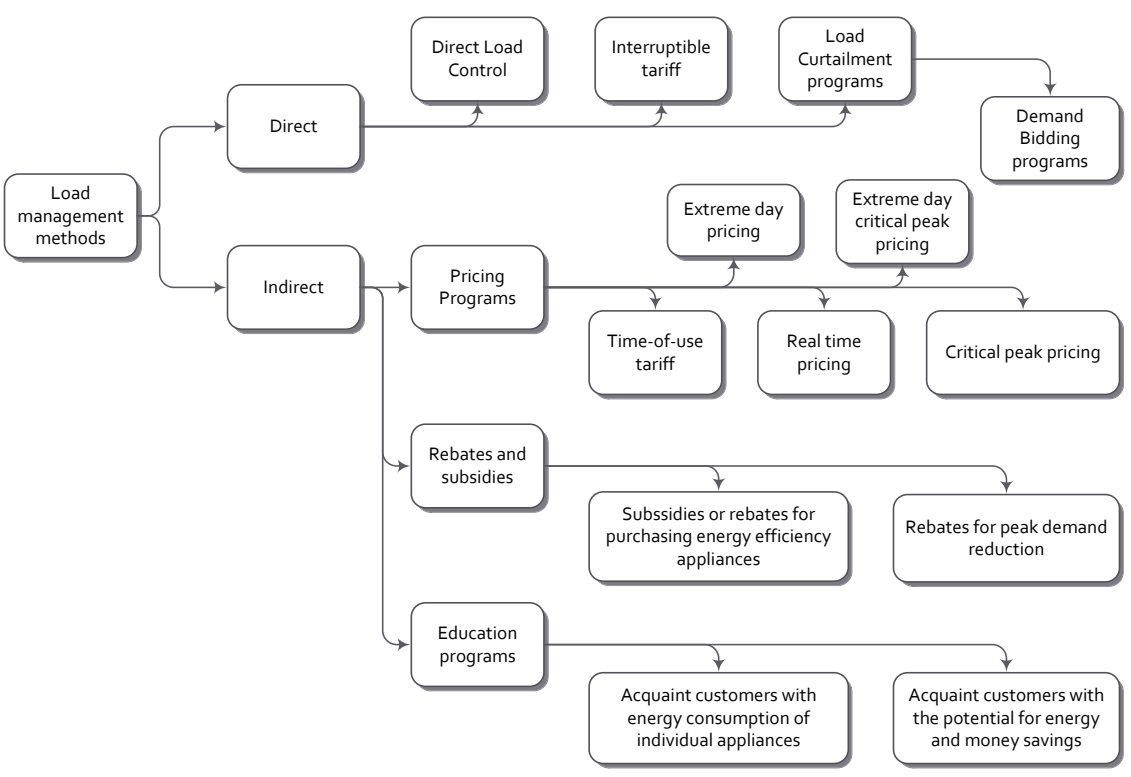

Figure 5 - Categorization of load management approaches (Kostková, Omelina, Kyčina, \& Jamrich, 2013).

In the direct LM programs, the utility company has the access to control some customer's loads, usually based on a contract. This enables the company to remotely change tariffs in electricity meters, inform about the current price of electricity or turn off or on the equipment thus performing peak demand reduction, handling an emergency situation or ensure grid stability (Gardner, 1995) (Albadi \& El-Saadany, 2007). This control involves an interaction between the utility and the end-use equipment, e.g., the water heater, the air conditioning or public lighting. The interruptible tariffs that are usually applied are agreed between the utility company and the consumer and depend on its type, e.g., residential consumer, industrial, among others. Since loads are time shifted to off-peak periods, usually the overall energy consumption does not decrease. The benefits that are negotiated between the utility companies and consumers can include incentive payments or discount rates, while not following the negotiated reduction may imply specified penalties to consumers (Albadi \& El-Saadany, 2008). Another type of direct LM program may include demand bidding, which can be understood as an extension of load curtailment programs (Charles River Associates, 2005). Such 
programs are based on consumers bids in the wholesale electricity market, based on electricity prices they are willing to pay or the amount of demand they can reduce (Gillingham, Newell, \& Palmer, 2004) (Albadi \& El-Saadany, 2007) (Albadi \& El-Saadany, 2008). It is also highlighted by Kostková, Omelina, Kyčina, \& Jamrich (2013) that the tariff which better reflects the actual situation of the electricity market is the real time tariff. The use of real-time pricing of electrical energy may help influence consumer behavior. The price can vary throughout the day, based on wholesale electricity tariffs, or different prices can be established for certain times of the day or the season. The price can also vary in critical peak periods as a response to grid requirements. This type of challenge requires technology, but also, enough incentives for the consumer to adhere. A complement to real time pricing is the deployment of smart appliances, benefiting from the Internet of Things paradigm. Smart appliances can include common household appliances like refrigerators, washing machines, air conditioning, water heaters or new resources like electric and plug in hybrid vehicles, lighting and automated shading. These appliances can act on behalf of the consumer, benefiting from the stimuli provided by the grid, e.g., RTP, and saving money and energy. But, without consumers realizing the extent of benefits it is unlikely they will purchase these types of appliances, especially if this means replacing still useful appliances.

According to Akkermans \& Ygge (1996) a common feature in indirect LM methods is the possibility of consumers to choose to participate in the load reduction effort. The invitation for the participation in reducing load demand starts with the utility company sending a signal to the consumer with the information about the time period when such reduction in required and the provided benefit for those who are willing to participate. Kostková, Omelina, Kyčina, \& Jamrich (2013) divided the indirect LM management programs in three main categories, namely, pricing programs, rebates and subsidies, and educational programs. The pricing programs include all tariffs for which the consumer earns a price discount to reduce load demand in a critical period, e.g. critical peak pricing, extreme day pricing, extreme day critical peak pricing. Another possibility in pricing programs includes providing information about electricity prices to the consumer to enable 
the decision on his participation, e.g. RTP or prices being set for constant time periods, e.g. time-of-use (TOU) (Charles River Associates, 2005) (Albadi \& ElSaadany, 2008). This pricing program differs from the direct LM methods because load control is not on the utilities side and there is no contractual penalty for not participating in the load demand effort. As for the rebates and subsidies category this may include utility companies rewarding consumers with a price rebate or a subsidy for purchasing more energy efficient equipment or participating in the peak demand effort (Nadel \& Geuer, 1996). The last category of indirect LM programs may include utility companies providing information to consumers (especially residential) with the purpose of increasing energy efficiency and awareness in electricity conservation (Albadi \& El-Saadany, 2008).

Considering the review that was described and the conclusions of the authors, for the purpose of this study, the real time tariff prices are assumed to be announced a day ahead. However, this tariff scheme requires fast response service levels and increased levels of granularity of control and of the speed of telemetry (Siano, 2014). The appointed DR benefit for the transmission and distribution operators of deferring investment in network reinforcement or increased long-term network reliability stated by Siano (2014) is worth investigating. The need for this study is strengthened by the existence of studies defending that DR can cause new demand peaks for electric utilities to deal with when day-ahead hourly prices are applied (Gottwalt, Ketter, Block, Collins, \& Weinhardt, 2011).

\subsubsection{Communication technologies}

Each of the programs and methods that were previously described in subsection 2.2.1.1 may have specific communications requirements to be implemented, e.g., the reaction time, the communication speed or the need to have one-way or twoway communications. The categorization of communication technologies is exhibited in Figure 6. 


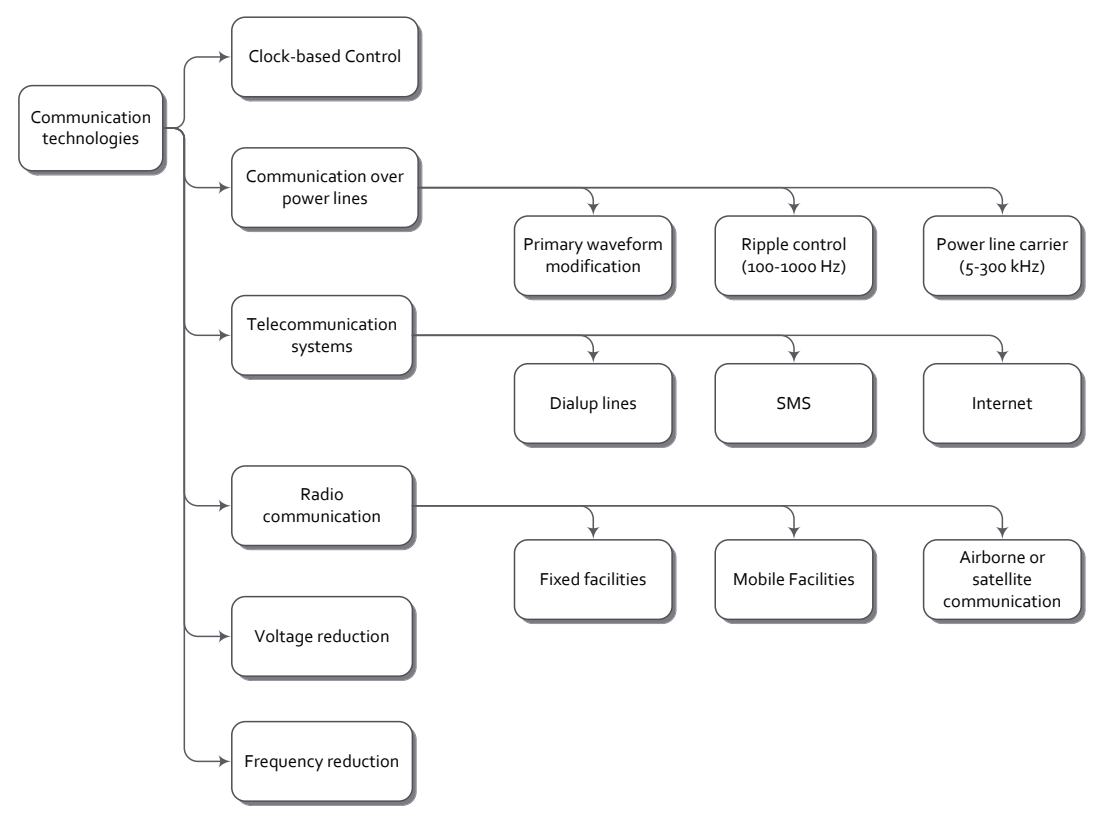

Figure 6 - Categorization of communication technologies (Kostková, Omelina, Kyčina, \& Jamrich, 2013).

Figure 6 present six branches comprising the most common types of control /communication and its subdivisions as referred to Kostková, Omelina, Kyčina, \& Jamrich (2013), which are now briefly described:

- The clock-based control is widely used and is considered one of the simplest control mechanisms. These devices can be manually or remotely preset. The remote communication implies an additional communication, as any of the bellow technologies can be used.

- The communication over power lines present three possibilities, namely primary wave frequency, ripple control and power line carrier.

- Telecommunication systems can use widely known technologies such as mobile GSM, SMS, UMTS or land line ISDN or DSL.

- Radio communication by means of radio ripple control is a special kind of ripple control system when signals sent to end-user appliances are transmitted through radio frequencies.

- Voltage reduction is another approach that utilities use to reduce load and transmission losses, particularly in peak periods. It is not used in the residential segment. 
- An ultimate way of control is through frequency, allowing adequate end-use appliances (e.g. certain motors) to reduce or increase load in response to control.

\subsubsection{New possibilities in the internet age: REMS}

The bi-directional flow of electricity from the distributed generation resources at households, like solar or wind, to the grid, is increasing. In Electrical Power Systems, both the demand and the energy generation from RE suffer cyclic and predictable, but also sudden changes, within seconds. Consequently, energy storage systems, either in the form of stand-alone systems or by using the connected electric vehicles, are a possible resource that is also being considered and analyzed (Gonçalves, Neves, \& Martins, 2015). These resources can be utilized to store RE from the grid as a response to a price signal or to act as a generation resource when needed. This is in fact the vision behind the proposed European electricity networks of the future (European Parliament and European Council, 2009) (Renner, et al., 2011).

Another possibility that arises from all the available demand-side options for increasing the efficiency of energy use in Europe, drawing significant attention, is demand response. As mentioned earlier, DR can be described as the attempt to induce consumers to adapt their consumption patterns to a desirable shape, in such way that it can match several management criteria, including taking into account the variability of energy production from RE sources (Sá, 2011).

The development of information and communication technologies (ICT) applied to the energy sector can help achieving this old ambition, which is the ability to balance a highly variable asymmetric load diagram over time in order to obtain a more economical solution.

According to Kockar, Davidson, Ault, \& Dolan (2010), due to the complexities of the power system, most end-users have a passive attitude. That may be the explanation behind the limited rate of change of suppliers in Europe (less than $10 \%$ after 9 years of market opening) (Sá, 2011). This led to the idealization of REMS. 
Other designations are used by different researchers to refer to REMS in related works, namely:

- $\quad$ Automated DR (Roe, Meliopoulos, Entriken, \& Chhaya, 2011) ;

- Automatic Load Management Systems (Franco \& Neves, 2011);

- Automated Energy Demand Side Management (Guo, Zeman, \& Li, 2009).

The purpose of these advanced management systems, like the Energy Box (Livengood \& Larson, 2009), exhibited in Figure 7, is to manage non-critical loads in residential and small commercial sectors, in response to real-time prices / tariffs of electricity suppliers or other stimuli.

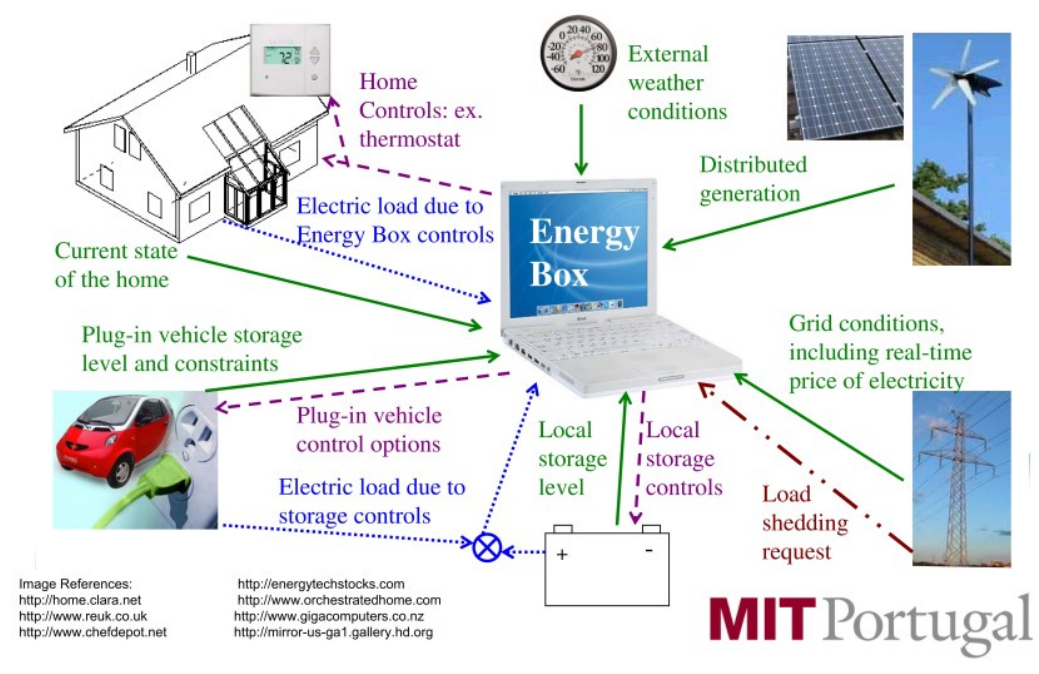

Figure 7 - Energy Box Illustration ${ }^{7}$.

The introduction of these managing systems could allow for real-time, accurate, consumption and energy flow monitoring, and in the case of the Energy Box, to act instantaneously on the end-uses (Livengood \& Larson, 2009) (Nunes, 2011).

The possibility of dynamically displacing energy consumption of non-critical loads to off-peak periods, when electricity tariffs are lower, may be of interest to consumers because of the potential to reduce their electricity bill. On the other hand, these devices can help operators to improve relationships with customers, and at the same time to perform load shedding, helping to reach desired load profiles and increasing efficiency, stability and quality of power systems operation.

7 Energy Box Illustration, source: https://esd.mit.edu/symp09/presentations/larson-livengoodleow.PDF. 
According to Schweppe, Daryanian, \& Tabors (1989) and more recently Soares (2011) the non-critical appliances that can be connected and controlled by REMS are dishwashers, washing machines, clothes dryers, thermostatically controlled appliances, air conditioning equipment, electric heaters and electric water heaters. Typically, these loads are switched on and off, in accordance with the decisions of consumers, following regular routines associated with the consumer behavior.

The introduction of energy management systems is a way to modernize Electrical Power Systems and improve the information available. Thus, a better management and control of energy is enabled, and when accompanied by tariff changes, it is possible to influence consumer behavior in order to balance the relationship between production and consumption (Nunes, 2011).

Aware of the potential of the integration of smart metering equipment in the electricity grid, the European Commission prepared two directives that act as catalysts for the introduction of AMR "Automated Meter Reading" equipment, namely the "Energy Services Directive" (2006/32/EC, ESD) and the third energy package, including the directive 2009/72/EC that states that by $2020,80 \%$ of European consumers should have an intelligent electrical energy meter equipment. However, the acquisition of this equipment represents a high economic burden to energy traders/customers (Renner, et al., 2011). The roll-out of smart meters begun in Portugal with one utility company installing around 30.000 smart meters in the City of Évora (Simões, 2008). According to the latest data, there are almost 300.000 smart meters installed in Portugal, deployed in 7 pilot projects in Guimarães, Lamego, Marinha Grande, São João da Madeira, Alcochete, llhas de Faro e Batalha, out of a universe of 6 million household consumers (Gonçalves A. , 2015).

A publication by EurActiv (2012) refers that the European Commission has asked member states to present their cost-benefit studies before September 2012 regarding the use of intelligent metering systems by 2020. Several national assessments of the impact of smart meters have so far shown conflicting savings predictions, ranging from $2 \%$ to $40 \%$. As an example, Monteiro (2013) analyses the effect of the reduction on the average daily consumption due to the city scale deployment of smart meters (without REMS features) in Évora, concluding that the 
Évora Inovcity effect consisted in an average electricity reduction of $-4.4 \%$ in years 2010-2012.

\subsection{Impact assessment of REMS}

The lack of information regarding the impact of REMS is a research gap that justifies this study. Nunes (2011) and Monteiro (2013) identified individual benefits of these systems which can be divided between the consumer side and the supply side, as described below:

\section{Consumer side:}

- Optimized adaptation of the consumption profile, in real time, in order to concentrate consumption in periods when the price of energy is lower;

- Best habits of consumption, through a constant installation analysis and real-time price;

- Ability to adhere to new services provided by the operator;

- Bill savings generated by the Energy Box capacity to manage consumption, production and storage taking into account tariff periods.

\section{Supply side:}

- Reduction of the energy production at peak periods, and improved pricing;

- Improvement of the purchasing flexibility which allows the distribution system operator to make better deals and therefore optimize its business;

- Reduction of the reserve margin requirements (Generation) and better use of the generation installed capacity;

- Reduction of energy supply disruptions in the distribution network;

- Possibility of selling new services to customers.

If the concept behind the Energy Box (Livengood \& Larson, 2009) intends to explore the energy resources potential in households, inducing changes in the electricity consumption patterns through time varying electricity pricing, in order to achieve an optimal system control, it is relevant for household resources to be seen from a broader perspective. The need for this research arises also from the 
need to balance the potential benefits of using the Energy Box resource over time, with the cost of purchasing, deploying and making this technology work.

The possibility of having an equipment managing one's household energy resources can provide significant changes that need to be studied. Former DSM and DR programs focusing in load management (LM) were run and almost completely controlled by the load manager (Utility Company) while Price Response Programs depended almost exclusively on the energy consumer (Gellings C. , 1996).

Yet, a broader view has to be considered, from both demand and supply perspectives. It will then be possible to have a complete overview of the consequences of the deployment of this resource under different circumstances in chosen scenarios.

\subsubsection{Simulation based approaches}

Several simulations of load control have been presented by researchers, using diverse techniques. However, a deployment at a larger scale has been weakly addressed.

The following works have addressed diverse methodologies and techniques to simulate REMS performance.

In order to perform a REMS simulation it is important to initially understand what kind of loads are currently present in households. Soares (2011) classifies loads in four different categories, according to the possible control to be performed, namely:

- loads whose operation can be displaced to other time periods, e.g. washing and drying machines;

- loads that can be parameterized by adjusting the set-point temperature and therefore dynamically changing electricity consumption, e.g., air conditioning equipment, electric storage water heaters;

- loads whose operation may be interrupted for a certain period of time, e.g. air conditioning equipment, refrigerators and freezers;

- non controllable loads, e.g. entertainment and computer equipment, lighting and other home appliances (toasters, mixers, among others). 
The possibility to use load control techniques or, more generically, to manage resources in households, exists because consumers do not need energy by itself. Instead, they need energy services, e.g., lighting, hot water, cooling/heating for the house, among others, which should be provided in the most efficient way. This idea is not in fact new, having been underlined more than 30 years ago by Schweppe, Tabors, Kirtley, Outhred, Pickel, \& Cox (1980).

Conte, Scaradozzi, Perdon , Cesaretti, \& Morganti (2007) used multiple agent theory for modeling and analyzing REMS, trying to achieve practical tools for the analysis of performance of control strategies over household agents.

The capacity to shift the demand of certain household appliances in a home was quantified by Teng \& Yamazaki (2010) according to the cost of electricity from two electric power sources, the energy grid and renewable energy locally produced in the household. Commercial supply was considered, when in use, to represent a high cost option, while RE was referred to as a low cost option. An energy cost model was introduced and an energy management approach for the home system was proposed. A time shift operation was performed on household appliances, following the cost of the power supply.

An open industry standard for system-level modeling called SystemC (Park, Kim, Moon, Heo, \& Yoon, August, 2010) was used to create a simulation framework to model a house equipped with several home appliances and a smart metering device. The proposed platform scheduled three working periods. By predicting the time of use of appliances the authors tried to lower peak-power consumption and to manage how energy consumption should be adjusted. The presented simulation reduced peak power consumption from $2.73 \mathrm{~kW}$ to $1.19 \mathrm{~kW}$ in a 4 hour period.

A real time simulation tool regarding the optimization of the operation of household appliances using DSM strategies was presented by Gudi, Wang, Devabhaktuni, \& Depuru (2010). The formulation problem was performed using particle swarm optimization, trying to automatically select which appliances will work at each moment, adjusting energy usage and minimizing energy costs. The optimization results revealed a reduction of $19-21 \%$ in electrical energy costs for the consumer. 
Molderink, Bakker, Bosman, Hurink, \& Smit (2010) used three techniques to create control structures for the simulation environment of REMS. Artificial Neural Networks (ANN) were used to predict a daily local production, using the consumption pattern, micro combined heat and power generation. A second technique consisted in performing a global programming approach in order to minimize the mismatch between what was consumed (demand) and what was produced (RE). A final approach consisted in using a linear integer program to optimize the control of equipment in households. Local prediction using ANN performed well for 39 residences, for a single day simulation. The authors concluded that it is possible to make a forecasting for a group of houses based on predicted heat demand.

RTP and DR stimulated by higher penetrations of RE were studied by Roscoe \& Ault (2010). This study had as its premise the use of real-time pricing of electricity, providing customers to be flexible but to retain overall control. Two main objectives were set, the first one consisted in assessing the likely financial benefits of such tariffs for consumers and for the power network in general, the second objective consisted of predicting possible problems with implementing real-time pricing, by examining the difficulty in predicting demand and setting prices. A time-domain simulation with probabilistic appliance events was developed, taking into consideration the percentage of all households with electrical load types, the average electrical demand $\mathrm{kWh} /$ house/day (for all houses), the average electrical demand $\mathrm{kWh} /$ house/day (households without gas) and the average UK electrical demand for 25 million households. The events were scheduled using Poisson distributions and were characterized by increments of a certain power value (e.g. $150 \mathrm{~W}$ ) and a temporal duration (0.5h) which are switched on at times of lower energy costs provided by the need to sell RE in certain periods of the day (excess production) and in order to balance demand and supply. The simulation was influenced by a process of delaying working cycles of electrical appliances and by price elasticity. This simulation estimated an 8-11 GW potential peak demand reduction for the United Kingdom, strongly depending on the level of assumed elasticity. The authors also concluded that many customers will perceive real-time pricing tariffs as better value than the fixed- price tariffs. This is suggested because, on average, simulated customers on real- time pricing tariffs manage to 
use more energy, but by spending less. This may explain why electricity suppliers may be unwilling to offer such tariffs, since their profits may be reduced. Finally, the authors recommend further work on demand-forecasting and the price-setting strategies.

Roe, Meliopoulos, Entriken, \& Chhaya (2011) developed a discrete event simulation to study DR action in a household. The working methodology of this simulation was divided in two steps. The first step delays controllable appliances so they are not used during the DR service time. The second step manages a stationary battery in order to help reducing residential power demand during DR request time (load reconnection). Each daily power demand was simulated 50 times for each scenario. Differences between simulations consist in slightly modifying appliance start times and in the number of controllable appliance events, in order to model random consumer behavior. The study considered the simulated results to compute the REMS simple payback period regarding the resulting energy savings. The conclusions of the study revealed that the simple payback period was in the order of one year for an REMS equipped household with no stationary battery. With a stationary battery the simple payback period was extended to over 10 years.

Another relevant issue when considering the global analysis of the Energy Box resource is related with the accessibility of consumers to this integrated management system and its impact on the daily load diagram. A recent simulation (Soares, 2011) tried to tackle this problem considering the following elements:

- number of households;

- equipment's ownership ratio;

- unbundled consumption in the residential sector;

- typical consumption of different equipment;

- equipment's use pattern during a 24 hour period and subsequent distribution throughout the day.

Soares (2011) considered two different time periods throughout the day, corresponding to off-peak hours and peak-hours, but not implying that these periods were identical to those used in any particular Portuguese dual rate tariff or 
that there were only two contiguous blocks per day. However, in this simulation, the consumer preferences and the evaluation of the use of Energy Box resource over time in a reality with different real time hourly prices for electricity was also not considered.

It is stated by Karnouskos \& de Holanda (2009) that if an REMS system can only be implemented with high technical and financial effort, only few devices can be controlled and the involvement of consumer with low power input is not profitable. If such a REMS system could be implemented in an affordable manner, using economies of scale and with a simple structure, it can be assumed that more consumers will adhere, benefiting the overall performance of Electrical Power Systems.

The simulation presented by Zeilinger (2011) tries, according to the author, to be as flexible as possible in order to cope with DR options. Therefore, the study separated the household appliances in groups. This way of thinking led the author to present a working methodology in which each appliance has a control unit installed that independently determines the need to influence the power consumption due to the current energy supply situation. This can also be used to analyze the demand flexibility of energy resources in households. Zeilinger (2011) defined end-uses behavior to perform simulation of appliances. The simulation of thermal storage appliances, e.g. refrigerators, boilers and heaters, used a simple thermal model . A stochastic simulation was included to simulate appliances whose operation is purely random, e.g. entertainment or lighting equipment. The program of each device is fixed. While the starting time of these appliances also presents a stochastic behavior, the power consumption of each appliance follows a fixed sequence. In order to develop an end-use model for the specific equipment, each appliance was characterized according to:

- the average power input;

- the stand-by consumption;

- typical starting times;

- average operating times;

- starting probabilities. 
This technique allowed the development of a cumulative load graph for each specific type of equipment. However, if this technique used a bigger sample of appliances instead of only one equipment, the results could be more accurate and more confined to a specific case study, e.g., the Portuguese situation. The thermal model used the values of thermal resistance and thermal capacity of an equipment.

The second part of the simulation, consisted in defining how local control units could be controlled in a simple manner.

The existence of different priority groups allowed for diverse actions to be performed at the equipment level, particularly:

- Switching off the equipment. As a consequence of a critical network status, the device is disconnected from the mains;

- Switching off stand-by consumption. As a result of a critical network status, the stand-by consumption is terminated, not affecting normal operation.

- Power reduction. Due to an unfavorable network condition, the power consumption is reduced, e.g., by dimming lamps;

- Changing temperature settings. The temperature setting of a thermal storage device is changed for the duration of a critical network state. After the recovery of the line frequency, regular temperature will be restored, increasing or prolonging power consumption;

- Postponing a program start. This is possible for devices that run certain programs, e.g., washing machines and dish-washers, in the event of a critical system status. A maximum delay time can be defined in order to start the program in a foreseeable future.

- Interrupting a running program. Due to an unfavorable network condition it is possible to define a maximum period of time for the interruption.

The simulation was performed using REMS through frequency variations which can be adequate to respond to emergency demand response situations. However, the normal operation of the Energy Boxes will require the existence of two-way communications, e.g., between the energy consumer and the utility company. 
These communications will allow the residential sector response to real time pricing or RTP (Faruqui \& Sergici, August, 2010). According to the European Commission vision, the introduction of AMR and bi-directional communications will enable RTP. Several researchers have studied the price elasticity phenomenon realizing that consumers respond to higher prices by reducing consumption. This reaction is usually related to the range of price increase, existence of heating and cooling equipment, the use of programmable thermostats and some sort of REMS resource in the household (Nunes, 2011) (Faruqui \& Sergici, August, 2010).

Since consumers do not respond in the same manner, at a larger scale in a RTP reality and to a certain access level, the existence of contracts with flexibility clauses was presented by (Faria, 2010), namely:

- Clients with inflexible supply contracts. Critical loads should always be supplied. Not supplying the loads will imply that the supplier must financially compensate the client;

- Clients with flexible supply contracts. In case of a supply shortage the DSO can control all or some selected loads/circuits.

One thing is certain, for the deployment of REMS to be possible: the agents acting on the electricity market need to realize what are the practical benefits of using household managing equipment in a DR framework and what type of programs are most fit to their reality, as shown in Table 6.

\begin{tabular}{lll}
\hline & \multicolumn{3}{c}{ Demand Response Programs } \\
\hline Incentive Based Programs (IBP) & Price Based Programs (PBP) \\
\hline Classical & Market Based & Time of Use (TOU) \\
\hline Direct Control & Demand Bidding & Critical Peak Pricing (CPP) \\
\hline Interruptible/Curtailable Programs & Emergency DR & Extreme Day CPP (ED-CPP) \\
\hline & Capacity Market & Extreme Day Pricing (EDP) \\
\hline & Ancillary services market & Real Time Pricing (RTP) \\
\hline
\end{tabular}

Table 6 - Classification of DR Programs (Albadi \& El-Saadany, 2008).

\subsubsection{Forecasting based approaches}

By understanding the willingness of consumers to participate in a DR program it may be possible to determine the impact of a defined number of REMS in households. The use of forecasting techniques is another possibility to devise the 
difference between a given deployment of REMS and its absence in response to the same variation in electricity prices and power generation conditions.

This can lead to the use of forecasting techniques to predict future demand/load and prices under certain circumstances. For the sake of this hypothesis, a very complete review and classification of forecasting methods was developed, including fuzzy logic, genetic algorithms and neural networks, in addition to econometric models (Hippert, Pedreira, \& Souza, February, 2001).

According to Sousa, Neves, \& Jorge (2009), these methods can be divided in time series models, using linear, polynomial or exponential regression, and are based on previous records of the variable being predicted and/or exogenous factors. Recent load forecasting research (Sousa, Neves, \& Jorge, 2009) (Santos, Martins, Pires, Martins, \& Mendes, 2006) adopts artificial intelligence and artificial neural networks as the most popular technique for this application.

Load demand can be influenced by endogenous variables and exogenous variables (Sousa, Neves, \& Jorge, 2009):

- Endogenous variables: related uniquely with past values of the variable being predicted;

- Exogenous variables: related with external variables, such as day type, season, weather, economic activity, macroeconomic indexes and can directly or indirectly affect the load behavior.

In this category, the electricity price can be pointed as a principal exogenous variable. The usual ways to achieve the relationships between those variables and load values is through auto-correlation functions or partial auto-correlation functions (this last one is often used to relate load with weather variables being appropriate to separate seasonal effects) (Sousa, Neves, \& Jorge, 2009).

Sousa, Jorge, \& Neves (2011) presented a method to forecast the next day load profile using load profiling information and meteorological variables. The paper presents a new approach to support the process of forecasting hourly electric load values for the following day by using ANN supported by detailed information concerning consumers' typical behavior and temperature data. The case study 
consisted in testing the chosen methodology in two real Portuguese substations output, demonstrating its effectiveness and practical applicability. The results were verified using the mean absolute percentage error (MAPE) and the percentage value of the root mean square error RMSE.

Another possibility for evaluating the variations of the price signal and infer possible consumer willingness to adopt an enabling technology is to use data clustering techniques. These clustering techniques can be applied to available hourly energy prices as in OMIP (2013), in order to identify groups of days with similar patterns. These clustering techniques can be divided in three main groups, hierarchical clustering, partitional clustering and also artificial neural networks (Sousa J. M., 2006). This is an innovative approach to test the potential of a device such as the Energy Box, trying to identify contingency price signals, resource shortage problems, overcapacity resource problems, as well as, the diversity of scenarios (or days) that are expected to be frequent.

\subsection{The Portuguese power system}

\subsubsection{Energy matrix}

On an average day of 2013, the latest data available, the generation of electricity in Portugal had the contributions per technology represented in Figure 8, according to the Portuguese Transmission System Operator, REN. The data included SRP the Special Regime Producers, which is the adopted designation for energy producers with non-dispatchable generation in Portugal, representing intermittent/stochastic generation technologies like wind and solar, waste, small hydro ( $<<10 \mathrm{MVA}$ or in special circumstances $\mathrm{P}<30 \mathrm{MW}$ ), cogeneration and generation of low voltage electricity (ERSE, 2009). 


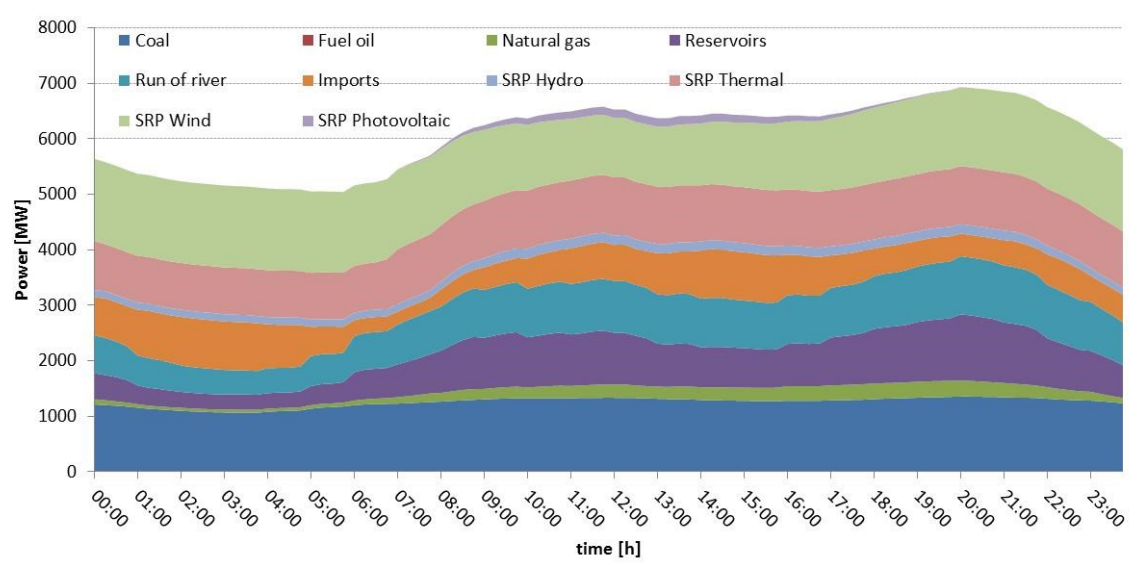

Figure 8 - Evolution of the contribution of each generation technology to the Portuguese demand during an average day of 2013.

According to the available data, in the average day of 2013, the Portuguese energy matrix included non-dispatchable renewable generation (SRP Wind) with 32,195MWh. SRP-Wind was followed by coal thermal power plants (30,090 MWh), SRP Thermal (23,413 MWh), Hydro - Run of River (19,403 MWh), Hydro - Dam with 17,403 MWh while imported electricity was 14,335 MWh. Below the 5,000 MWh threshold, it is possible to identify natural gas (4,293 MWh), SRP Hydro (3,659 MWh) and SRP Photovoltaic (1,212MWh). The impact of fuel oil in 2013 was negligible, when compared to the electricity produced by all the other generation technologies.

\subsubsection{Environmental impact of producing electricity}

The $15 \mathrm{EU}$ member states at the time of the Kyoto Protocol settlement agreed to a common target for the reduction of greenhouse gas emissions of $8 \%$ during the period 2008-2012 relatively to their emissions for the reference year of 1990 . However, Portugal was allowed to increase emissions by $27 \%$ due to the different development status. Later, the EU member states committed to a $20 \%$ reduction in greenhouse gas emissions by 2020 (Eurostat, 2014).

In 23 October 2014, EU leaders agreed to a greenhouse gas reduction target of at least $40 \%$ compared to 1990 . This target is inserted in the 2030 framework for climate and energy policies that also sets a target of increasing the share of renewable energy to at least $27 \%$ of the EU's energy consumption by 2030 , also 
increasing energy savings in $27 \%$ during the same period (European Council, 2014).

The development over the years of this commitment at the European level and Portuguese level are represented in Figure 9.

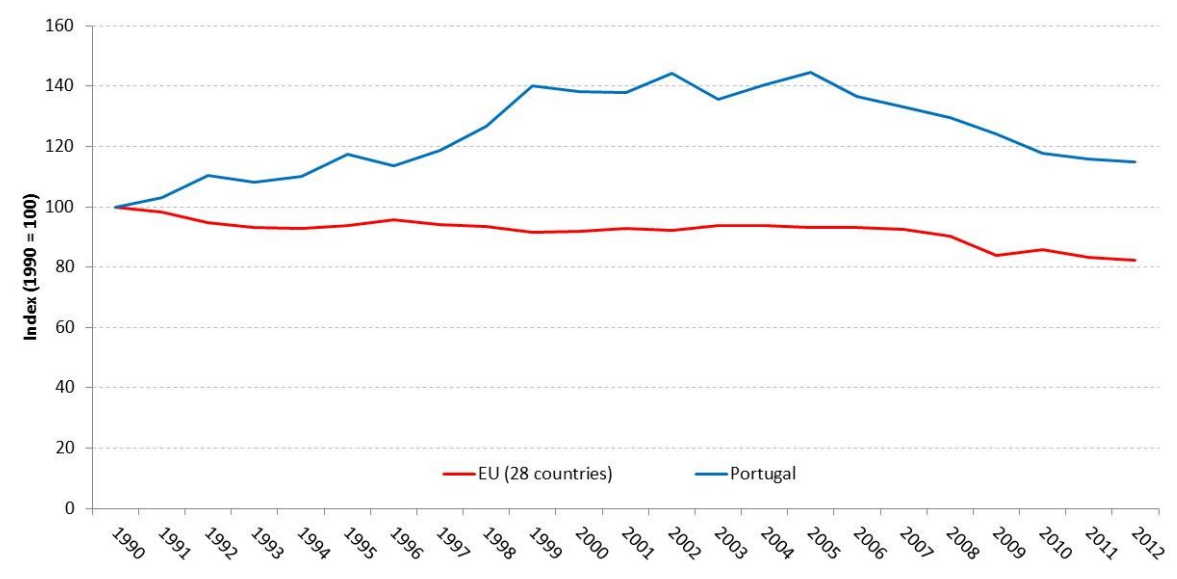

Figure 9 - Greenhouse gas emissions, base year 1990 (Eurostat, 2014).

In this context, and considering the development of a large scale EB actions simulator, it is pertinent to assess to what extent demand response may help mitigating $\mathrm{CO}_{2}$ emissions.

\subsubsection{Load research studies in Portugal}

Similarly to what happened in other European countries, several studies regarding electrical energy use (especially consumption) have been developed in the past years giving a special attention to the Portuguese household sector. This attention is explainable due to the overall and growing importance of electrical energy consumption in this sector and its share of the total electricity consumption of the country (29\% in 2010). Portugal accounts for a total of 3,927,733 households with electricity usage ( 13,946 GWh for 3,769,896 hh in Portugal mainland , $258 \mathrm{GWh}$ for 77,222 hh in the Azores islands and $239 \mathrm{GWh}$ for 80,615 hh in Madeira (INE, I.P. \& DGEG, 2011)). Another reason for the existence of these studies has to do with the alleged homogeneity of this sector in terms of appliances or equipment, energy usage patterns and energy behaviors, which allowed the development of typical load profiles that intend to represent the energy consumption in households. According to a recent study (INE, I.P. \& DGEG, 2011), electricity in 
Portugal arises as the main source of energy used in households with $42.6 \%$ share, clearly surpassing the $15.8 \%$ share obtained in 1989 and $27.5 \%$ in 1996 .

The popularity of equipment/appliances that use electric energy increased significantly, contributing to the growing importance of the use of this type of energy in the household sector and motivating researchers to develop studies on the electrical energy usage in dwellings.

The contribution for the assessment can be divided in four major branches, namely, monitoring studies, statistical studies and surveys, behavioral studies and also the current regulatory framework regarding the measurement, reading and electrical energy data availability in Portugal.

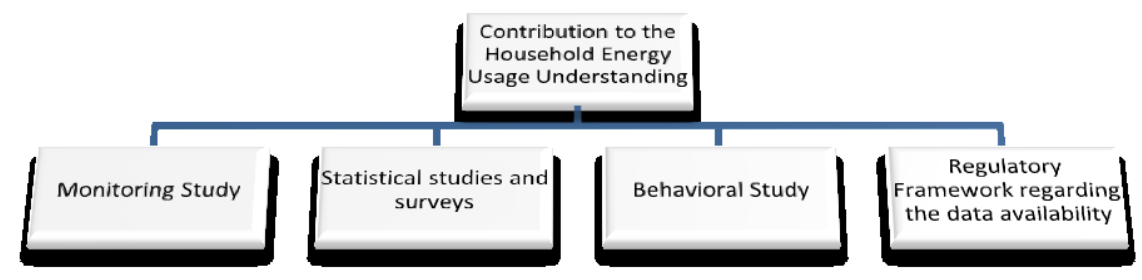

Figure 10 - Contribution to the household energy usage understanding.

An extended review of the state of the art for these four subjects was published by Miguel P. , Neves, Martins, \& Sousa (2013) focusing on load studies regarding the Portuguese household sector. An international review of bottom-up and top-down studies were cross analyzed by Grandjean, Adnot, \& Binet (2012).

\subsubsection{Monitoring studies}

The first branch refers to the monitoring studies that have been made, with European and/or National public and private funding. These studies generally intend to identify Demand Side Management (DSM) actions and measures in order to encourage the end-user to be more energy efficient. These studies are also a good support for the evaluation of Demand Response (DR) programs which are designed to encourage end-users to make short-term reductions in energy demand in response to a price signal from the electricity hourly market, or a trigger initiated by the electricity grid operator. However, for the studies presented, only in (Ribeiro, 2012) the use of DR is considered. 
The EURECO project (EURECO, 2002) was one of the first joint European projects to describe the state and structure of the specific electricity end-uses in the residential sector of Denmark, Greece, Italy and Portugal. This project intended at a first stage to confirm the results of the ECODROME project (Sidler, 1998) regarding DSM actions (especially in lighting) that were evaluated in France. A simpler, cheaper methodology was also attempted that allowed the project to be replicated in those four countries also taking into account the imperatives of the European Commission. The second purpose of ECODROME was to discover new trends, or consumptions that are still not accurately defined or comprehended, which could represent an important share of total consumption in the near future, e.g. standby consumption. The need to evaluate standby consumption came also from ECODROME (Sidler, 1998) where a standby power of $117 \mathrm{~W}$ in a low income family apartment, which consumed 1,025 kWh/year in standby mode. With the conclusion of the EURECO project (EURECO, 2002) a characterization of electricity end-uses was provided in normal operation and in standby mode, and the potential electricity savings of DSM actions were assessed.

The Ecofamilias study (Quercus - Associação Nacional de Conservação da Natureza, 2007) was a Portuguese project that consisted in evaluating energy consumption through the monitoring of 30 Portuguese families (equipment consumption and temperature/humidity of dwellings) and implementing measures to reduce consumption. The main conclusions of this study regarding energy savings was the identification of the potential of replacing incandescent lamps by compact fluorescent lamps, the quantification of power-off and stand-by consumption and the identification of possible economic advantages for families of the adoption of a double rate tariff instead of a flat rate tariff.

The REMODECE (2008) monitoring project was a European partnership involving Belgium, Bulgarian, Czech Republic, Denmark, France, Germany, Greece, Hungary, Italy, Portugal and Romania. This study intended to better understand the electric energy use in households, consumer lifestyles and comfort levels, taking into account the $2 \%$ yearly increase of electrical energy consumption in the EU-25 household sector that prevailed at the time. The study allowed an estimation of $2.700 \mathrm{kWh}$ for the average electricity consumption per household, 
excluding electric space heating and water heating, and also a segregation of electricity end-uses according to the following percentages (Lighting $17 \%$, refrigerator $25 \%$, washing \& drying $16 \%$, office equipment $10 \%$, entertainment $9 \%$, air conditioning $10 \%$, cooking $9 \%$ and others $4 \%$ ). These percentages were drawn from the average daily load profiles.

The last monitoring study referenced is the Selina (2010) project, which focused exclusively on standby and off-mode energy losses in new appliances measured in shops. One of the findings of the project was the existence of a large share of equipment in shops that do not respect the current legislation (The Comission of the European Communities, 2008) regarding the consumption (power) in off mode, in standby for reactivation only and in standby for information and status display. The Selina project considered that the monitored values are similar to others from other regions of the world reflecting the global nature of the world market of electrical and electronic appliances. The result of the retailer's survey shows that the most used selling arguments are the appliance functionalities and price instead of the energy efficiency. Retailers also admitted that sometimes they advise products that are not the most efficient in order to avoid stock problems. The Selina project recommendations include the need for information programs, financial and fiscal incentives, energy labeling, minimum efficiency standards, advertising standby and off mode consumption in labeling.

\subsubsection{Statistical studies and surveys}

The second branch comprises statistical studies and surveys. These studies, especially the surveys, are very helpful to illustrate the current household sector in terms of housing, the type of energy sources used, but especially, present enduses.

The study entitled Eficiência Energética em Equipamentos e Sistemas Eléctricos no Sector Residencial developed by DGGE/IP-3E (2004) makes use of data from monitoring studies, but especially information to characterize, rather extensively, the electrical appliances that are used in Portuguese households and to define a set of policies regarding two types of DSM actions. The first action intends to reduce consumptions by using more efficient equipment and also make 
recommendations for a more rational use of the equipment/appliances (not quantified). The second DSM measure consisted of time shifting consumption from peak hours (peak and partial peak) to off peak hours (off peak and super off peak), especially of clothes and dish washers. This strategy consisted in providing the energy consumer with the advice of adopting a two hourly tariff and manually managing the time period of household consumption of such appliances that could operate in the cheaper blocks. As for the impact of the second measure, yearly savings between $€ 33$ and $€ 48$ per household were referred. Another project output, a major one, was the estimation of the hourly structure of the load diagram for the residential sector segregated by major end-uses. From the diagram of DGGE/IP-3E (2004) it is possible to verify that three specific uses of electricity (lighting, audiovisual equipment and cold) represent more than a third of the total evening peak demand. The project updated knowledge about end-uses shares.

The Portuguese energy agency ADENE (2009) performed a study to analyze the energy usage in residential buildings in Portugal which assessed energy reduction and growth rates in relation to feasibility and cost, thus evaluating the most beneficial options (within the chosen criteria) to be adopted in the residential sector.

The recommendations of this study point to the need of awareness raising campaigns, of having segmented financial schemes (according to consumers income), of supporting community based projects in order to raise awareness, the advantages of using solar thermal collectors and also of training the public to measure the energy usage, making an important statement that the average Portuguese consumer does not know the amount of energy he/she consumes.

The official survey by INE, I.P. \& DGEG (2011) intended to provide an up-to-date knowledge of the energy usage in the household sector for the different energy sources segregated by end-use. The total energy consumption for the household sector was estimated at 5,902,024 toe in 2010 (being $49.4 \%$ consumed in the household and $50.6 \%$ in individual transportation). In 2010 electricity was the main source of energy used (42.6\%). In terms of segregated consumption by living quarters, the kitchen accounted for $39 \%$, water heating represented $23 \%$, heating 
the household accounted for $21 \%$, corresponding other electrical appliances to $11 \%$ and lighting to $5 \%$.

\subsubsection{Behavioral studies}

The third branch portraits studies regarding the study of behaviors. According to Lopes, Antunes, \& Martins (2012), energy behaviors represent a significant untapped potential for the increase of end-use energy efficiency, being usually neglected although it is as high as that of technological solutions.

In Portugal the only study aiming at the identification of the use people make of time was published in (INE, 2001). Usually these studies are a possible contribution, e.g., for building bottom-up models (Seryak \& Kissock, 2003) (Swan \& Ugursal, 2009) using people's routines by making use of statistical data as a basis to simulate behaviors and therefore estimate energy usage. According to the findings of this study (INE, 2001) the way people use their time strongly depends of gender, if people are employed, however, it is more probable for women to keep the house and tend for children. Women spend also, an average of one hour less than men in paid work, but on the other hand, women spend 4.07 hours in housework for an average of 1.30 hours for men. The TV occupied three quarters of the whole time spent in recreation and leisure activities.

A more recent study entitled EnergyProfiler (2011) was developed with a focus exclusively on the energy profiles of the Portuguese household sector. This study was based upon the presupposition that there is a need to change current energy consumption patterns, increase the knowledge over this subject and constitutes a reason to save energy and surpass barriers to enable decisions for saving energy. This study identified five types of household consumers, namely the ones that are: receptive to energy efficiency, action oriented, responsibility diffusers, energy responsible and energy efficient. Such types of consumers were also split by gender, age and region. Despite the very positive type of profiles found by the authors, they state that there is still the need to embrace awareness programs regarding political measures and behavioral programs. The political measures comprise: programs that allow to value the energy efficiency factor in times of increased investment; additional information in labeling; measures and 
partnerships promoted by PPEC and ERSE; Programs based on incentives; programs that encourage the purchase of more energy efficient technologies. The behavioral programs that were targeted identified: promotion of knowledge concerning concrete actions for energy savings; promotion of individual responsibility; promotion of active and continued information; increase of the knowledge of the population regarding their own consumption; more and better information in retailers; specific consumer information to the identified profiles and investment towards education of the younger population.

Lopes, Peixoto, Antunes, \& Martins (2014) provided relevant information regarding Portuguese consumption, namely that they are currently very sensitive to the cost factor in several dimensions expectedly to be delivered by smart grids, regardless the high income of the sample analyzed. Another conclusion was that $68 \%$ of the respondents of a questionnaire that was delivered stated that they would be willing to change the time of use of their appliances, with a higher availability for the laundry machine and the dishwasher. While $35 \%$ of respondents were willing to accept the control of their appliances by the utility, in a hypothetical future scenario of dynamic electricity pricing the willingness increased to $44 \%$. Lopes, Peixoto, Antunes, \& Martins (2014) also stated that consumers demonstrated a moderate willingness to adapt household activities to grid requests, e.g., time shifting the operation of the clothes washer and the dish washer to lower peak demand.

\subsubsection{Regulatory framework}

The fourth branch highlights the regulatory framework according to which commercial relations are regulated in the Portuguese electric sector and presents the contribution of the measurement, reading and data availability in Portugal.

The regulation of commercial relations $(R R C)$ set by the Portuguese regulator of energy services (ERSE) was approved by ERSE (2005) and published by Imprensa Nacional da Casa da Moeda (2005) establishes that the responsibility for approving the measuring, reading and data disposition guide belongs to ERSE. The approval of this regulatory instrument intends to systematize in a single document several matters relating to the measurement of electricity, reading of the measuring equipment and provision of data to the agents acting in the electricity market. 
According to ERSE (2007) the approval of the measuring, reading and data disposition guide is particularly important in a fully liberalized electricity market which requires full transparency and exemption in the activities of network operators, responsible for the supply, installation and reading measuring equipment, as well as for validating and segregating data consumption associated with client portfolios of suppliers on the market regime.

In one of the most recent disposition guides published by Imprensa Nacional da Casa da Moeda (2012) estimates of consumption and the methodological approach for establishing consumption profiles are provided.

The consumption profiles are applied to all final consumers that do not have a measurement equipment with the capacity to register consumption with a time resolution of 15 minutes. The estimation of consumption broken down in periods of 15 minutes is made from consumption recorded in other final customers measurement equipment or estimated, and the final profile applied.

There are two sets of LV profiles, initial and final. The ERSE profiles (initial profiles) and the reference load diagrams are approved and published yearly by this entity after the joint presentation by network operators.

The end-use profiles are obtained by adjusting the initial profiles, based on differences between the Load Reference Diagram and the System Load Diagram. This adjustment intends to minimize the mistakes eventually created by load fluctuations due to unpredictable factors such as temperature and luminosity. These profiles are made available by REN the Portuguese Transmission System Operator (TSO).

There are three regular LV profiles, namely:

- Class A profile for consumers with contracted power above $13.8 \mathrm{kVA}$;

- Class B profile for consumers with contracted power below or equal to $13.8 \mathrm{kVA}$ and annual consumption above $7140 \mathrm{kWh}$;

- Class $C$ profile for consumers with contracted power below or equal to $13.8 \mathrm{kVA}$ and annual consumption inferior to $7140 \mathrm{kWh}$.

The profiles are prepared on a monthly basis, so it is expected that during each month: 
- all workdays assume a similar load shape;

- Saturdays and Sundays have particular profiles and also different from each other;

- in the presence of a holiday, the associated profile assumes a profile similar to a Sunday.

One of the last reports provided by ERSE provides expected electricity demand to calculate tariffs for 2013 (ERSE, 2012). This report intends to present the assumptions that comprise the different tariff schemes for the year of 2013 , as well as, the premises considered for defining the typical load diagrams used for the tariff calculation, according to the tariff regulation (ERSE, 2011).

Table 7 summarizes the studies that were previously mentioned including, year, reference number, target region, suggestion of DSM and DR actions, if the study includes behavior evaluation, if electrical energy consumption is characterized and finally if a typical load profile is provided.

\begin{tabular}{|c|c|c|c|c|c|c|c|}
\hline Year & Reference & Target & $\begin{array}{l}\text { Suggests } \\
\text { DSM } \\
\text { actions }\end{array}$ & $\begin{array}{ll}\text { S } & \text { Suggests } \\
\text { DR } \\
\text { actions }\end{array}$ & $\begin{array}{l}\text { Studies } \\
\text { regarding } \\
\text { behavior }\end{array}$ & $\begin{array}{l}\text { Characterizes } \\
\text { Electrical } \\
\text { Energy } \\
\text { Consumption }\end{array}$ & $\begin{array}{l}\text { Presents a } \\
\text { typical load } \\
\text { profile }\end{array}$ \\
\hline 2001 & (INE, 2001) & Portugal & $x$ & $x$ & $\checkmark$ & $x$ & $x$ \\
\hline 2002 & (EURECO, 2002) & EU & $\checkmark$ & $x$ & $x$ & $\checkmark$ & $\checkmark$ \\
\hline 2004 & (DGGE/IP-3E, 2004) & Portugal & $\checkmark$ & $x$ & $x$ & $\checkmark$ & $\checkmark$ \\
\hline 2007 & $\begin{array}{l}\text { (Quercus - Associação } \\
\text { Nacional de Conservação } \\
\text { da Natureza, 2007) }\end{array}$ & Portugal & $\checkmark$ & $x$ & $x$ & $\checkmark$ & $x$ \\
\hline 2008 & (REMODECE, 2008) & EU & $\checkmark$ & $x$ & $x$ & $\checkmark$ & $\checkmark$ \\
\hline 2009 & (ADENE, 2009) & Portugal & $\checkmark$ & $x$ & $x$ & $\checkmark$ & $x$ \\
\hline 2010 & (SELINA, 2010) & EU & $\checkmark$ & $x$ & $x$ & $\checkmark$ & $x$ \\
\hline 2011 & $\begin{array}{l}\text { (Energaia, Factor Social, } \\
\text { TerraSystemics, 2011) }\end{array}$ & Portugal & $\checkmark$ & $x$ & $\checkmark$ & $x$ & $x$ \\
\hline 2011 & (INE, I.P. \& DGEG, 2011) & Portugal & $x$ & $x$ & $x$ & $\checkmark$ & $x$ \\
\hline 2011 & $\begin{array}{l}\text { (Imprensa Nacional da } \\
\text { Casa da Moeda, 2012) \& } \\
\text { (ERSE, 2011) }\end{array}$ & Portugal & $x$ & $x$ & $x$ & $x$ & $\checkmark$ \\
\hline 2012 & (Ribeiro, 2012) & Portugal & $x$ & $\checkmark$ & $x$ & $\checkmark$ & $\checkmark$ \\
\hline 2012 & (ERSE, 2012) & Portugal & $x$ & $x$ & $x$ & $\checkmark$ & $\checkmark$ \\
\hline
\end{tabular}

Table 7 - Review of studies regarding electrical energy usage/influence for the Portuguese household sector. 
THIS PAGE INTENTIONALLY LEFT BLANK 


\section{The Energy Box model}

The following section provides the description of the methodologies that were developed to simulate the impact of the Energy Box effect on the electricity grid. This impact will be measured in terms of the range of energy and power resources that can be made available due to the deployment and usage of such demand response technology. A possible methodology will also be provided to assess the environmental impact of Demand Response at a city scale.

\subsection{Estimating the average load diagram of a city}

The present subsection encompasses the initial steps of the research that were taken to better understand what data was available to help characterize electricity consumption in the Portuguese domestic sector, therefore providing the basis to assess the development of the methodology to simulate the actions of demand response.

For that reason, a specific methodology was developed to evaluate profiles, aimed to compare load profiles of the residential sector. The general idea consisted in comparing the load profiles which are approved for the civil year by the Portuguese national energy regulator (ERSE) ${ }^{8}$ with typical load profiles provided by load research studies. For these comparisons, the load profiles approved by the regulator are used before the changes applied by the transmission operator $(\mathrm{REN})^{9}$ due to load fluctuations and to unpredictable changes of variables such as temperature and luminosity.

Each profile provided by ERSE and REN represents the load diagram of a complete year in 15 minutes average power values.

This methodology can be applicable to end-use global load diagrams as used by DGGE/IP-3E (2004) or typical/average individual end-use load profiles such as in REMODECE (2008).

\footnotetext{
${ }^{8}$ www.erse.pt

${ }^{9}$ www.ren.pt
} 
In order to compare the profiles, they must have the same area, the same average and the same integration period duration (96 15 minute periods to 241 hour period). The fitting operations are represented in the following flowchart.

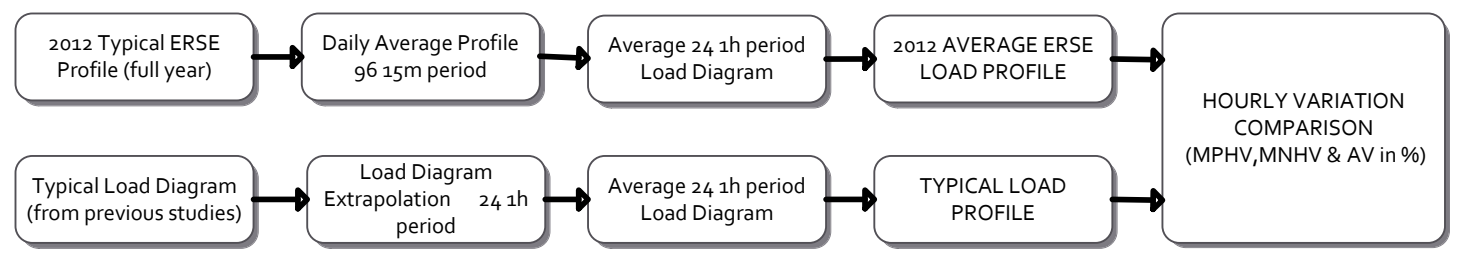

Figure 11 - Fitting operation flowchart for the profile comparison.

The scheme shown in Figure 11 provides the hourly differences between the load profile from ERSE and other chosen profile, calculating the maximum positive hourly variation (MPHV), the maximum negative hourly variation (MNHV) and the average variation (AV) for the profiles under study. After this initial investigation it was possible to assemble another load diagram on top of the ERSE profile, using available information (e.g., yearly domestic average electrical energy consumption combined with the hourly weight of each load) and estimating the energy consumed per each end-use equipment type in a region or city, as in Figure 12.

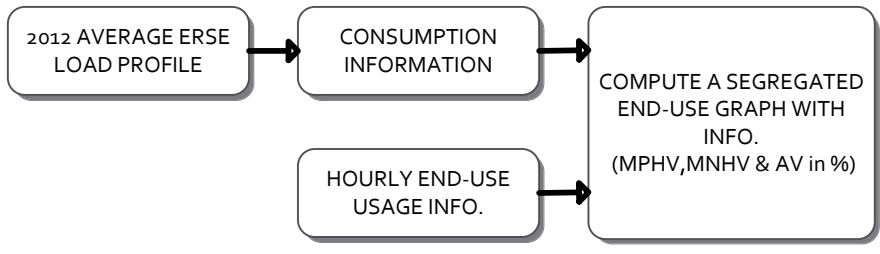

Figure 12 - Methodology for obtaining daily average load diagrams segregated per end-use for a city or a region.

\subsubsection{Comparing load profiles}

Previous load research studies used different methodologies, techniques, timespan and even target audiences. Therefore some caution is required when comparing results obtained per end-use type.

For example, in DGGE/IP-3E (2004) and in Ribeiro (2012) the end-use consumption shares were obtained from previous studies, e.g. in EURECO (2002) it was forecasted an increased role of electricity in the residential sector, the replacement of already older appliances/equipment and the application of DSM actions. An uncertainty mentioned in DGGE/IP-3E (2004) was the impact of the recent energy consumption regulation for buildings and the usage consequences 
for heating, ventilation and air conditioning (HVAC). This change, associated also with the increased thermal comfort required by people led to an increase in the percentages of electrical heating/cooling as shown in REMODECE (2008) and more recently in INE, I.P. \& DGEG (2011). These end-use percentages are represented in Table 8.

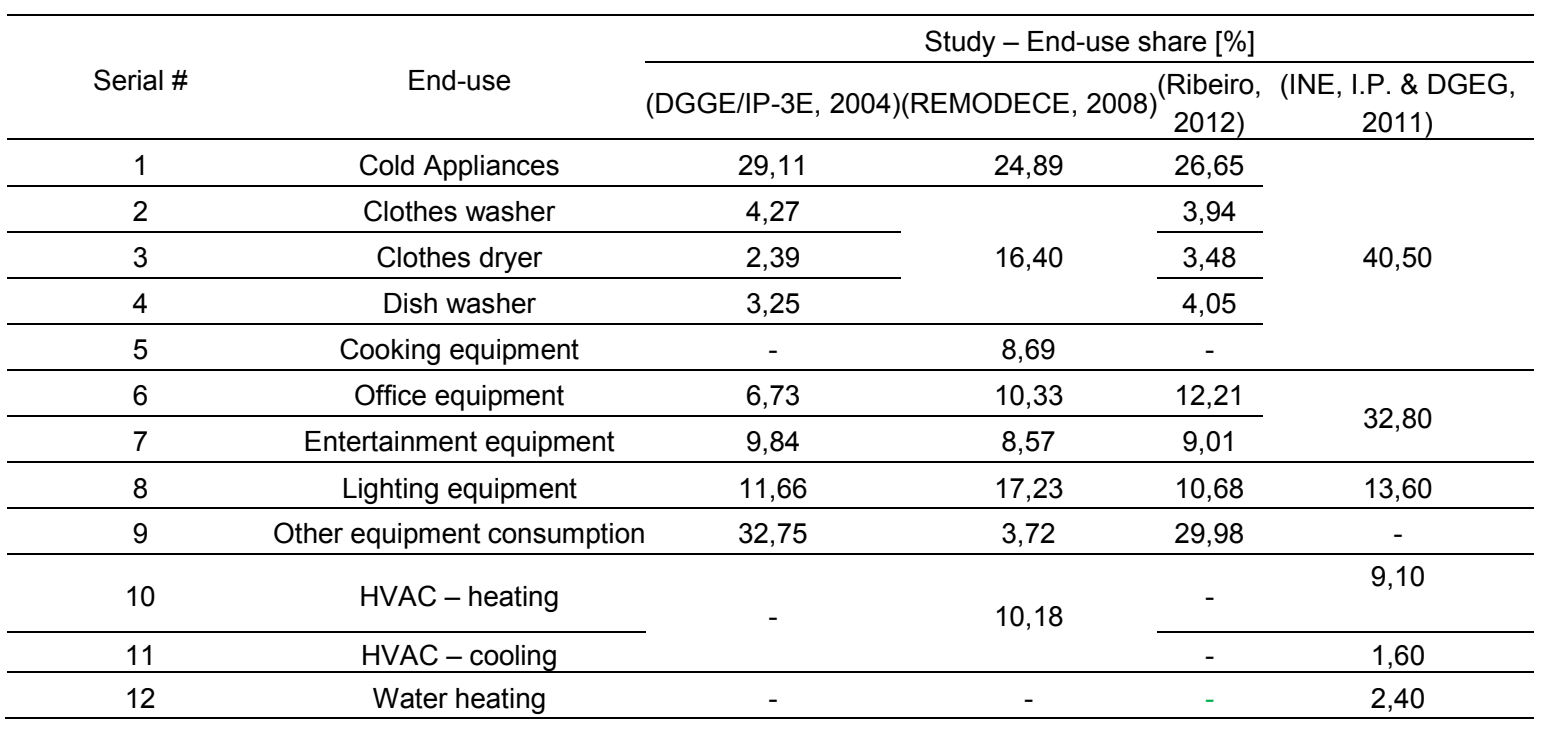

Table 8 - Comparison between end-use weights in the average consumption of reference studies.

Evaluating and comparing the data provided by these studies, a similar share can be assigned to refrigeration equipment with $29.11 \%$ in DGGE/IP-3E (2004), $24.89 \%$ in REMODECE (2008) and $26.65 \%$ in Ribeiro (2012). The combined share of kitchen appliances (serial \#1 to \#5) amounts between $38.12 \%$ to Ribeiro (2012), 39.02\% for DGGE/IP-3E (2004), 40.5\% for INE, I.P. \& DGEG (2011) and $49.98 \%$ for REMODECE (2008).

The percentage for the office equipment (\#6) and the entertainment equipment (\#7) is similar in both DGGE/IP-3E (2004), REMODECE (2008) and Ribeiro (2012), but lower than their combined share of $32.9 \%$ in INE, I.P. \& DGEG (2011). This difference may be explained in the latter study by the inclusion in this combined share of equipment like vacuum cleaners, irons and dehumidifiers, included in serial \#9 in other studies.

The share for the lighting equipment is similar in two studies, $10.68 \%$ in Ribeiro (2012) and $13.60 \%$ in INE, I.P. \& DGEG (2011). 
The most recent statistical study (INE, I.P. \& DGEG, 2011) estimates a $9.10 \%$ ratio for HVAC heating and a more modest $1.60 \%$ for HVAC-cooling. The cited study also provides, for the first time, the inclusion of a share for electrical water heating, possibly due to the former government support/incentive for solar thermal energy in households (http://www.paineissolares.gov.pt/) which may use electricity as a backup energy.

Using the methodology described in Figure 11, initial calculations were performed regarding the value for the hourly difference between the adjusted average REN profile and the average ERSE type $C$ profile, which is considered to be the profile (among those provided by ERSE/REN) that can better represent/describe electrical consumption in Portuguese households.

Figure 13 presents the profiles for 2012 covering the full year for the ERSE profile and the period between the first of January and the thirty-first of September for the REN profile, both are normalized, being 1 the total daily consumption integral of daily demand.

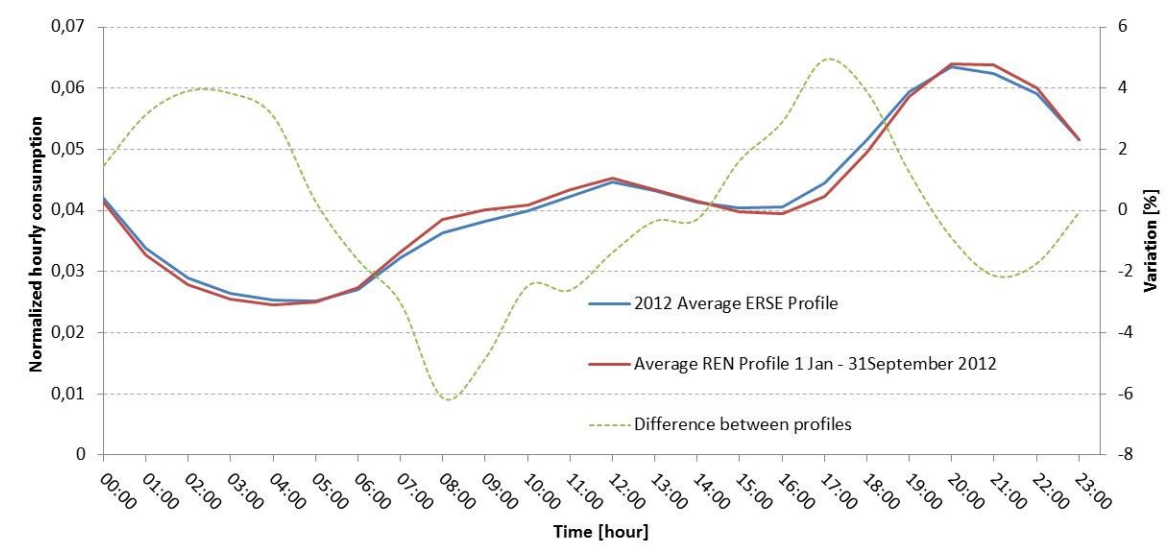

Figure 13 - Comparison between type C average ERSE and REN profiles.

For the ERSE and REN profiles, a maximum positive hourly variation (MPHV) of $4.93 \%$ and a maximum negative hourly variation (MNHV) of $-6.14 \%$, as well as an average variation (AV) of $0.11 \%$ was found. These figures (and similarity) demonstrate the reliability of the initial values provided by the ERSE profile.

The following profile comparison (Figure 14) considers the EEESECR2004 original profile (DGGE/IP-3E, 2004) which represents an average for the total demand, segregated by end-use, for the Portuguese household sector in 2004. The results 
obtained consisted in an MPHV of $17.26 \%$, and an MNHV of $-28.91 \%$ with an average variation of $-1.16 \%$.

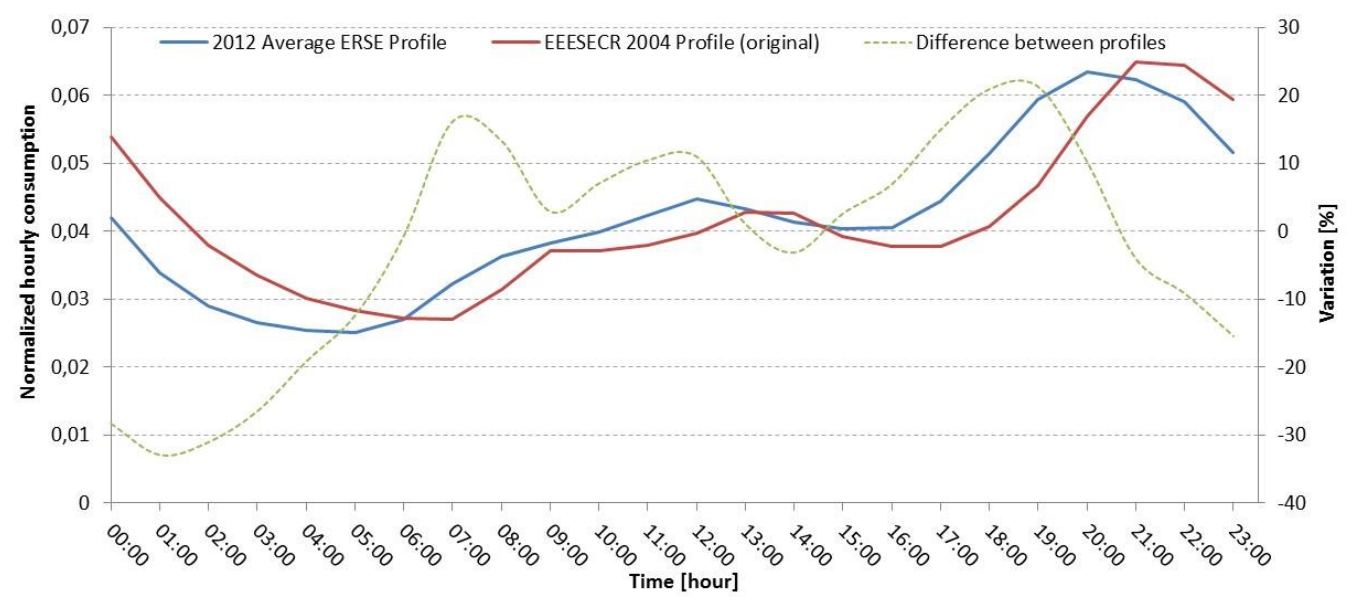

Figure 14 - Comparison between type C average ERSE for 2012 and the EEESECR2004 original profiles.

In Figure 15 the ERSE type C profile is compared with the updated values provided by (Ribeiro, 2012). Although the figure looks similar to the one with the original profile, the results consisted in an MPHV of $20.39 \%$, and MNHV of $36.32 \%$ with an average variation of $-1.40 \%$.

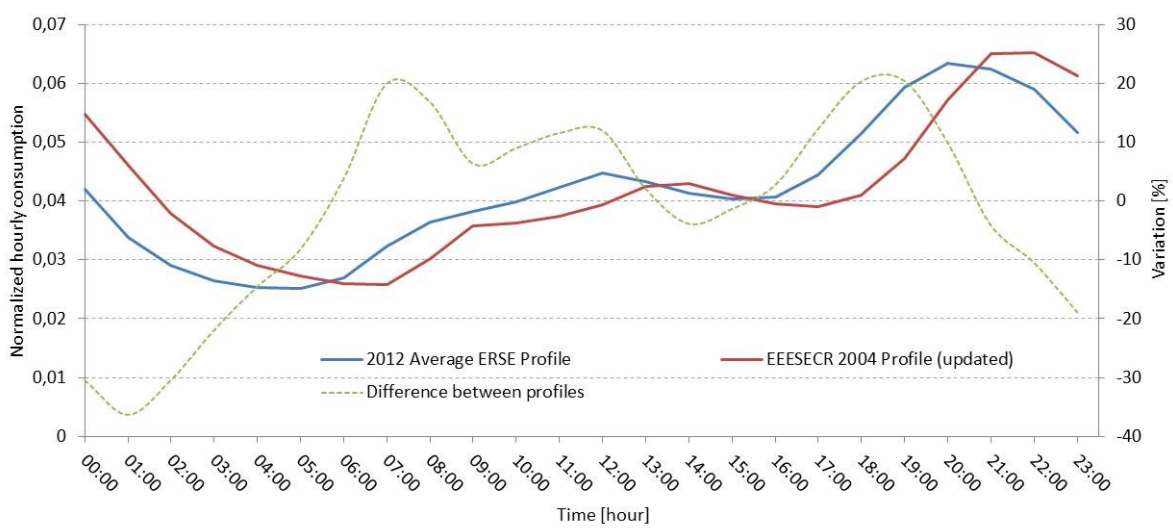

Figure 15 - Comparison between type C average ERSE for 2012 and the EEESECR2004 updated profiles.

Figure 16 presents the comparison between the ERSE type $\mathrm{C}$ profile and the REMODECE2008 diagram which represents a residential European average profile by end-use, for a typical day in Europe. 


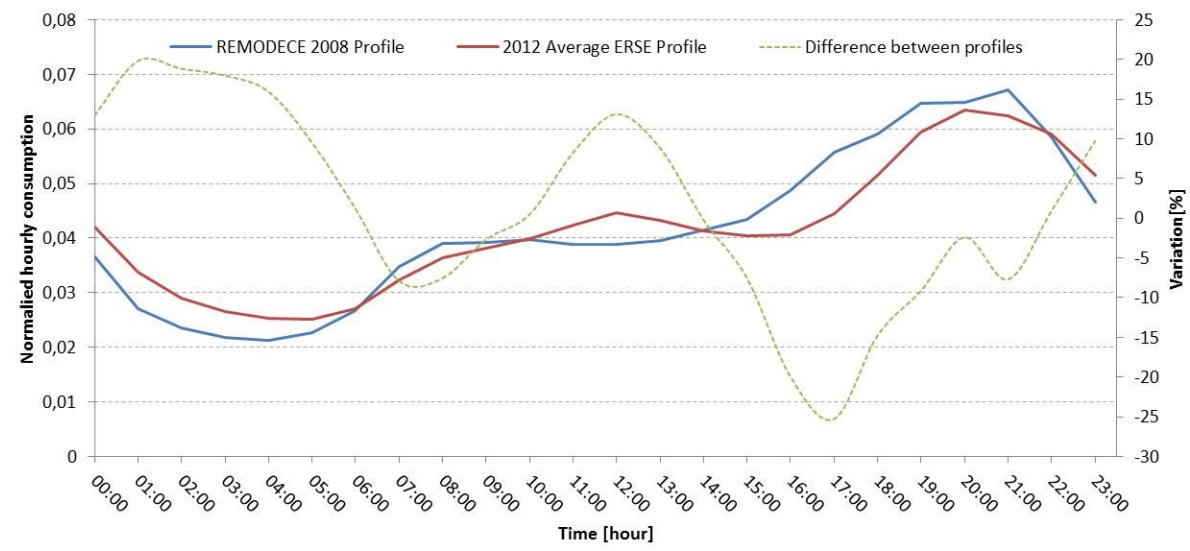

Figure 16 - Comparison between type C average ERSE for 2012 and the REMODECE2008 profiles.

Within this methodology and considering the concept for the regulated load profile it is also possible to compare the profiles provided by (DGGE/IP-3E, 2004) and (REMODECE, 2008) with the ERSE profile multiplied by the integral of consumption over time for each load diagram provided by the studies. Since the load profiles have the same sum and average, the MPHV, MNHV and AV are equal to the unitary vector counterparts.

\begin{tabular}{|c|c|c|c|}
\hline $\begin{array}{l}\text { Comparing the } 2012 \text { type C } \\
\text { ERSE profile with: }\end{array}$ & $\begin{array}{l}\text { Maximum Positive Hourly } \\
\text { Variation [\%] }\end{array}$ & $\begin{array}{l}\text { Maximum Negative Hourly } \\
\text { Variation [\%] }\end{array}$ & $\begin{array}{l}\text { Average } \\
\text { Variation [\%] }\end{array}$ \\
\hline 2012 REN type C average profile & 4.93 & -6.14 & 0.11 \\
\hline $\begin{array}{l}\text { (DGGE/IP-3E, 2004) } \\
\text { (EEESECR2004 original) }\end{array}$ & 21.31 & -32.94 & -1.81 \\
\hline $\begin{array}{l}\text { (Ribeiro, 2012) (EEESECR2004 } \\
\text { updated) }\end{array}$ & 20.39 & -36.21 & -1.40 \\
\hline (REMODECE, 2008) & 19.84 & -25.27 & 1.36 \\
\hline
\end{tabular}

Table 9 - Summary table of the differences between profiles.

Table 9 presents the summary table of results comparing the profile provided by ERSE which has more similarity to domestic consumption with the other profiles under study.

\subsubsection{Estimating an average load profile for Demand Response simulation}

Ribeiro (2012) used the updated ownership rates of INE, I.P. \& DGEG (2011) to change the hourly end-use impact of the consumption diagram presented by (DGGE/IP-3E, 2004). Using this information and separating the household equipment by different types of control, namely, schedulable and interruptible, interruptible and controllable, and non-controllable loads (Livengood \& Larson, 2009) (Livengood D. J., 2011) (Zeilinger, 2011), it is possible to verify that on 
average some kind of control is possible over $48,79 \%$ of loads. This information is provided in Table 10.

\begin{tabular}{cccccccc}
\hline \multicolumn{7}{c}{ Type of loads [\%] } \\
\hline \multicolumn{2}{l}{ Schedulable \& Interruptible } & \multicolumn{2}{c}{$\begin{array}{c}\text { Interruptible and } \\
\text { Controllable }\end{array}$} \\
\hline $\begin{array}{c}\text { Clothes } \\
\text { Washer }\end{array}$ & $\begin{array}{c}\text { Dish } \\
\text { Washer }\end{array}$ & $\begin{array}{c}\text { Clothes } \\
\text { dryer }\end{array}$ & Lighting & $\begin{array}{c}\text { Cold } \\
\text { Appliances }\end{array}$ & $\begin{array}{c}\text { Office } \\
\text { Equipment }\end{array}$ & $\begin{array}{c}\text { Entertainment } \\
\text { Equipment }\end{array}$ & $\begin{array}{c}\text { Other } \\
\text { Applications }\end{array}$ \\
\hline 3,94 & 4,05 & 3,48 & 10,68 & 26,65 & 12,21 & 9,01 & 29,98 \\
\hline
\end{tabular}

Table 10 - Type of load by possibility of control (Miguel P. , Neves, Martins, \& Sousa, Review of load research studies applied to the Portuguese household sector, 2013).

Table 11 presents the electric domestic consumption in the city of Coimbra in 2010 , with the average electricity consumption, number of domestic electricity consumers and the values of total domestic and total electricity consumption.

\begin{tabular}{lllll}
\hline City & $\begin{array}{l}\text { Average Electrical } \\
\text { Consumption } \\
{[\mathrm{kWh} / \mathrm{year}]}\end{array}$ & $\begin{array}{l}\text { \# Domestic Electricity } \\
\text { Consumers }\end{array}$ & $\begin{array}{l}\text { Total domestic } \\
\text { consumption }(\mathrm{kWh}]\end{array}$ & $\begin{array}{l}\text { Total electric } \\
\text { consumption [kWh] }\end{array}$ \\
\hline Coimbra & $2.966,10$ & 76.642 & $227.327 .836,20$ & 807.695 .514 \\
\hline
\end{tabular}

Table 11 - Electric domestic consumption in the City of Coimbra for the year of 2010 (Miguel, Neves, \& Martins, 2014).

The final fitting process considered the updated ownership rate of appliances of (Ribeiro, 2012) and the domestic sector electricity consumption as in Table 11. The hourly impact (percentage) of each appliance/equipment is maintained. Using the methodology represented in Figure 12, this hourly impact is multiplied by the total load demand for each hour, obtaining the load demand per equipment for a specific city, as in Figure 17.

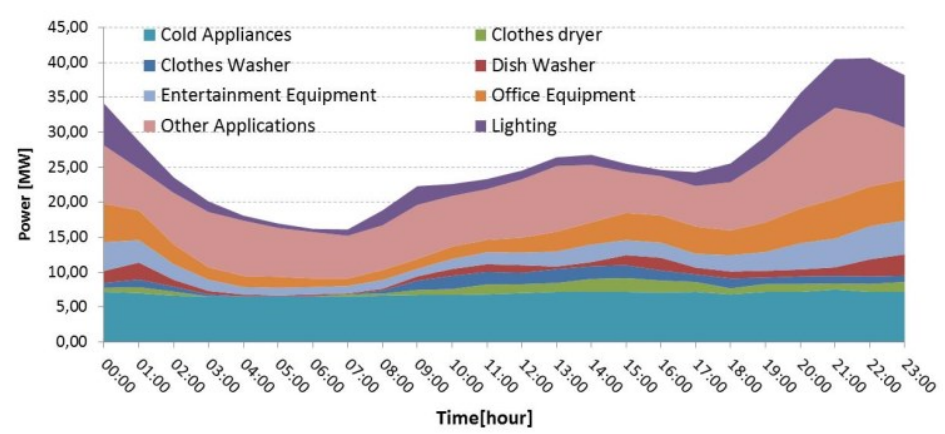

Figure 17 - Estimation of the distribution of electrical energy for the average day for the city of Coimbra with loads represented by decreasing regularity of the standard deviation (Miguel P. , Neves, Martins, \& Sousa, 2013). 
This consumption end use graph is obtained with an MPHV of $20.39 \%$, MNHV of $36.21 \%$ and AV of $-1.40 \%$. The load diagram provided by Ribeiro (2012) was selected because there was a larger segregation of end-uses and this was considered more favorable for the set of possible actions of Demand Response. For example, in REMODECE (2008) there was an end-use segregation between refrigeration, lighting, laundry washing and drying (these two were combined), pc \& peripherals, cooking, tv and peripherals, hvac and others. The national study performed by DGGE/IP-3E (2004) with updated information provided by Ribeiro (2012) took into consideration individual equipment for refrigeration, clothes washer, clothes dryer, dish washer, office equipment, entertainment, lighting and other applications. Both studies considered 24 hour load diagrams.

From the obtained results it is possible to conclude that a relation exists between the regulated typical profiles with profiles provided by load research studies considering the variation/difference among them.

One possible advantage of the developed methodology is the capability to assess the relevance of the Energy Box for a municipality or other relevant circumscription as a city or neighborhood by using information regarding: the electrical energy consumption, the existence of regulated consumption profiles, the hourly information regarding the average energy usage of households.

The information provided by this methodology is useful to model the importance of each end-use, therefore enabling the study of DSM and DR actions.

A limitation of this methodology, represented in Figure 18, is that there is only information on national shares of equipment/appliances and hourly rates of consumption for Portugal Mainland at the national level. Another limitation is that the result is an average value for the whole year, not allowing an evaluation of the different seasons of the year. 


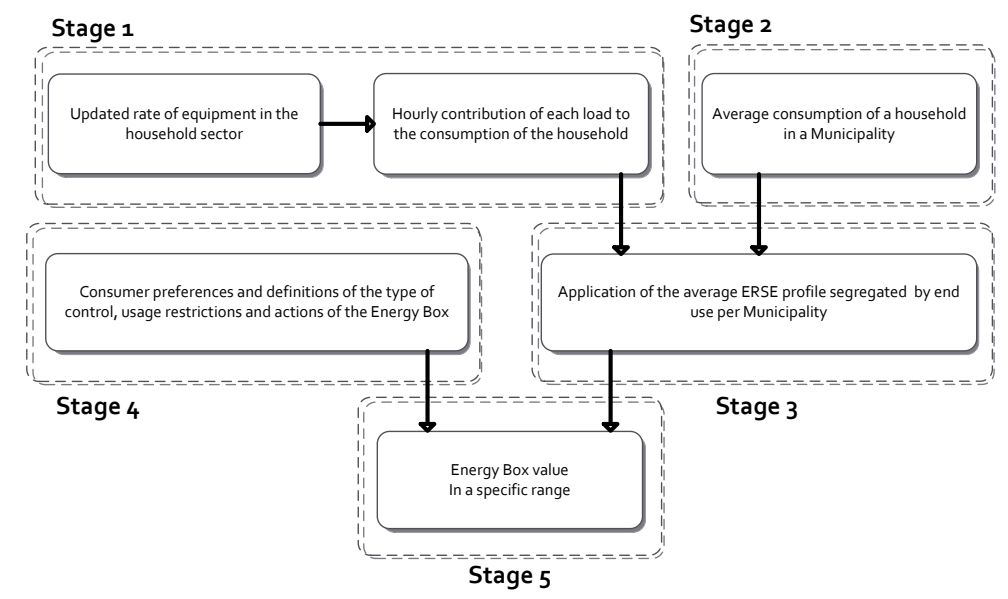

Figure 18 - Methodology to determine the Energy Box value in 5 stages.

A more extensive description regarding the methodology represented in Figure 18 is provided in Table 12. Stages 4 and 5 were not possible to reach.

\begin{tabular}{ccc}
\hline Stage \# & Description & Status \\
\hline Stage 1 & $\begin{array}{c}\text { Obtaining an up-to-date information regarding the hourly impact of major equipment in the } \\
\text { household split by type/possibility of control. }\end{array}$ & $\checkmark$ \\
\hline Stage 2 & $\begin{array}{c}\text { Obtaining an updated average electrical energy consumption value for the residential } \\
\text { sector for a Municipality. }\end{array}$ & $\checkmark$ \\
\hline Stage 3 & $\begin{array}{c}\text { Using the ERSE type C profile to integrate two types of information: The energy } \\
\text { consumption value per Municipality and the hourly distribution share of each type of load } \\
\text { will consist in a load diagram (LD). An individual average household LD is provided per } \\
\text { Municipality. }\end{array}$ & $\checkmark$ \\
\hline Stage 4 & $\begin{array}{c}\text { Obtaining a set of manipulated load diagrams from the stage 3 LD result. The type of } \\
\text { control over the household resources allowed by homeowners has to be considered. }\end{array}$ & $\mathbf{x}$ \\
\hline Stage 5 & $\begin{array}{c}\text { The Energy Box range value is determined in a specific confidence interval. Subtraction } \\
\text { of the results achieved in stage 3 and stage 4. }\end{array}$ & $\mathbf{x}$ \\
\hline
\end{tabular}

Table 12 - Description of the initial idea for the developed methodology and status.

So far, this methodology resembles a top-down approach, however, it is not possible to reach stages number four and five (apply DR actions), because there are still many unknowns, such as:

- The number of appliances/equipment that operate in an average day.

- The number of appliances/equipment that operate in each hour of the day.

The possibility of applying DR actions without answering these two questions first is quite remote, but the already achieved results can be used to help implementing a bottom-up simulation per end-use, representing the individual contribution of each load or appliance, e.g., at a city level.

This method, described in the next section, will make use of the average diagram for the whole year. 


\subsection{Simulating the household energy usage in the city of Coimbra}

According to Livengood \& Larson (2009), and later, Livengood D. J (2011), the Energy Box is best operated in an environment of demand-sensitive real-time pricing. The capacity of automatic decision of the Energy Box will enable minuteby-minute decisions over the course of the day. The possibility to act on the load diagram is also an advantage and an old ambition, performing peak clipping, valley filling and load shifting, thereby reducing the need for capacity expansion in electrical power generation and distribution. The Energy Box also manages on-site energy generation, storage and sale of electricity back to the grid. The use of the Energy Box should result in reduced electrical energy costs to the electric energy consumer. Therefore, it is relevant in a smart grid context to evaluate the Energy Box resource as a way to determine the motivation for a distribution system operator to encourage or stimulate its installation.

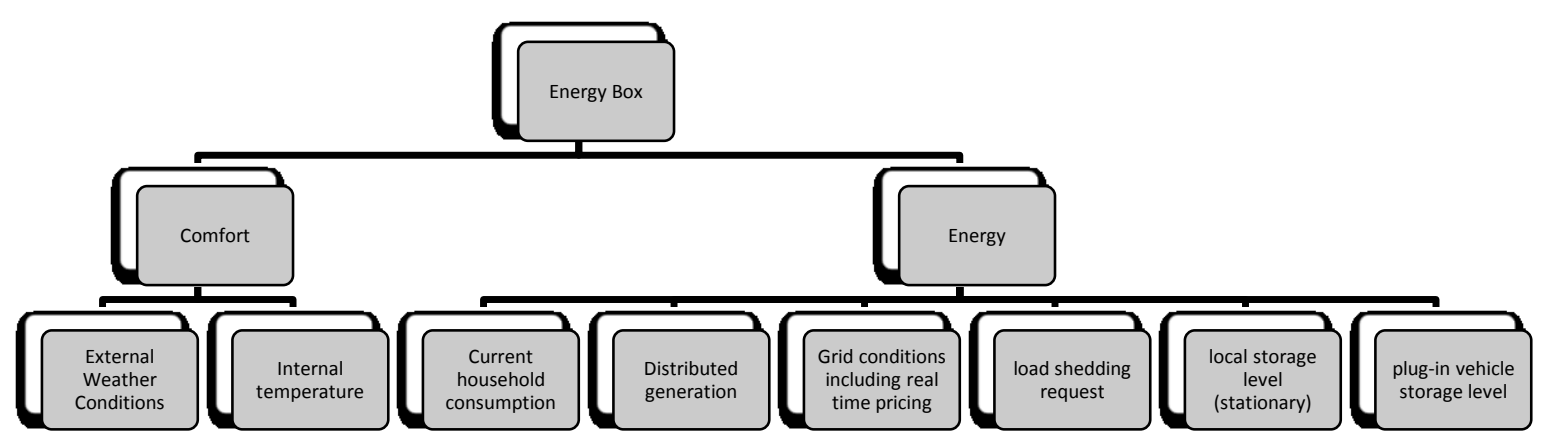

Figure 19 - Energy Box operating conditions, based on (Livengood \& Larson, 2009).

The idea expressed in Figure 19, based in the original vision of Livengood \& Larson (2009), analyzing the set of resources available in households, combining consumer preferences and restrictions related to load control and simulating different scenarios to analyze the Energy Box resource according, e.g., to the resource deployment status, type of consumers and season of the year, can bring an innovative perspective to residential energy management systems. 


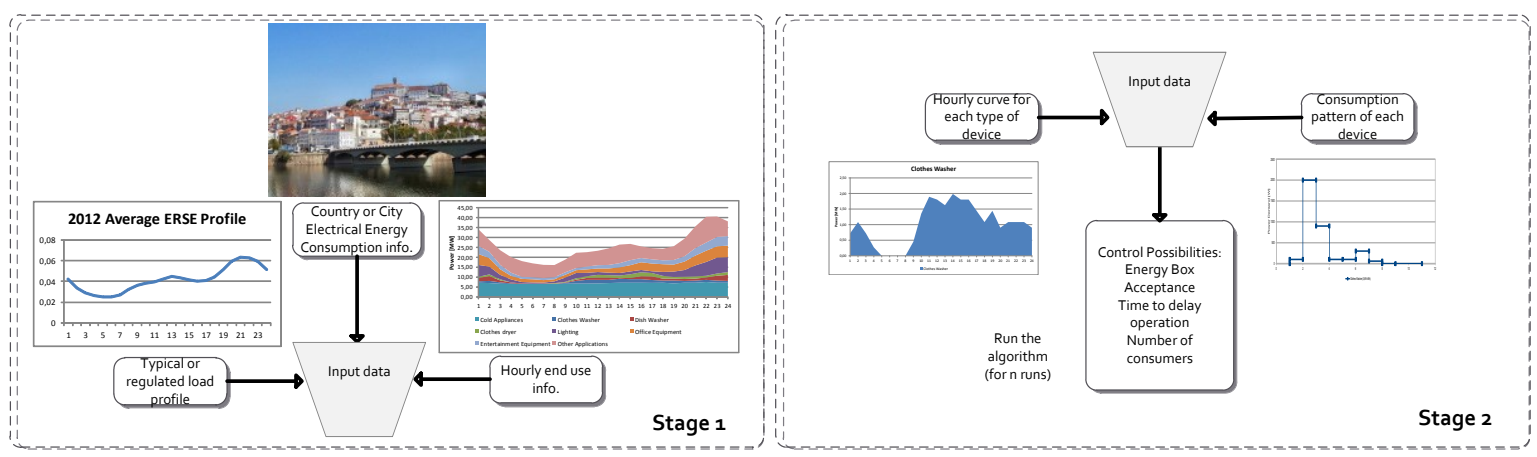

Figure 20 - Developed Methodology for determining the value of the Energy Box (redefined).

The redesigned methodology was developed in a top-down approach and later on in a bottom-up strategy, trying on one hand to make use of existent information for posterior modeling in the bottom-up framework, as represented in Figure 20 (in stage 1), and later on, to have some sort of control over household resources (stage 2).

\subsection{Selecting appliances for DR actions - Possible control over S\&I loads}

For the purposes of the selected simulation, an indirect load management method was chosen, based on a real time pricing program, making use of consumer reaction to price. However, in order to implement a simulation, there is still the need to know the amount of time that consumers allow the operation of appliances to be postponed, and what is the consumer acceptance for this kind of technological aid. Another relevant aspect is to know what appliances are seen as more appropriate to make use of demand response actions.

The Smart-A project (Mert, 2008) can shed some light around these topics. In (Mert, 2008) consumers were confronted with three simplified scenarios in order to estimate what possible control could be exerted over appliances, namely:

- Mode A: The user defines the instant when the energy service must be provided. The start of the operation is defined by some sort of signal that indicates, e.g. the availability of renewable energy. This mode may be applied to the washing machine, tumble dryer, dish washer and air conditioner.

- Mode B: The user decides (after evaluating) what is the best period for the appliance to start its energy service, allowing or not allowing the delay of 
the start of the machine. This mode may be applicable to the washing machine, tumble dryer, dish washer and air conditioner.

- Mode C: The existence of short interruptions during the operation of appliances is allowed. This mode may be applied to the air conditioner, refrigerator, freezer, electric water heater, electric heated boiler and central heating pump.

It was also stated in the Smart-A project (Mert, 2008) that consumers would accept all three presented options and that there were no clear preferences for one of the presented operation mode. Simulations were based on the B mode since it provides the user a good flexibility of choice and has no identifiable drawbacks, as shown in Table 13. For the sake of simplicity, the feature of waiting for the availability of renewable power generation was not included.

The survey performed by (Lopes, Peixoto, Antunes, \& Martins, 2014) regarding the willingness of consumers to smart operation in Portugal, states that only $35 \%$ of respondents were willing to accept the control of their appliances by an outside entity. This share of willingness was increased to $44 \%$ under an hypothetical future scenario of dynamic electricity pricing, which was also selected.

As for the appliances that were selected to perform the simulations of demand response, they are the ones that are described in Mode $B$, with the exception of the air conditioner, because not enough information was available to characterize this end use at the residential sector.

\begin{tabular}{|c|c|c|}
\hline Mode & Advantages & Disadvantages \\
\hline A & $\begin{array}{l}\text { Requires less user interaction, only setting } \\
\text { the appliance and users are able to } \\
\text { determine the finish of operation. }\end{array}$ & $\begin{array}{l}\text { Users do not define the start of operation because it depends of the } \\
\text { availability of renewable energy. This mode may use conventional energy } \\
\text { sources because the finish of the operation is user defined. }\end{array}$ \\
\hline$B$ & $\begin{array}{l}\text { The users are given more control over } \\
\text { appliances and it is possible to force the } \\
\text { usage of renewable energies (wait for } \\
\text { renewables). }\end{array}$ & Not identified. \\
\hline C & $\begin{array}{l}\text { The most convenient operation for users } \\
\text { because no user intervention is required. }\end{array}$ & $\begin{array}{l}\text { Fear of loss of control and comfort, technological reliability, doubts } \\
\text { regarding energy efficiency. Because of the existence of night tariffs and } \\
\text { the operation of appliances during this period, users could not see the } \\
\text { advantages of this operation. }\end{array}$ \\
\hline
\end{tabular}

Table 13 - Advantages and disadvantages for different operation modes in appliances, based on Smart-A project (Mert, 2008).

The acceptance of smart operation by consumers, assessed by (Mert, 2008), was very high for all three operation modes. This acceptance ranged from $88 \%$ to $97 \%$ 
for the clothes washer, from $85 \%$ to $96 \%$ for the clothes dryer and between $88 \%$ to $96 \%$ for the dish washer.

The survey performed by Lopes, Peixoto, Antunes, \& Martins (2014) confirms the validity of these choices, for the Portuguese reality. According to these authors, $68 \%$ of consumers are willing to voluntary change the time of use of their appliances, despite not having been given any benefit. The appliances that exhibited the higher availability to postpone the start of operation were the laundry machine and the dishwasher.

Despite the fact that consumers that participated in the Smart-A project expressed a very high acceptance, they also conveyed the message of some concern regarding the automatic operation of appliances.

For instance, in regard to the clothes washer, consumers are afraid that: clothes may be damaged due to smart operation, clothes might get moldy or the quality of the wash may be affected due to a long stay in the machine or even the noise of the machine working in the night may disturb people who want to sleep in the household.

As for concerns of consumers regarding the automatic operation of the clothes dryer and despite the fact that the acceptance was very high, a postponement may not always make sense because consumers may want to wait for the end of the washing cycle. According to Mert (2008) this acceptance might be explained because the clothes dryer is seen as a non-ecological appliance for which the appearance of a smart clothes washer is seen as positive for the environment. Another objection regards the quality of the drying process. Consumers are afraid that leaving the laundry in the machine for an extended period of time can wrinkle clothes.

The dish washer is the appliance that consumers see as more flexible. This might be explainable because consumers are not concerned with the time of operation of this appliance and because the operation of this appliance already occurs at night or when consumers are not at home, despite the concern with noise during the night. 
However, without further information it is difficult to predict the overall acceptance and adherence of consumers to smart operation as well as other restrictions to the operation of appliances.

Mert (2008) verified the level of consumer acceptance for smart operation in Austria, Germany, Italy, Slovenia and UK. The average acceptance of smart operation for the combination of these countries was referred to as "Average EU".

Figure 21 presents the acceptance of smart operation for the clothes washer. This acceptance for smart operation was the highest among the appliances under study. Generally, the acceptance of smart operation for the clothes washer was very high, with the average EU ranging from $94 \%$ value in operation mode A and mode $B$, to $95 \%$ value in operation mode $C$.

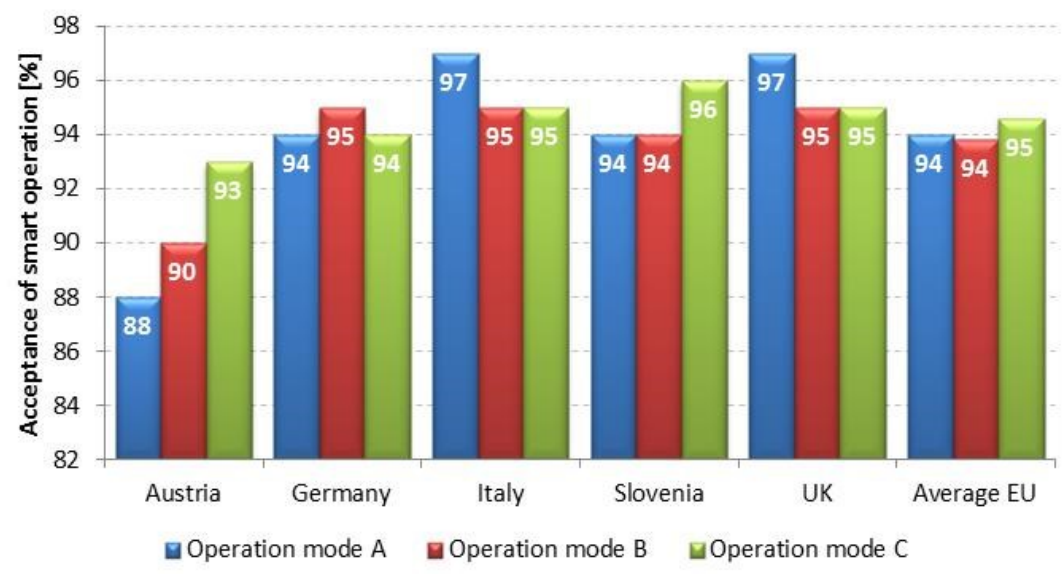

Figure 21 - Clothes Washer: Acceptance of Smart Operation, based on Smart-A (Mert, 2008).

Figure 22 presents the acceptance for the smart operation of the clothes dryer. This appliance is, among those that were considered, the one with less consumer willingness to such operation. However, this difference may be considered negligible due to high values of acceptance for all operation modes, ranging from $89 \%$ to $92 \%$ for the operation modes. 


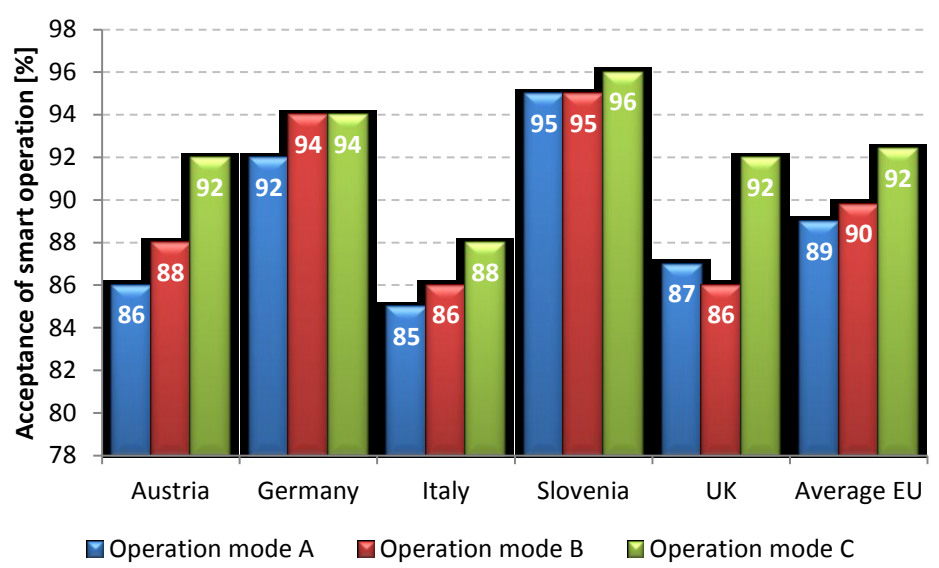

Figure 22 - Clothes Dryer: Acceptance of Smart Operation, based on Smart-A (Mert, 2008).

Figure 23 presents the acceptance of smart operation for the dish washer. The willingness for smart operation was also extremely high, ranging from $91 \%$ for mode $B, 92 \%$ for mode $A$ and $93 \%$ for mode $C$.

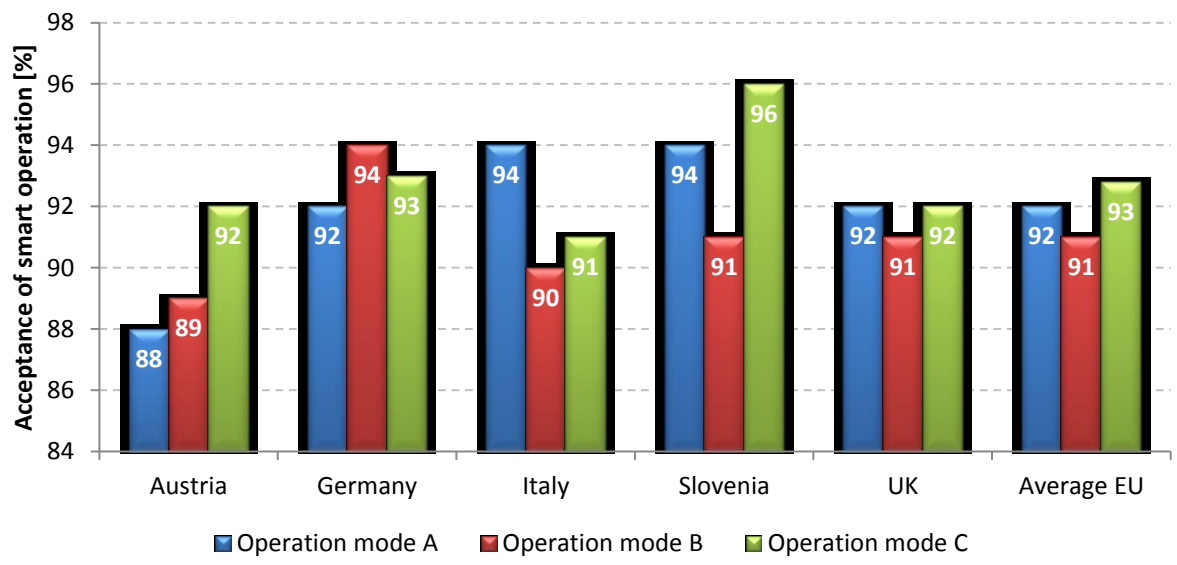

Figure 23 - Dish Washer: Acceptance of Smart Operation, based on Smart-A (Mert, 2008).

Three scenarios of consumer tolerances were assumed in the matlab simulation of the postponement of the start of appliances.

Scenario 1 uses the consumer tolerances as indicated in (Mert, 2008) for all appliances under study, Figure 24. 


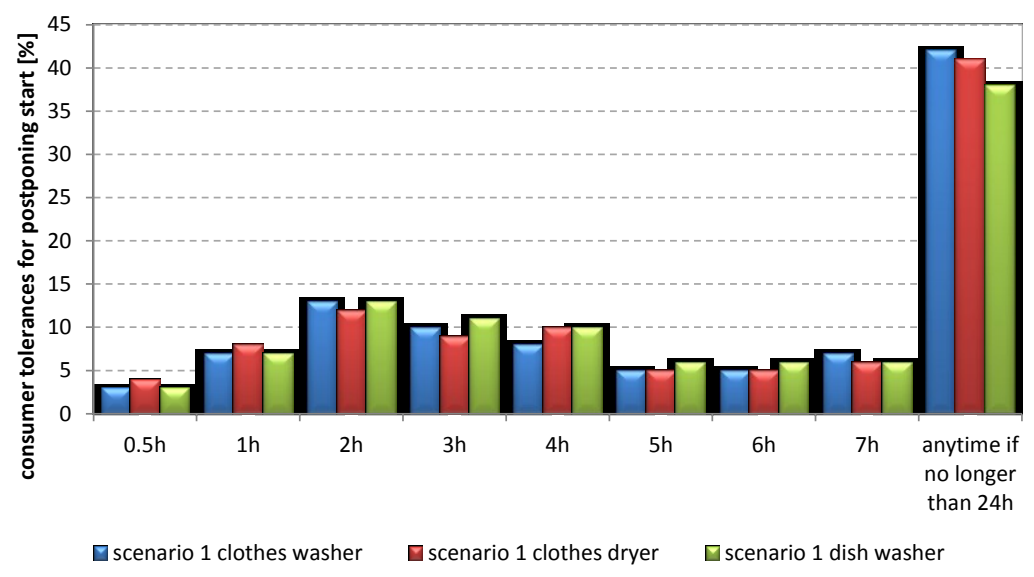

Figure 24 -Scenario 1 consumer tolerance for postponing start based on (Mert, 2008).

The consumer willingness in scenario 2, shown in Figure 25, use the Smart-A changed probabilities with the possibility for $24 \mathrm{~h}$ postponed start disabled. The expressed tolerance for postponing the start for $24 \mathrm{~h}$ was proportionally distributed by the other possible choices.

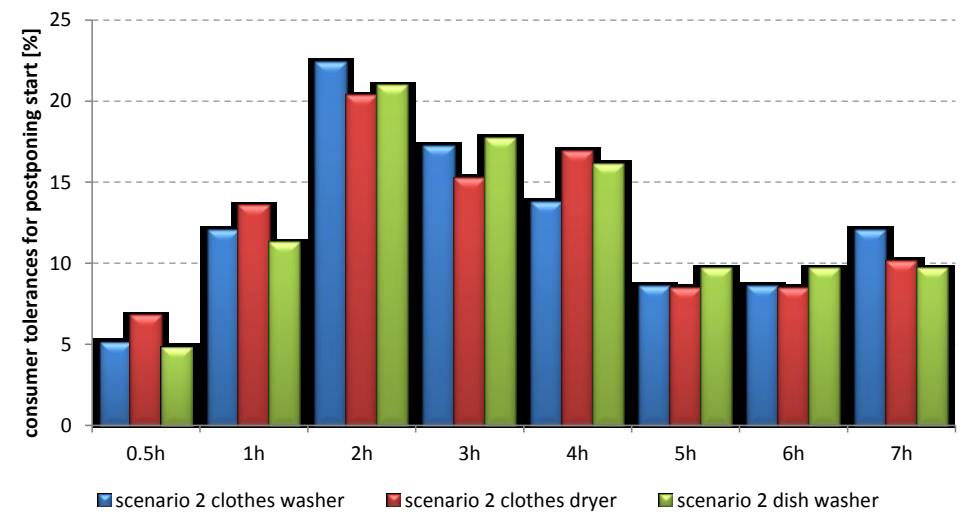

Figure 25 - Scenario 2 - Smart - A probabilities without the possibility of postponing $24 \mathrm{~h}$.

The probabilities for postponing start which are shown in Table 14, are adapted from (Jamasb \& Pollitt, 2011) and comprise the boundaries of scenario 3.

\begin{tabular}{ccccc}
\hline Type of appliance & \multicolumn{5}{c}{ Penetration factor Shifting Capabilities Duration per Cycle No. of Cycles per day (million) } \\
\hline Washing machine 1h & $20 \%$ & $1 \mathrm{~h}$ & $2 \mathrm{~h}$ & 5 \\
\hline Washing machine $2 \mathrm{~h}$ & $20 \%$ & $2 \mathrm{~h}$ & $2 \mathrm{~h}$ & 5 \\
\hline Washing machine 3h & $20 \%$ & $3 \mathrm{~h}$ & $2 \mathrm{~h}$ & 5 \\
\hline Aggregated WM & $60 \%$ & Up to $3 \mathrm{~h}$ & $2 \mathrm{~h}$ & 15 \\
\hline Dishwasher & $80 \%$ & $6 \mathrm{~h}$ & $2 \mathrm{~h}$ & 20 \\
\hline Washer-Dryer & $20 \%$ & $3 \mathrm{~h}$ & $4 \mathrm{~h}$ & 5.3 \\
\hline
\end{tabular}

Table 14 - Appliances information from (Jamasb \& Pollitt, 2011). 
A summary of the adapted probabilities of scenario 3 is presented in the graphical visualization provided by Figure 26.

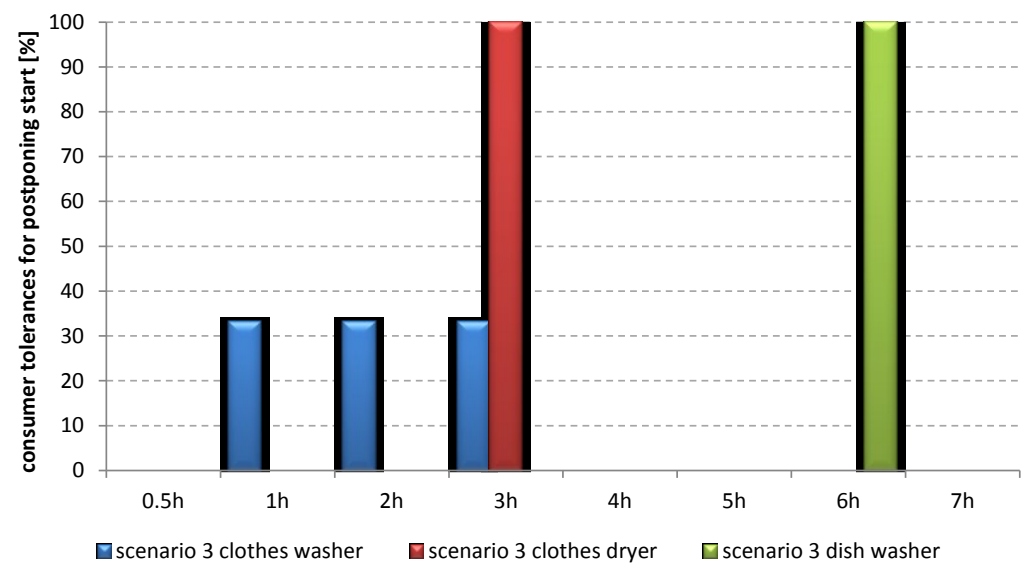

Figure 26 - Scenario 3, Adapted probabilities from (Jamasb \& Pollitt, 2011).

In Figure 27, the three scenarios of consumer tolerances that were used in the simulation for postponing the start of appliances, and their respective maximum postponement time, are presented. In summary, this figure depicts scenario 1 which is based on Mert (2008), scenario 2 adapted from Mert (2008) without the possibility to postpone start $24 \mathrm{~h}$ and scenario 3 which is adapted from Jamasb \& Pollitt (2011).

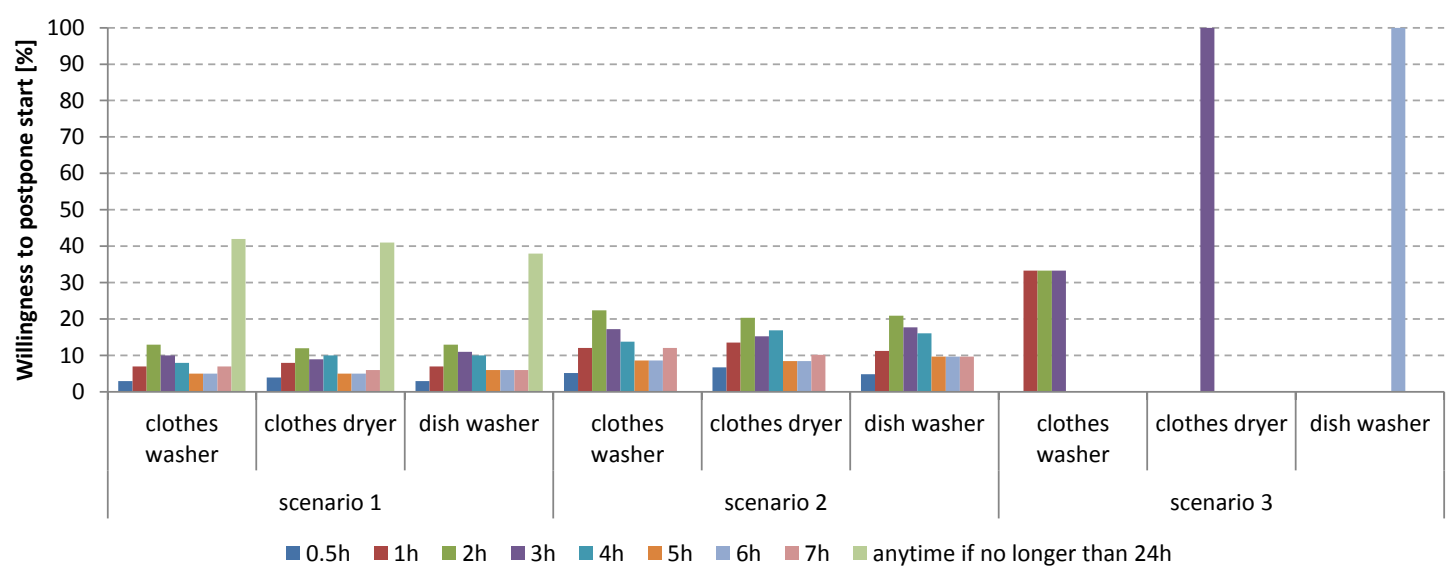

Figure 27 - Willingness to postpone start [\%] for the considered appliances. 


\subsection{Simulating schedulable \& interruptible (S\&I) loads}

\subsubsection{Clothes washer}

In order to simulate the effect of the intervention of the Energy Box first it is necessary to simulate the consumption for each load (or resource) under study.

Stamminger (2008) presents the power demand curve for an average washing process of a clothes washer with an energy consumption of $0.89 \mathrm{kWh}$ per cycle, for an average load of $5 \mathrm{~kg}$. The power demand curve represented in Figure 28 corresponds to a normal cotton washing program.

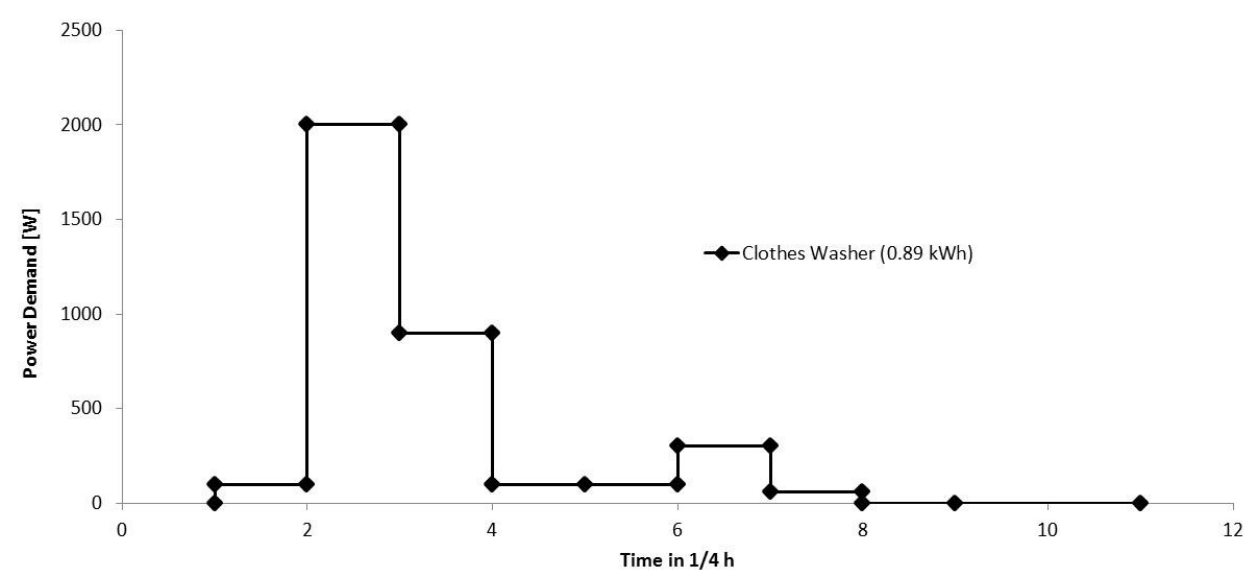

Figure 28 - General Pattern of a Power Demand Curve of a clothes washing machine cycle in $1 / 4$ hour steps (Stamminger, 2008).

The energy used for clothes washing in the city of Coimbra on an average day is 24.54 MWh (Miguel P. , Neves, Martins, \& Sousa, 2013). The data regarding the number of households, the ownership rate and the number of household electricity consumers with clothes washer is provided in Table 15.

\begin{tabular}{ccc}
\hline $\begin{array}{c}\text { Number of household electricity } \\
\text { consumers }\end{array}$ & ownership rate of clothes washer & $\begin{array}{c}\text { Number of household electricity } \\
\text { consumers w/ clothes washer }\end{array}$ \\
\hline 76.642 & 0.907 & 69.514 \\
\hline
\end{tabular}

Table 15 - Data regarding the penetration of the clothes washer in the city of Coimbra (INE, I.P. \& DGEG, 2011) and (PORDATA, 2013).

It is now possible to determine an approximate number of daily running cycles for the clothes washer by knowing the energy consumption in the entire electricity network and the individual energy consumption of the average equipment (eq. 1). 
Number of cycles per average day $=\frac{\text { Energy Consumption }[\mathrm{kWh} / \text { average day }]}{\text { Energy Consumption }[\mathrm{kWh} / \mathrm{cycle}]} \quad$ (eq. 1$)$

$$
=\frac{24.540,82}{0,89} \cong 27.574[\text { cycles/average day }]
$$

A final number of cycles to be simulated (27.574) is estimated multiplying the probability for each $1 / 4$ hour cycle (96 total for one day) by the total number of cycles of the average day. The determined number of cycles means that only $39.67 \%$ of the clothes washer appliances perform a complete cycle on the average day.

The probability of energy consumption for each quarter-hour is determined by multiplying the power demand of each quarter-hour of the original estimated clothes washer diagram (Figure 17) per this time frame duration and dividing the result by the total daily energy demand for all the appliances and finally multiplying it by 100 . The distribution of the number of cycles that occur in each quarter-hour and its corresponding approximated distribution of probability is exhibited in Figure 29.

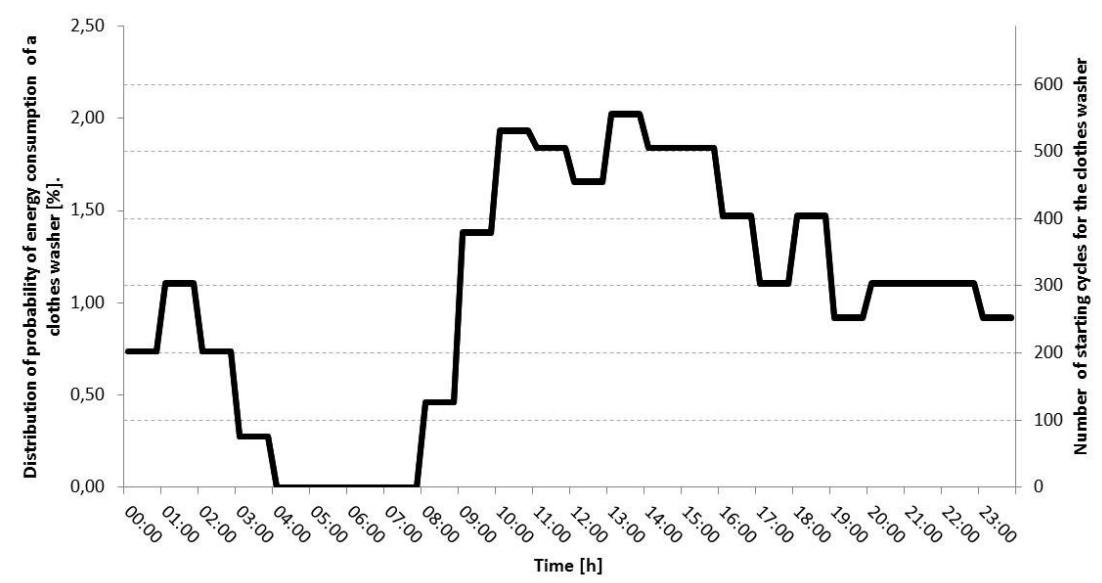

Figure 29 - Probability of energy consumption and number of cycles for the average day for clothes washing in the City of Coimbra (Miguel, Neves, \& Martins, 2014). 
By understanding how many cycles occur in each quarter-hour it is possible to develop a simulation that reproduces load demand for the average day, as plotted in Figure 30.

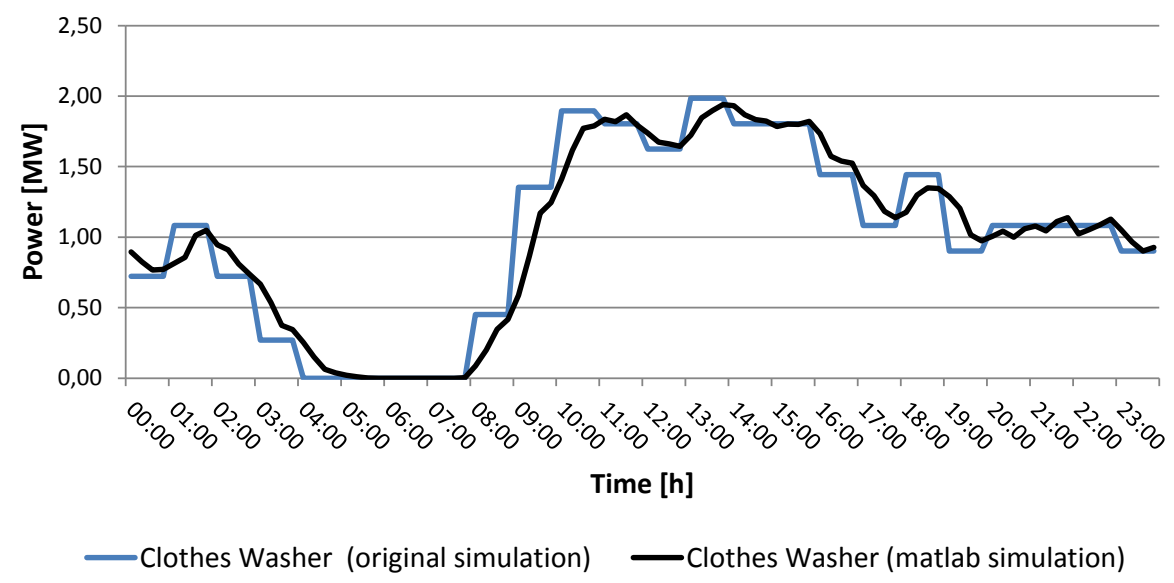

Figure 30 -Simulating the average consumption of clothes washing at Coimbra in Matlab (Miguel, Neves, \& Martins, 2014).

The results presented in Table 16 which enable the comparison between the original simulation and the matlab simulation are rather similar.

\begin{tabular}{llll}
\hline & Descriptive Statistics & Original & Simulation \\
\hline & Mean & 1.0225 & 1.0217 \\
& Standard Error & 0.0651 & 0.0629 \\
& Median & 1.0827 & 1.0495 \\
& Standard Deviation & 0.6374 & 0.6164 \\
& Sample Variance & 0.4063 & 0.3800 \\
& Minimum & 0 & 0 \\
& Maximum & 1.9850 & 1.9399 \\
\hline & Consumption [MWh] & 24.54 & 24.52 \\
\hline
\end{tabular}

Table 16 - Descriptive Statistics for the clothes washer.

\subsubsection{Clothes dryer}

The average power demand curve for the clothes dryer is also presented by Stamminger (2008). The profile represented in Figure 31 exhibits an energy consumption of $2.49 \mathrm{kWh}$ per cycle. 


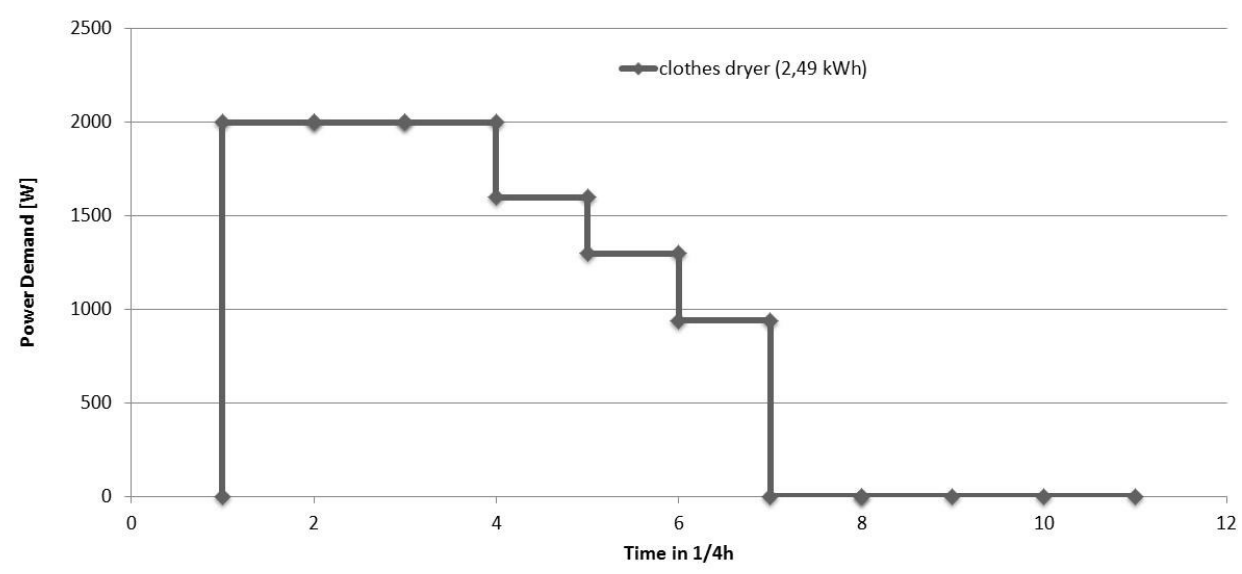

Figure 31 - General Pattern of a Power Demand Curve of a clothes dryer cycle in 1/4 hour steps (Stamminger, 2008).

The data regarding the number of households, the ownership rate and the number of household electricity consumers with clothes dryer, is provided in Table 17.

\begin{tabular}{ccc}
\hline $\begin{array}{c}\text { Number of household electricity } \\
\text { consumers }\end{array}$ & $\begin{array}{c}\text { Ownership rate of clothes dryer } \\
\text { (INE 2010) }\end{array}$ & $\begin{array}{c}\text { Number of household electricity } \\
\text { consumers w/ clothes washer }\end{array}$ \\
\hline 76.642 & 0.223 & 17.091 \\
\hline
\end{tabular}

Table 17 - Data regarding the penetration of the clothes dryer in the city of Coimbra.

The ownership rate of the clothes dryer is lower than the clothes washer's ownership rate, despite the similar total energy consumption in the City. This is explainable due to the higher energy consumption value: $0.89 \mathrm{kWh}$ per cycle for the clothes washer and $2.49 \mathrm{kWh}$ per cycle for the clothes dryer. Miguel P. , Neves, Martins, \& Sousa (2013) determined that the load demand to perform clothes drying for the average day was $21,659.52 \mathrm{kWh}$. By applying equation 1, a total of 8.699 cycles per day was determined.

The difference between the consumption of these two appliances is reflected on the calculated daily number of cycles and its distribution throughout the average day, as observable in Figure 32. 


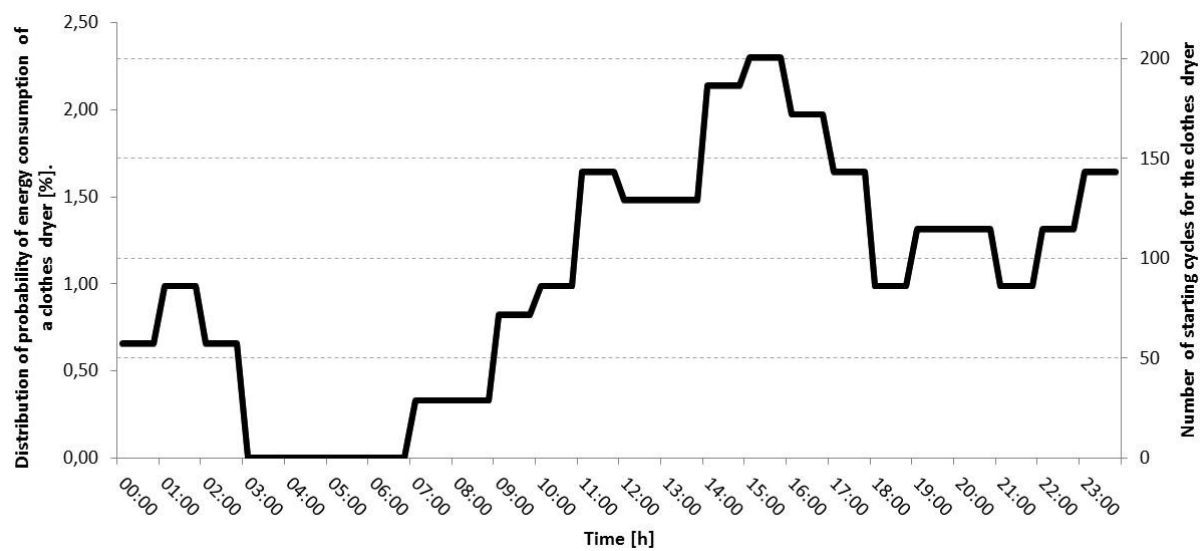

Figure 32 - Probability of energy consumption and number of cycles for the average day for clothes drying in the City of Coimbra (Miguel, Neves, \& Martins, 2014).

Figure 33 shows the clothes drying daily demand for both the original and the matlab simulations.

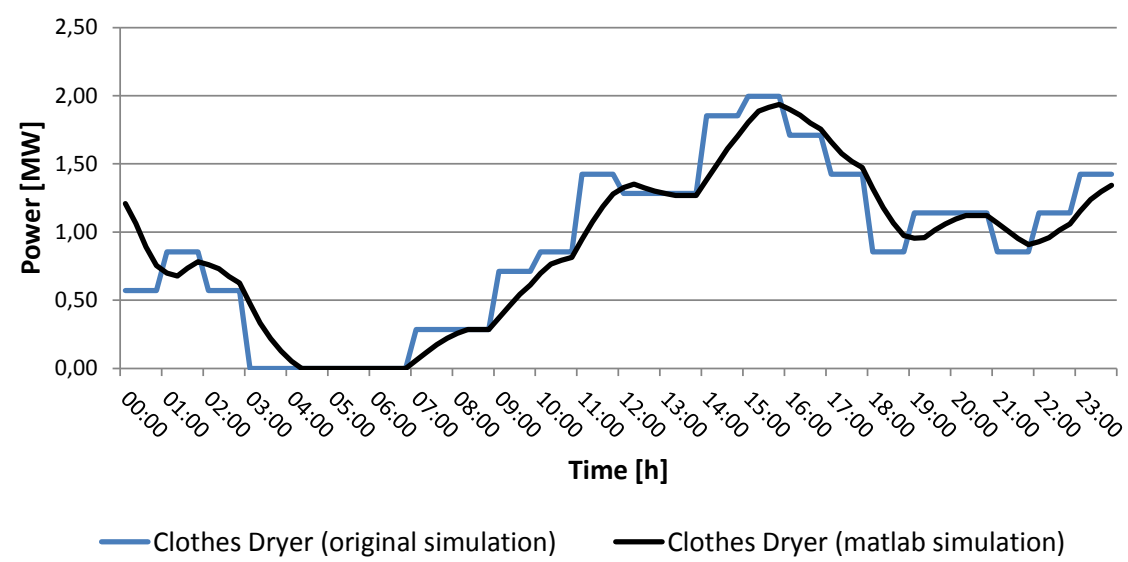

Figure 33 - Simulating the average consumption of clothes drying at Coimbra in Matlab (Miguel, Neves, \& Martins, 2014).

Similarly to what happened with the clothes washer, there is a great proximity between the statistical results for the original simulation and the matlab simulation, as observable in Table 18.

\begin{tabular}{llll}
\hline & Descriptive Statistics & Original & Simulation \\
\hline & Mean & 0.9025 & 0.8918 \\
& Standard Error & 0.0604 & 0.0571 \\
& Median & 0.8550 & 0.9582 \\
\multirow{3}{*}{ Power [MW] } & Standard Deviation & 0.5916 & 0.5597 \\
& Sample Variance & 0.3500 & 0.3133 \\
& Minimum & 0 & 0 \\
& Maximum & 1.99499 & 1.93664 \\
\hline & Consumption [MWh] & 21.66 & 21.40 \\
\hline
\end{tabular}

Table 18 - Descriptive Statistics for the clothes dryer (Miguel, Neves, \& Martins, 2014). 


\subsubsection{Dish washer}

The average power demand curve for the dish washer was also presented by Stamminger (2008). The profile exhibited in Figure 34 presents an energy consumption of $1.19 \mathrm{kWh}$ per cycle.

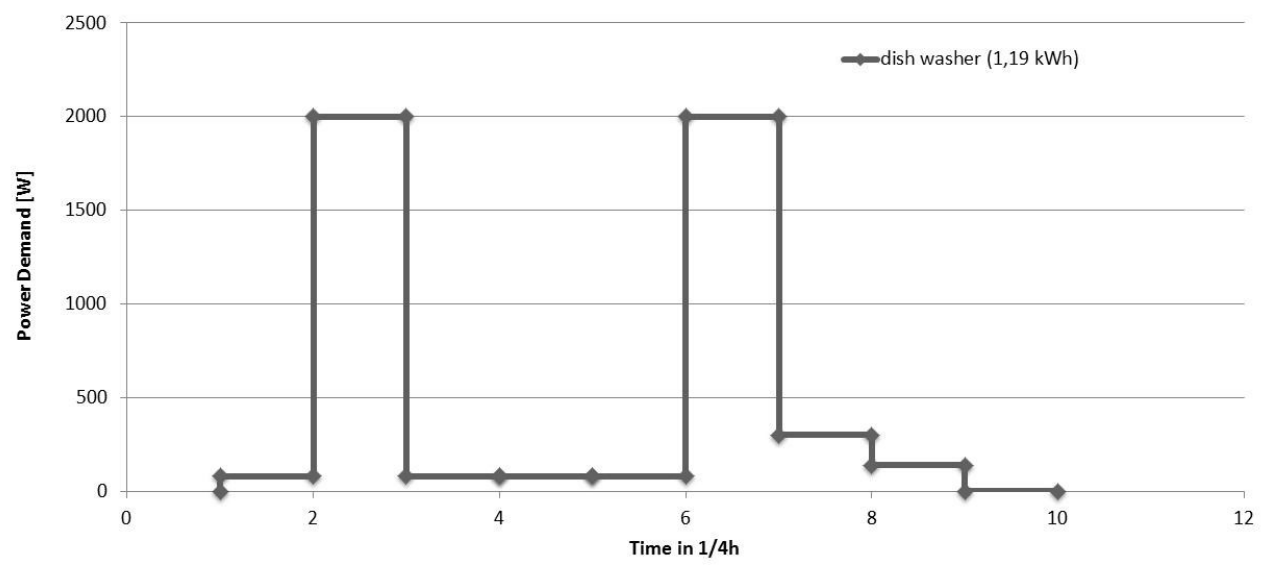

Figure 34 - General Pattern of a Power Demand Curve of a dish washer cycle in 1/4 hour steps (Stamminger, 2008).

The dish washer ownership rate in the city of Coimbra as shown in Table 19, stands between the ownership rates of the clothes washer and the clothes dryer.

\begin{tabular}{lll}
\hline $\begin{array}{l}\text { Number of household electricity } \\
\text { consumers }\end{array}$ & $\begin{array}{l}\text { Ownership rate of dish washers } \\
\text { (INE2010) }\end{array}$ & $\begin{array}{l}\text { Number of household electricity } \\
\text { consumers w/ dish washers }\end{array}$ \\
\hline $\mathbf{7 6 . 6 4 2}$ & 0,408 & 31.270 \\
\hline
\end{tabular}

Table 19 - Data regarding the penetration of the dish washers in the city of Coimbra (INE, I.P. \& DGEG, 2011) and (PORDATA, 2013).

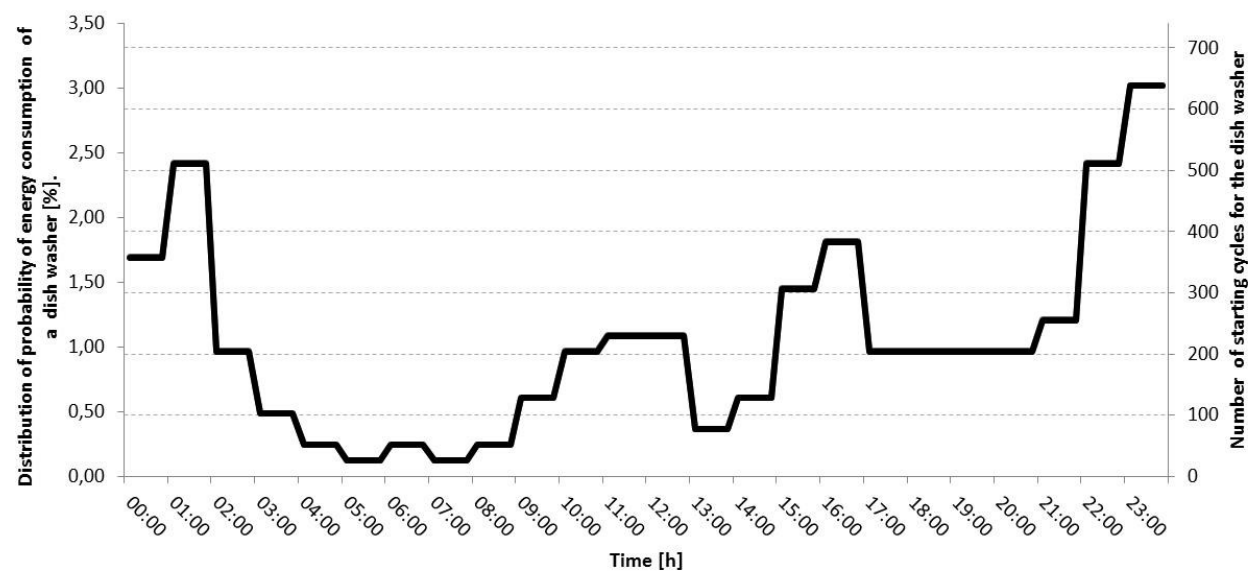

Figure 35 - Probability of energy consumption and number of cycles for the average day for dish washing in the City of Coimbra (Miguel, Neves, \& Martins, 2014). 
The original simulation presented the dish washer with an average daily load demand of $25,203.31 \mathrm{kWh}$, representing approximately 21,179 cycles per day, that are distributed along the day as shown in Figure 35.

Figure 36 displays the original simulation and the matlab simulation concerning dish washing operation.

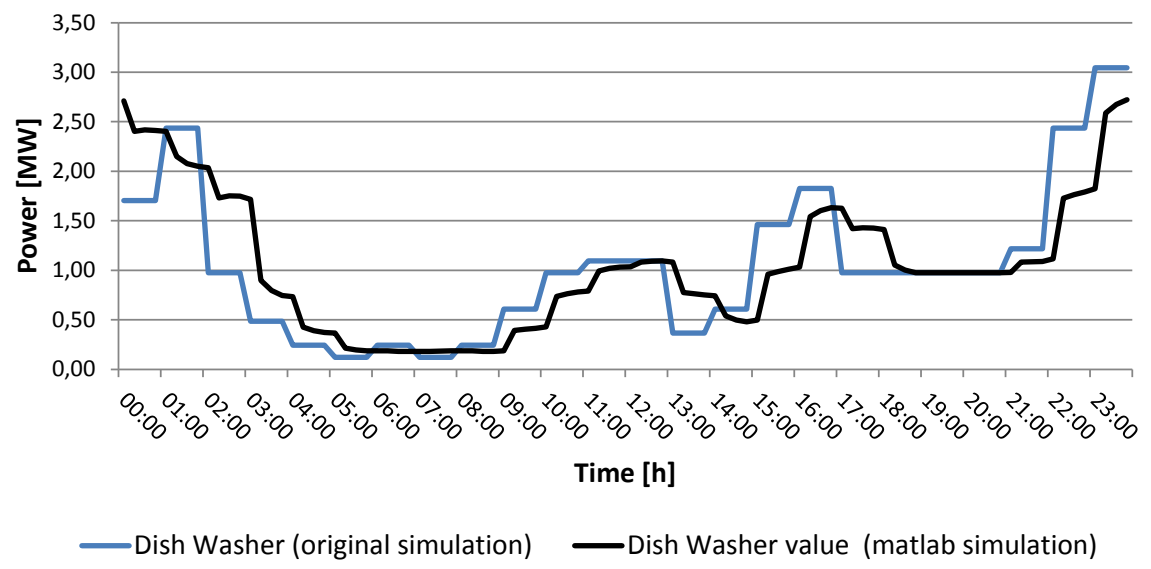

Figure 36 - Simulating the average consumption of dish washing at Coimbra in Matlab (Miguel, Neves, \& Martins, 2014).

The results comparing the original and the matlab simulations are provided in Table 20.

\begin{tabular}{llll}
\hline & Descriptive Statistics & Original & Simulation \\
\hline & Mean & 1.0501 & 1.0508 \\
& Standard Error & 0.0782 & 0.0706 \\
& Median & 0.9740 & 0.9758 \\
Power [MW] & Standard Deviation & 0.7658 & 0.6921 \\
& Sample Variance & 0.5865 & 0.4789 \\
& Minimum & 0.1218 & 0.1798 \\
& Maximum & 3.0439 & 2.7216 \\
\hline & Consumption [MWh] & 25.20 & 25.22 \\
\hline
\end{tabular}

Table 20 - Descriptive Statistics for the dish washer (Miguel, Neves, \& Martins, 2014).

\subsection{Simulation scenarios for the smart grid}

\subsubsection{Clustering techniques}

The need for developing a diversity of test scenarios concerning the deployment of the EB presents an opportunity for data classification, considering the large data sets for dynamic grid analysis, especially for the annual monitoring of distribution and residential load demand, energy prices and renewable generation. Cluster analysis is a convenient method for identifying homogenous groups of objects 
called clusters (Mooi \& Sarstedt, 2011), aiming to group objects by similarity, but keeping a significant difference between them.

This section presents a methodology to group information by similarity, to be used for analyzing the impact on the grid of the deployment of two competitive technologies, namely, a residential energy management system (Miguel, Neves, \& Martins, 2014) and a distributed energy storage system (Gonçalves, Vitorino, Neves, \& Martins, 2013), by providing reliable simulation prototypes of price, consumption and renewable generation daily profiles ${ }^{10}$. For the analysis of the deployment of the EB and its impact, this section will only consider price and residential load demand prototypes.

The cluster analysis which the current section describes used a hierarchical clustering method and an artificial neural networks method, implemented as toolboxes of the Matlab software.

\subsubsection{Hierarchical method (HM)}

According to Sousa J. M. (2006), the hierarchical clustering method investigates possible groupings of data by creating a structure similar to a hierarchical tree. Such tree, is comprised not only of a simple set of clusters, but rather of a multiple level hierarchy, where clusters at one level are grouped in clusters of a higher level. The basic procedure for developing the cluster prototypes is performed according to the following steps (Sousa J. M., 2006):

First, the input data is evaluated (price diagrams and consumption profiles) and a decision is taken on what kind of clustering results are valuable to obtain later on. This decision is based on either the amplitude difference between cluster members (defined as the difference between extreme values of a daily profile) or based on the diagram shape. For the price diagrams it was assumed that what is relevant to differentiate prototypes is the amplitude difference, while in electricity profiles (consumption) what is relevant is the diagram shape, which allows a better segmentation by type of the day (weekday/weekend).

\footnotetext{
10 The methodology for producing prototypes of load demand, price and renewable generation was jointly developed with other colleague and is currently submitted for publication in a scientific journal.
} 
The hierarchical classification method consists in performing a series of partitions that originate from one single cluster that contain all objects to $n$ clusters containing each one a single object. Still according to Sousa J. M. (2006) the hierarchical clustering techniques can be subdivided into agglomerative methods, identified as probably the most used method and for that reason was selected in this study, which carry out a series of successive mergers of $n$ objects into groups, or in a dividing method, that successively separate $\mathrm{n}$ objects into smaller groups. In both methods, divisions or mergers, once established are impossible to undo.

Sousa J. M. (2006) defines that such merges or divisions generate a series of data partitions: at the beginning there will be $\mathrm{n}$ clusters of a single object and at the end there will be only a single group which contains $\mathrm{n}$ objects. The basic operation of the methods will be, at each stage of the process, the fusion of objects or groups of objects which are closer to each other (or otherwise that are more similar). The methods arise from differences between the different forms of defining the distances between an object and a group containing various objects, or between two groups of objects. The divisions made at each stage of analysis are possible to represent by means of a diagram commonly referred to as two-dimensional dendogram.

As stated earlier, the hierarchical method consists in merging objects according to their linkage distance, namely: single, complete, average, centroid or ward distance, the latter being used in the present case. The ward distance is calculated based on the sum of the squares of the distances between all objects that compose the cluster and the cluster center.

After calculating distances between data members it is possible to group diagrams, according to their proximity (the shortest distance). As new clusters are created, comprised by more members, it is necessary to determine the distance between clusters until the hierarchical tree is composed by one single cluster.

Selecting the optimum point for interrupting the hierarchical method is a critical problem of this method, meaning that is necessary to determine a solution with the optimal number of clusters. This technique will be graphically exhibited in Figure 41 located in section 4.1 . 
A complete description on how to perform this technique can be either found in Sousa J. M. (2006) or in Everitt, Landau, Leese, \& Stalh (2011).

\subsubsection{Artificial neural networks (ANN) method}

The chosen artificial neural network method is based on the Kohonen selforganizing map (Kohonen, 1998). This method is able to convert nonlinear statistical relationships between elements of data into a simple geometric relationship on a low dimensional display, based on similarity and topology. Similarly to the hierarchical method, this clustering method is also an example of unsupervised learning because the classes for the output vectors are not initially known. The neural networks contain two layers: an input layer of $p$-dimensional observations and an output layer representing $k$ nodes for the $k$ clusters. The clustering process occurs when an input vector is assigned to an output node with a $p$-dimensional vector with $w$ weight. According to (Everitt, Landau, Leese, \& Stalh, 2011), a random weight is assigned to the output node which changes with the learning process, temporarily assigning neurons to clusters. The stabilization of the iterative process occurs when weights correspond to cluster centers in such a way that clusters that are similar to one another are situated close together on the map.

Sousa J. M. (2006) described the mathematical process of this method, as follows:

- The weight vectors with dimension $p$ associated to different neurons, initially with random values in the range $[0,1]$, are considered;

- The input data with dimension $p$, also in the range between $[0,1]$, will then be presented and confronted with the figures for the weight vectors;

- the Euclidean distance (or another type of distance that may also be specified) is calculated between the observation and the weight vector associated with each of the neurons;

- the neuron with the shortest distance ("winner" neuron) is then updated, as well as a small neighborhood of neurons around the "Winner" neuron. The weight of the neuron must become closer to the input $x$ standards, and then updated. 
The proposed methodology, represented in Figure 37, deals with two types of input data, namely, one year on a quarter hour time step for load generation diagrams and one year of hourly electricity gross market prices.

In order to choose how the data could be used, an experimental setup was performed for benchmarking the conclusions that derive from load profiling and forecasting (Sousa, Jorge, \& Neves, 2013).

The data clustering techniques were applied in two different modes: one using the input data without any treatment and a second one where the input data was subjected to a normalizing procedure. This experiment showed that in the case of the electricity profiles, the shape of the diagram is the relevant attribute while in the case of the price diagrams, the amplitude similarity between diagrams should be used. In both cases, it was necessary to initially adjust the data to the two daylight savings clock changes, namely, on March 30 and October 26 for that year.

In the clustering stage, the hierarchical method helps to choose the appropriate number of clusters, through the analysis of the tree dendogram and of the inflection point on the curve that relates the distances between clusters with the number of clusters (Salvador \& Chan, Nov. 2004). A comparison was made of the output of both methods regarding the assignment of day types (working day, Saturday, Sunday and holiday) to clusters.

As for the selection of the tariff schemes, there are currently three types of tariff schemes in Portugal: a flat rate, time-of-use rates with two different prices distributed during the day (peak hours and off-peak hours) and time-of-use rates with three prices (peak, partial peak and off-peak). (ERSE, 2012). Due to the organization of such schemes, only hourly tariff schemes will be considered for simulation purposes. The prices were obtained from the Iberian Energy Derivatives Exchange (OMIP, 2013). Although the spot price only reflects the gross market price, it is the best available proxy to be used. 


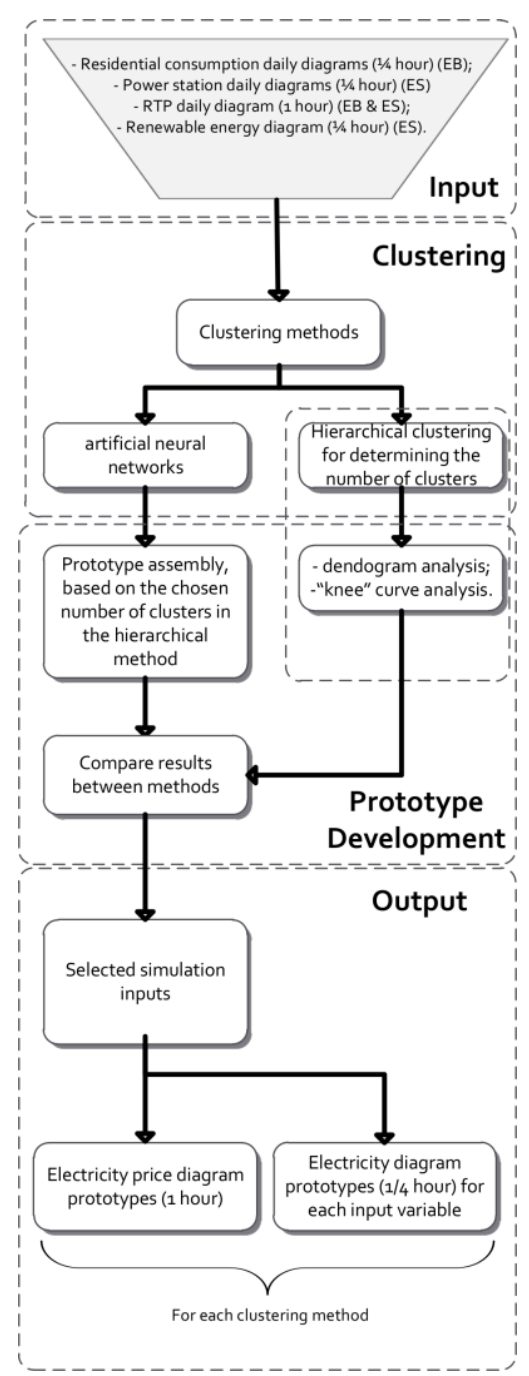

Figure 37 - Methodology for profile cluster prototypes of price, residential electricity consumption and renewable generation.

The output of this process, using each clustering technique, provides one prototype for each cluster.

With this information it is also possible to determine the range of variation (maximum and minimum) for the profiles. The outcome of this methodology intends to provide different scenarios for studies that evaluate the deployment of new technologies, such as in (Miguel, Neves, \& Martins, 2014) and (Gonçalves, Neves, \& Martins, 2015).

To test the proposed methodology, data from different sources pertaining to the Portuguese market were used. The information regarding market prices was extracted from "The Iberian Energy Derivatives Market Exchange or MIBEL" 
website. The low voltage (LV) household diagrams were kindly provided by EDP, the Portuguese electric utility.

\subsection{Methodology to simulate demand response actions}

The common strategies to load modeling are normally based on top-down or bottom-up approaches, the first kind trying to derive load models from statistical data and the second kind building an aggregated model from engineering models of end-uses. These methodologies can be improved by the growing availability of data from smart-grids and smart-meters, thus taking advantage of these new types of data, as well as reducing costs associated with energy modeling, avoiding the complexity of such models and reducing the time required to perform these simulations.

The initial idea for the development of this model consisted in the attempt to primarily represent the domestic consumption diagram for the city of Coimbra. It was intended that the developed model could be capable of incorporating information regarding the consumption patterns through a random choice of the operating cycles of equipment (controllable loads only), taking into consideration the probable schedules, based on the exhibited load diagram.

The diversity of the response of the different Energy Boxes, consequence of the diversity of the preferences of the household owners, should assure a degree of randomness when reacting to price stimuli. However, fundamental questions still remain:

- What is the value for the grid of the aggregated resource composed by the total number of deployed Energy Boxes?

- What power can be made available to the grid in each hour or quarter-hour by the combined effect of all the Energy Boxes and what is the resultant rebound?

In order to answer these questions it was necessary to set up an additional simulation that made use of DR actions, e.g., postponing the start of appliances.

Some assumptions were made to simulate the operation of the EB regarding the acceptance of the delay on the operation of appliances: the consumer tolerance 
for postponing the start of operation does not depend on the time of day and there is no priority among appliances for delaying their operation. The methodology assumes that each Energy Box decides whether the new schedule of operation of the equipment is more economical, depending on the current appliance cycles schedule over a price signal. Simultaneously, the availability of consumers that allow postponing the start of their appliances is taken into account.

The selected or chosen method of operation of the Energy Box (for controllable appliances with potential of postponing the operation) must consider a percentage of acceptance based on the results of a survey regarding the tolerance or willingness of users to delay the operation of appliances according to economic criteria (Mert, 2008), as well as the level of deployment of the device. These two inputs are provided by the user each time the routine is called. The distribution diagram for the appliances daily cycles, the day ahead prices and the individual appliances load diagrams, must be included as part of the variables of the problem. Since the operation of the Energy Box follows a price signal, load shifting was based on the spot price for an average day of 2012 according to the Iberian Energy Derivatives Exchange (OMIP, 2013). This allows determining the cost of running the appliance with a start at each quarter-hour of the three days.

The consumption is delayed / rescheduled according to the willingness to accept the postponement of the start of appliances, following the energy price, (which can ultimately include also renewable energy preferences or other preferences to be monetarily valued).

To represent the individual decisions made by each Energy Box owner, regarding how long a delay is allowed in the operation of a certain end-use $(0.5 \mathrm{~h}, 1 \mathrm{~h}, 2 \mathrm{~h}, 3 \mathrm{~h}$ to $24 \mathrm{~h}$ ), a Monte-Carlo based procedure was used, generating random numbers to represent possible decisions regarding each of the considered Energy Boxes in each run. In order to increase reliability, the routine executes a batch of runs and stores the results for statistical purposes.

Figure 38 presents the structure of the developed routine. 


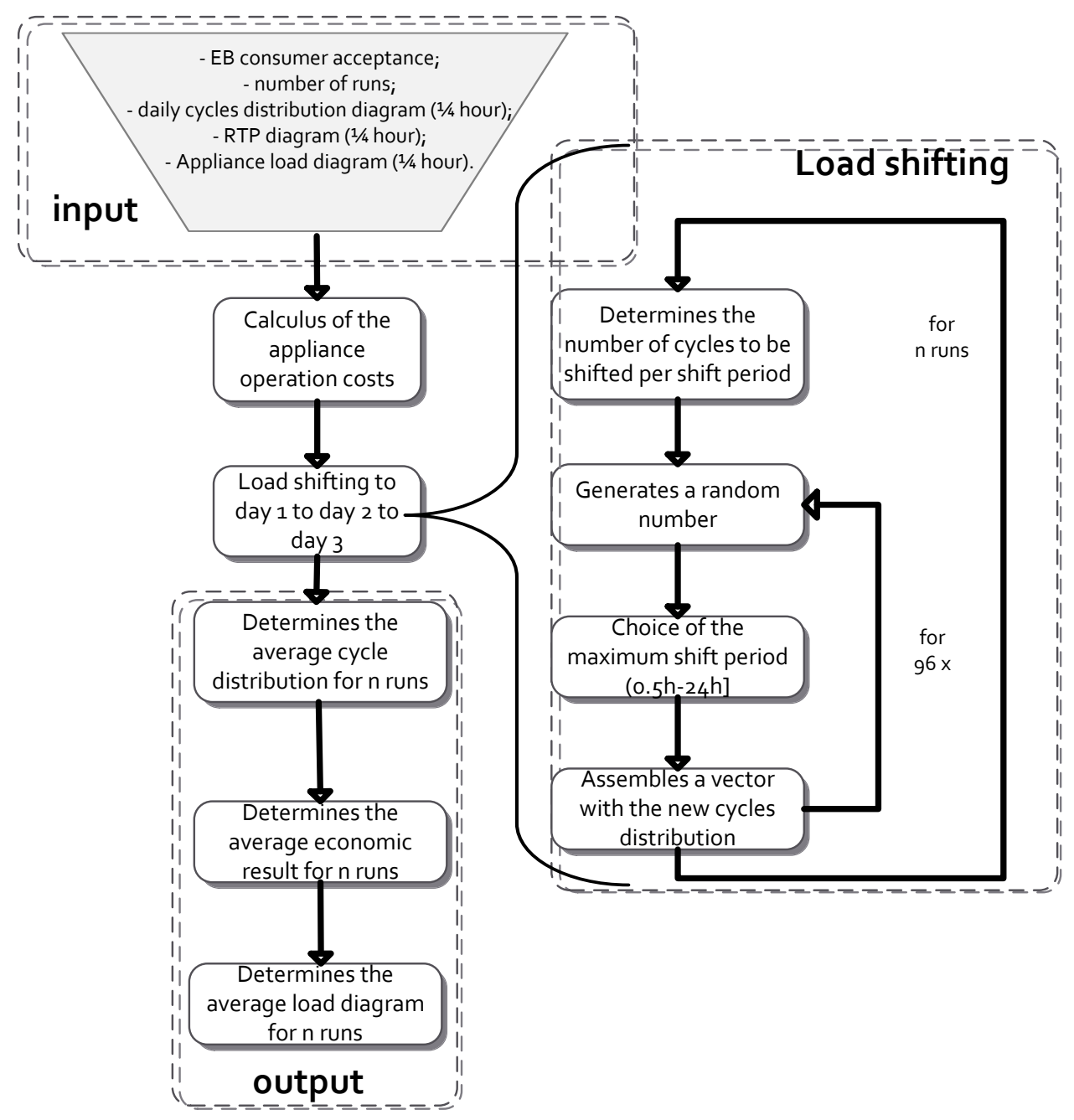

Figure 38 - Structure of the developed simulation routine.

The model uses three consecutive days in order to obtain a clean outcome of the central day, avoiding first-day and last-day effects that would be minimized in the long run.

The total number of load cycles of the appliances is maintained during the three day simulations.

As a final result, what is intended is to understand the value of the aggregated Energy Boxes for the system operator, by calculating the power that can be made available in every hour of the day. The output of the model provides the distribution of the average cycles for $\mathrm{n}$ runs, the average economic results and the average load diagram per appliance. For the purpose of this work, only the average load diagram will be considered. 


\subsection{Methodology to assess the environmental impact of demand response}

Demand response (DR) has been widely referred to as a valuable option in a smart grid environment towards efficient use of resources, with benefits both to consumers and to distribution system operators (DSO). Demand response requires automated reaction capabilities on the consumer side, by means of smart meters, to price variations and/or to DSO requests whenever demand alleviation may be beneficial to network management.

In the case of load alleviation it is arguable that it leads to a more sustainable use of resources, because the DSO is aiming at a very short-term management benefit and not at a long-term efficiency. However, it remains to be assessed whether price elasticity enabled by automatic demand response to price may be environmentally beneficial.

The present section aims at contributing to help the DSO, as well as public authorities, to assess whether demand response can reduce the environmental impact of electricity consumption, adding environmental value to the smart grid paradigm.

According to (WMO, 2014) the volume of greenhouse gases retained in planet Earth's atmosphere reached in 2013 a new record, the highest level since 1984. Still according to the same report, the amount of carbon dioxide $\left(\mathrm{CO}_{2}\right)$ in the atmosphere reached 396 parts per million. It is estimated that the global annual average $\mathrm{CO}_{2}$ concentration will cross the 400 parts per million threshold in 2015 or 2016.

Considering the $\mathrm{CO}_{2}$ impact of the Energy Industries (European Union (EU) - 28 Countries $1,409 \mathrm{MtCO}_{2} \mathrm{e}$ and Portugal $17 \mathrm{MtCO}_{2} \mathrm{e}$ in 2012) (Eurostat, 2014), it is necessary to evaluate the possible contribution of the introduction of renewable energy technologies, smart grids and smart meters to help reduce such impact.

The present work aims to provide a contribution for the discussion of a possible methodology to assess the environmental impact of the deployment of a residential demand response technology such as the Energy Box (EB) proposed by (Livengood \& Larson, 2009) in the electricity grid. The environmental impact of 
demand response will be assessed for deployments of the EB covering 20 to $100 \%$ of households in a city, considering the current energy matrix framework for electricity generation in Portugal.

This subsection analyzes different situations that are referred to as "cases". These cases are structured in order to allow the comparison to a reference scenario (without actions of DR), considering on one hand the national energy generation matrix and on the other hand, considering actions of Demand Response.

\subsubsection{Assessing the environmental impact of demand response}

For simplifying reasons, the method for assessing the environmental impact of demand response considered the quarter-hour contribution of each energy source to the electricity generation system for the average day. In this case, the information was provided by REN the Portuguese Transmission System Operator. The data consisted in a spreadsheet for every day of the year 2013, segregated by quarter-hour, with the discrimination of the power contribution of each energy source to the generation diagram.

Using the methodology developed to evaluate the impact of the deployment of the EB in the electricity grid, under different scenarios and deployment rates, it was possible to rehearse demand response actions. The data regarding the hourly impact of each energy source for the average day, combined with the simulations of the EB impact, provided a framework of a total of twelve simulations with three distinct consumer tolerance values, in the following manner: one simulation uses the average price day diagram for the year of 2012, a second uses the average price day diagram from October 2012 to September 2013, five used price prototypes extracted from the HM and, finally, five used price prototypes extracted from the ANN method. The combination between simulations (12) and scenarios (3) with five deployment rates, from $20 \%$ to $100 \%$, accounted for a total of 180 simulations.

The environmental impact of demand response was estimated using the average share of load by each generation technology at each quarter of an hour in the average day. 
The average contribution of each generation technology to the load diagram is represented in Figure 39.

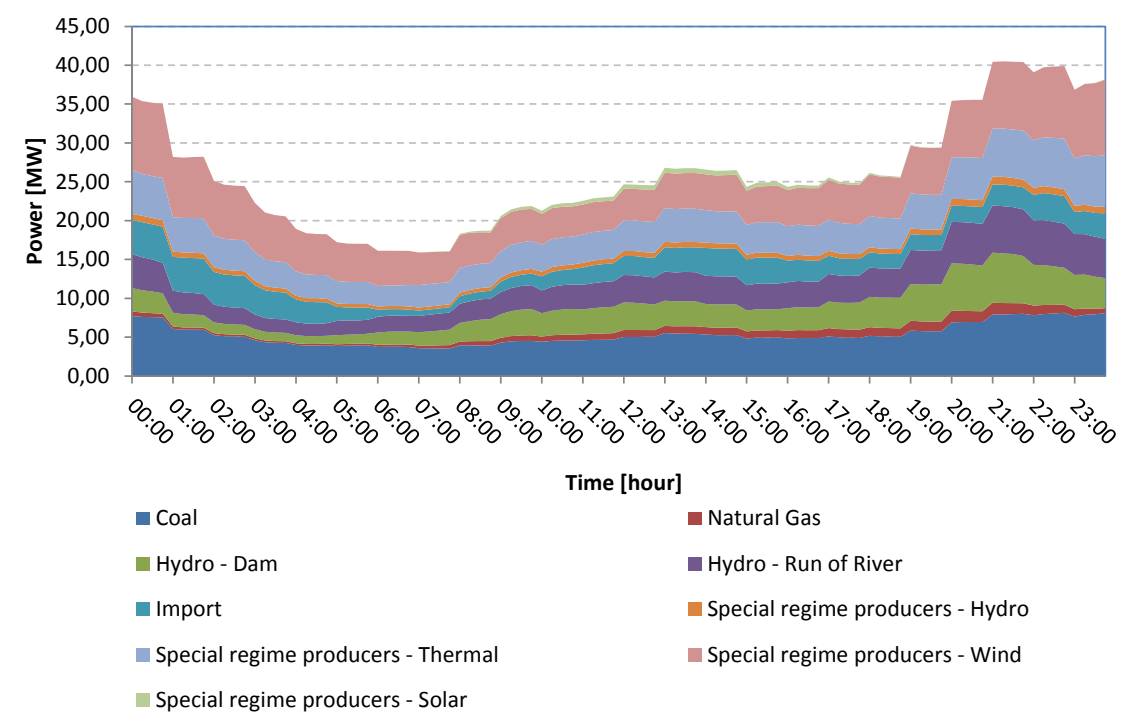

Figure 39 -Average load diagram of the city of Coimbra, with the quarter-hour contribution of each energy source.

The method for assessing the demand response environmental impact is represented in Figure 40. In order to assess such environmental impact, the output or the contribution of renewable energy sources (Hydro - Run of River, SRPHydro, SRP-Wind and SRP-Solar), plus Imported electricity and SRP-Thermal is conserved equal to the average day simulation. The generation technologies and fuels that were affected by demand response actions were the following:

Hydro-dam, as this is usually the technology that reacts to demand peaks due to its fast response;

Combined cycle gas turbine (CCGT), due to its increasing weight in the generation system and its higher generation efficiency;

Coal based steam turbine, due to usual high share of usage in the generation system, assuming that it is the most economic generation technology;

Mixed coal based steam turbine and CCGT, using their respective shares in each quarter-hour of the average day.

The variations reflect changes in the composition of the generation mix resulting from demand response. Thus, the new generation technology contributions are 
redefined, ensuring that the required power is supplied to the electricity system under the modified load conditions.

Emissions can be calculated applying appropriate conversion factors to the energy outputs of the generation technologies at stake.

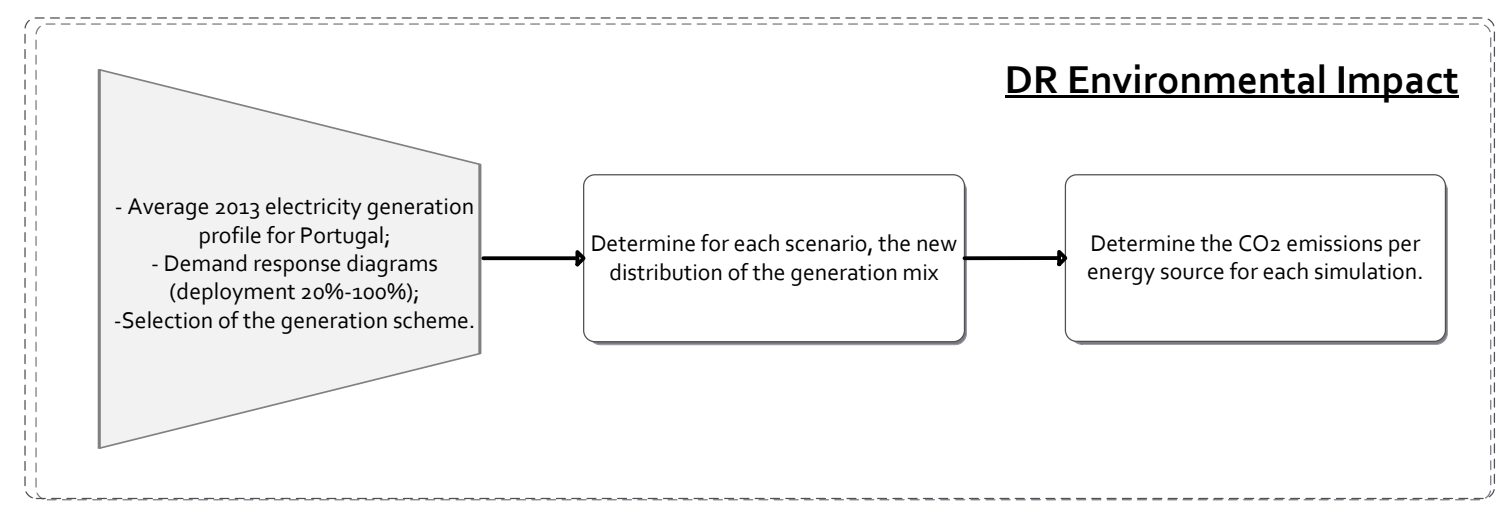

Figure 40 - Method for assessing the energy transfer and $\mathrm{CO}_{2}$ changes due to demand response actions. 


\section{Energy Box results}

\subsection{Clustering results}

An important step consisted in choosing the appropriate number of clusters to be considered in the ANN method. The number of clusters to be defined can be based on the analysis of the dendogram tree and, ideally, on the occurrence of the first situation where too small a decrease of the distance between centres of clusters would occur for an increase of the number of clusters, configuring an inflection point of a curve relating these two variables. However, as can be observed in Figure 41, which relates the number of clusters and the distances between the centers of clusters, the selection of the number of clusters can be difficult to accurately justify due to an uncertain location of the inflection point.

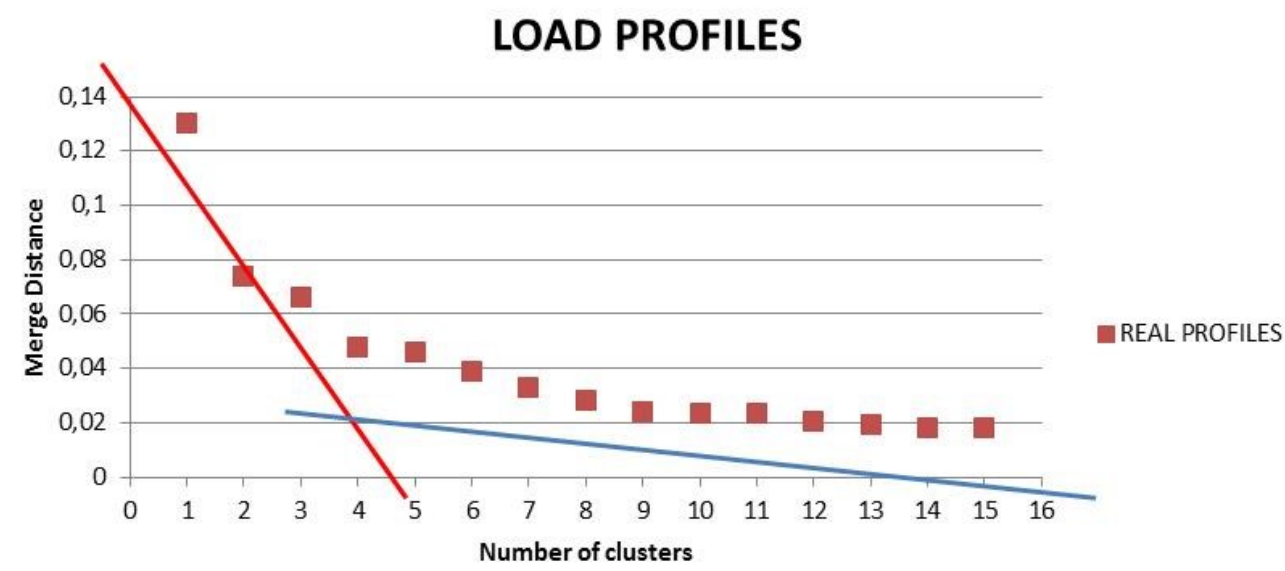

Figure 41 - Relation between the number of clusters and the distance between centers of clusters for the normalized LV load demand in 2012-2013.

By applying this technique and by aiming a wider diversity of plausible scenarios, a total of 5 clusters were selected, for all inputs, and for all methods.

In order to compare the data allocation, verify the similarity of results with both methods, and to understand the meaning of the clusters, the obtained outputs were analyzed in terms of total number of allocated days (hits) on weekdays, weekends and holidays.

As an example, Table 21 and Table 22 allow the comparison of electricity price profiles. 


\begin{tabular}{cccccc}
\hline \multicolumn{6}{c}{ 5 CLUSTER'S ANALYSIS FOR HIERACHICAL METHOD } \\
\hline Cluster N. & Total hits & Week days & Saturdays & Sundays & Holidays \\
$\mathbf{1}$ & 42 & 35 & 3 & 2 & 2 \\
$\mathbf{2}$ & 71 & 27 & 20 & 22 & 2 \\
$\mathbf{3}$ & 93 & 81 & 9 & 3 & 0 \\
$\mathbf{4}$ & 44 & 44 & 0 & 0 & 0 \\
$\mathbf{5}$ & 116 & 64 & 20 & 25 & 7 \\
Total & $\mathbf{3 6 6}$ & $\mathbf{2 5 1}$ & $\mathbf{5 2}$ & $\mathbf{5 2}$ & $\mathbf{1 1}$ \\
\hline
\end{tabular}

Table 21 - Data allocation for 2008 electricity prices using the hierarchical method.

\begin{tabular}{cccccc}
\hline \multicolumn{5}{c}{ 5 CLUSTER'S ANALYSIS FOR ARTIFICIAL NEURAL NETWORKS } \\
\hline Cluster N. & Total hits & Week days & Saturdays & Sundays & Holidays \\
$\mathbf{1}$ & 36 & 36 & 0 & 0 & 0 \\
$\mathbf{2}$ & 101 & 84 & 9 & 8 & 0 \\
$\mathbf{3}$ & 108 & 63 & 24 & 17 & 4 \\
$\mathbf{4}$ & 69 & 49 & 9 & 8 & 3 \\
$\mathbf{5}$ & 52 & 19 & 10 & 19 & 4 \\
Total & $\mathbf{3 6 6}$ & $\mathbf{2 5 1}$ & $\mathbf{5 2}$ & $\mathbf{5 2}$ & $\mathbf{1 1}$ \\
\hline
\end{tabular}

Table 22 - Data allocation for 2008 electricity prices using the artificial neural networks method.

The resulting clusters for the electricity prices did not show a particular correspondence to the type of day, no cluster being formed more with a type than other, with the electricity prices being decoupled from the type of day. Although the current market situation creates conditions for this to happen, it suggests also that the natural consumption variation between workdays and weekends is not influencing prices.

\subsubsection{Clustering of load profiles}

Regarding energy consumption, both methods presented rather segmented clusters, based on weekdays and weekends, in the electricity demand profiles. The differences between methods were essentially related to the total number of allocated days. For different distributions, another measurement method may be used (e.g. complete linkage). The holidays were not represented in any particular cluster, perhaps because these days normally represent patterns similar to weekends.

The results for both methods, regarding the 2012-2013 LV load demand are presented in Table 23 and Table 24. 


\begin{tabular}{|c|c|c|c|c|c|}
\hline \multicolumn{6}{|c|}{5 CLUSTER'S ANALYSIS FOR HIERACHICAL METHOD } \\
\hline${\text { Cluster } \mathrm{N}^{\circ}}^{\circ}$ & Total hits & Week days & Saturdays & Sundays & Holidays \\
\hline 1 & 32 & 31 & 0 & 0 & 1 \\
\hline 2 & 110 & 110 & 0 & 0 & 0 \\
\hline 3 & 59 & 4 & 25 & 26 & 4 \\
\hline 4 & 76 & 18 & 27 & 26 & 5 \\
\hline 5 & 88 & 88 & 0 & 0 & 0 \\
\hline Total & 365 & 251 & 52 & 52 & 10 \\
\hline
\end{tabular}

Table 23 - Data allocation for 2012-2013 LV load demand performed in the hierarchical method.

\begin{tabular}{|c|c|c|c|c|c|}
\hline \multicolumn{6}{|c|}{5 CLUSTER'S ANALYSIS FOR ARTIFICIAL NEURAL NETWORKS } \\
\hline 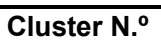 & Total hits & Week days & Saturdays & Sundays & Holidays \\
\hline 1 & 40 & 6 & 16 & 15 & 3 \\
\hline 2 & 64 & 64 & 0 & 0 & 0 \\
\hline 3 & 53 & 39 & 6 & 7 & 1 \\
\hline 4 & 43 & 24 & 8 & 9 & 2 \\
\hline 5 & 165 & 118 & 22 & 21 & 4 \\
\hline Total & 365 & 251 & 52 & 52 & 10 \\
\hline
\end{tabular}

Table 24 - Data allocation for 2012-2013 LV load demand performed in the artificial neural networks method.

In order to develop a prototype, the clustered data was used to obtain an average profile of each cluster. The developed prototypes, for each method, are presented in Figure 42.

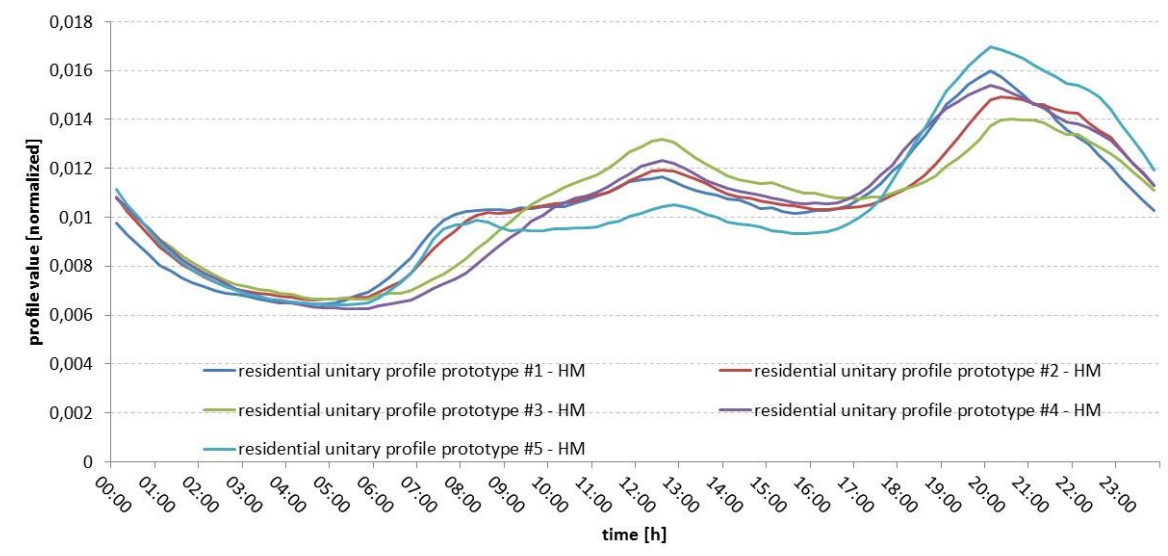

Figure 42 - HM 2012-2013 cluster prototypes for the residential load profiles.

The obtained prototypes are similar for both methods in the residential sector profiles. This may be explainable, because the residential consumption has a quite stable and defined pattern. 


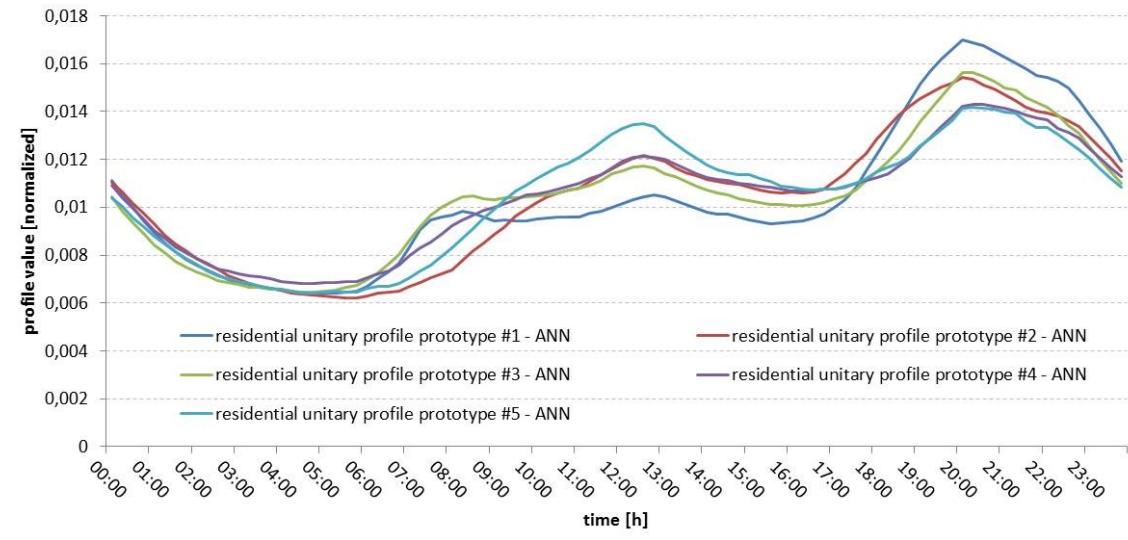

Figure 43 - ANN method 2012-2013 cluster prototypes for the residential load profiles.

In order to determine the range of variation of the profiles, the average profile for all data was compared to all five obtained prototypes. This process allowed obtaining the average variation range of the profiles, as presented in Figure 44 and Figure 45, respectively.

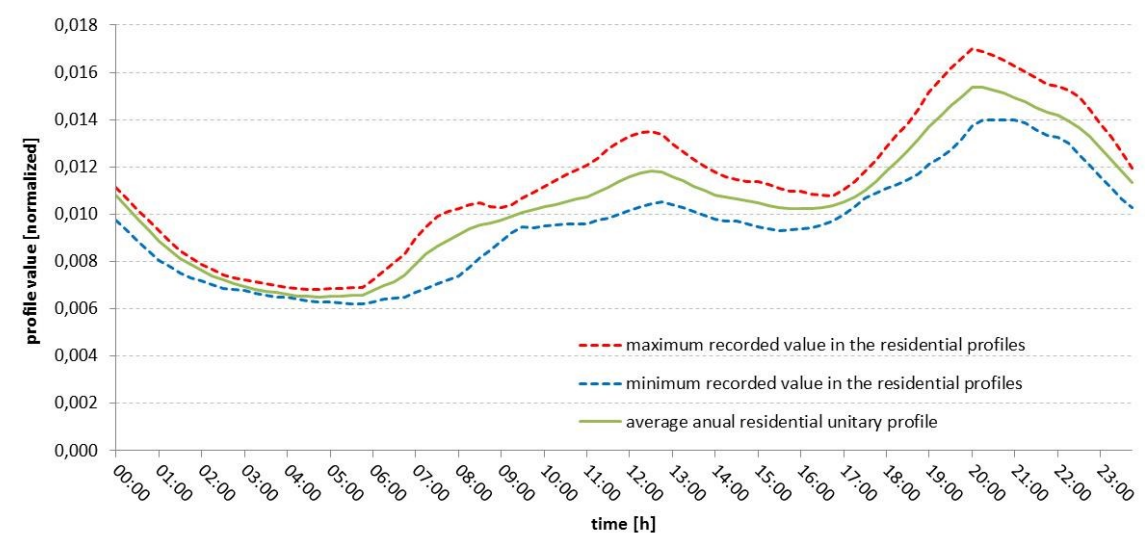

Figure 44 - Clustering evaluation of household load demand for the 2012-2013 cluster profiles.

Taking into consideration the differences between extreme values, and based on one year of data, Figure 44 suggests that the average profile may be used as a benchmark reference for DR studies in the residential sector. 


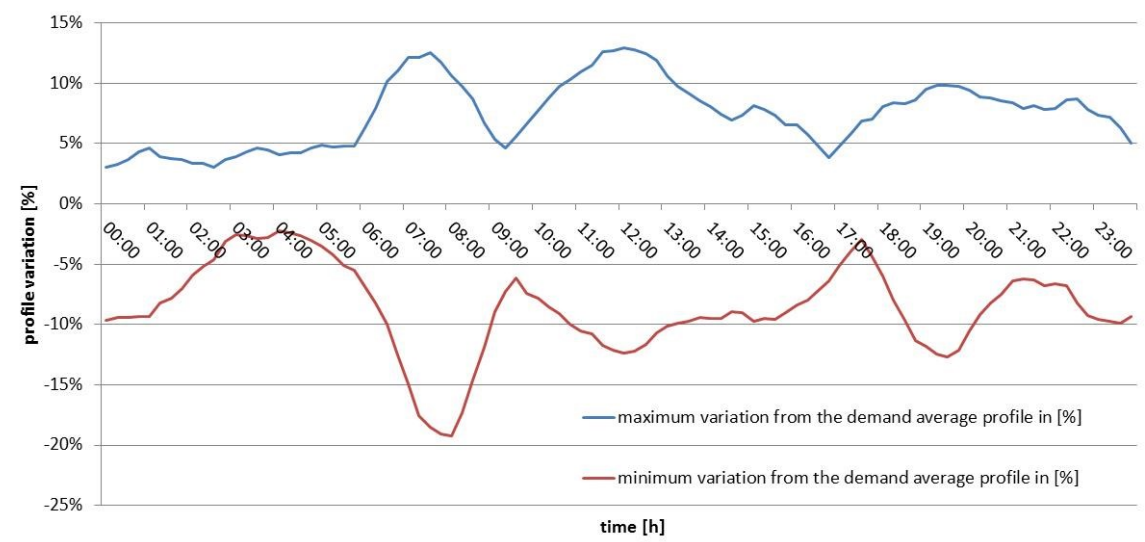

Figure 45 - Range of variation of household load demand for the 2012-2013 cluster profiles (around the average profile).

The information provided by Figure 45 can be used to assess the range of variation of the average profile in relative terms.

\subsubsection{Clustering of gross market price profiles}

The resulting clustering price prototypes can be visualized in Figure 46 and Figure 47. Both methods present similar types of price prototypes and the approximate same number of hits. This resemblance ensures that any of the clustering methods may be used for generating reliable simulation prototypes.

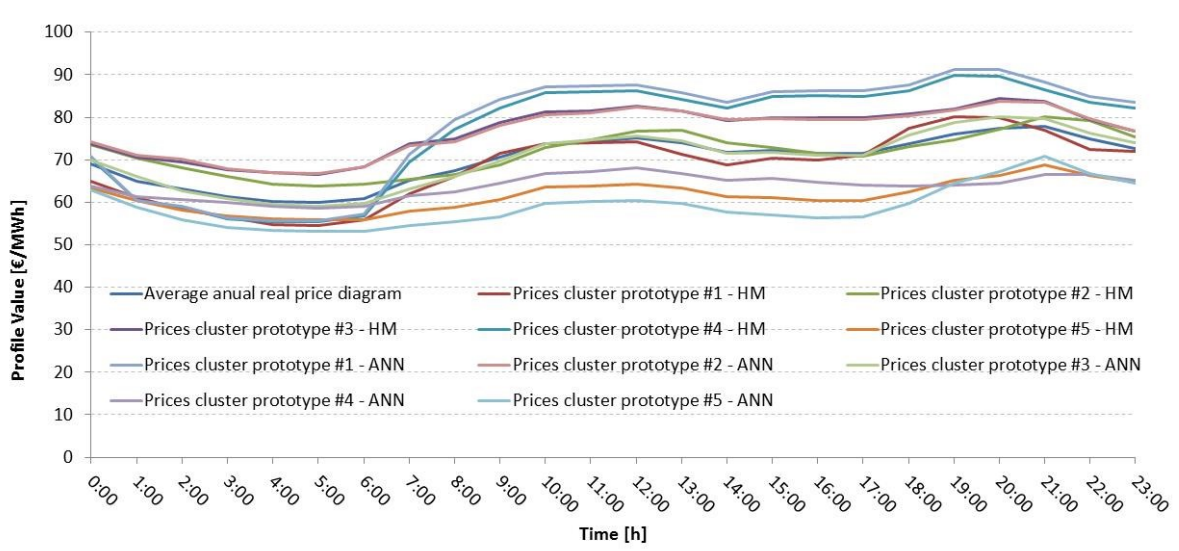

Figure 46 - Clustering price prototypes for the HM and the ANN method, for the 2008 year.

Larger hourly price differences are more prone to stimulate active load shifting. Using data from the period between October 2012 and September 2013, it was possible to identify a particular cluster of price daily profiles, the HM \#3 which is similar to the ANN \#3, that seems interesting for the test of DR. Prototype \#3 presents approximately the price of $20 € / \mathrm{MWh}$ at $04: 00$ and almost $60 € / \mathrm{MWh}$ at 
20:00, with an impressive yearly number of hits, namely: 74/365 in the HM and $65 / 365$ in the ANN method. Profiles with smaller hourly differences are expected to be less interesting for DR application.

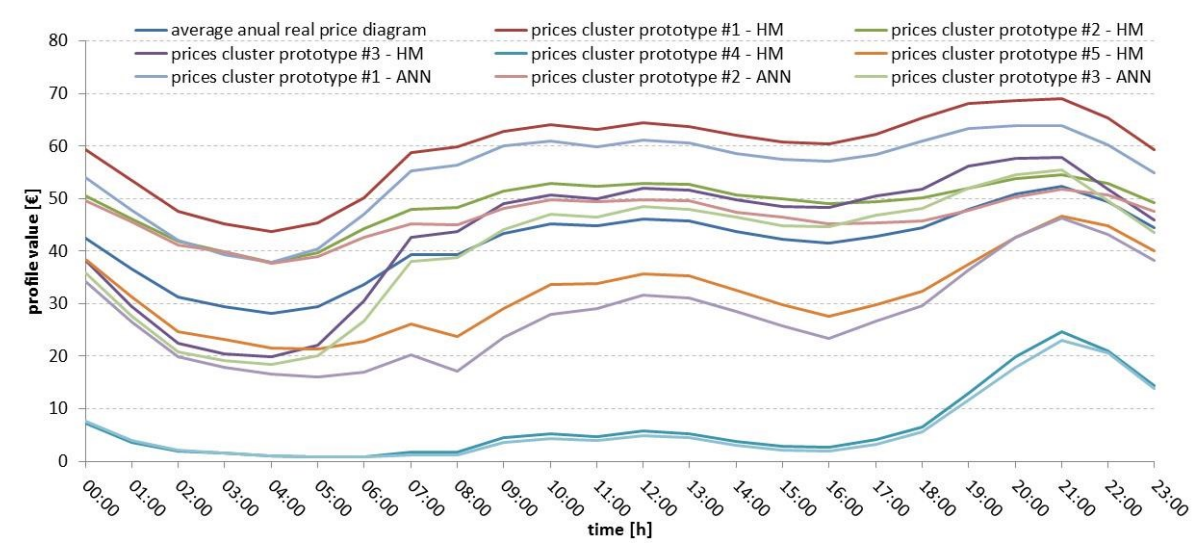

Figure 47 - Clustering price prototypes for the HM and the ANN method, for the 2012 year.

As for the evaluation of the fluctuation of the maximum and the minimum hourly values as regards to the average price diagram, a significantly increased amplitude variation can be verified between the 2008 and the 2012-2013 prototypes, as shown in Figure 48 and in Figure 49.

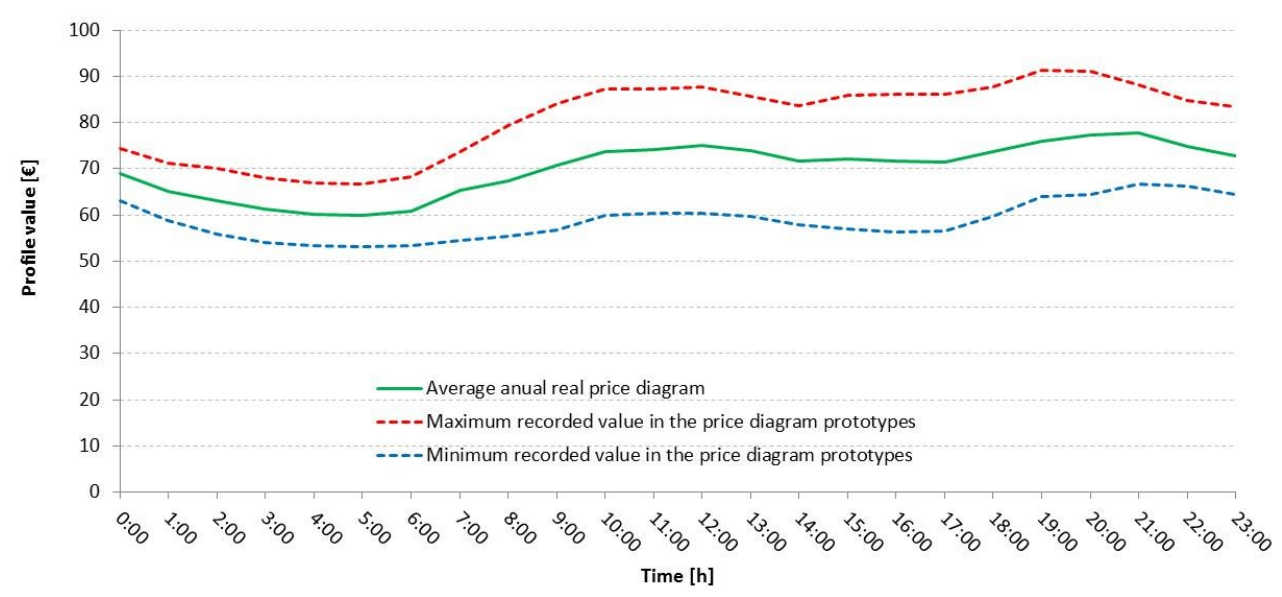

Figure 48 - Prototypes price range variation, for the year of 2008.

It is possible to identify that electricity reaches higher hourly prices in both the maximum and the minimum obtained prototypes than in the 2012-2013 diagrams. In addition, there is an increased price amplitude difference in the 2012-2013 prototypes with regard to the 2008 diagrams, possibly due to the market liberalization since January 2008 and the increased integration of energy from renewable generation combined with a lower demand, as observable in Table 25. 


\begin{tabular}{ccc}
\hline Year & Electricity generation (Gigawatt-hour) \\
\cline { 2 - 3 } & Total & $\begin{array}{c}\text { From renewable } \\
\text { generation } \\
\text { Total }\end{array}$ \\
$\mathbf{2 0 0 7}$ & 47.253 & 16.869 \\
$\mathbf{2 0 0 8}$ & 45.969 & 15.421 \\
$\mathbf{2 0 0 9}$ & 50.207 & 19.306 \\
$\mathbf{2 0 1 0}$ & 54.093 & 29.042 \\
$\mathbf{2 0 1 2}$ & 52.462 & 24.985 \\
$\mathbf{2 0 1 3}$ & 46.614 & 20.655 \\
\hline
\end{tabular}

Table 25 - Generation of electricity in Portugal ${ }^{11}$.

Figure 49 shows very low minimum prices of almost $0 € / \mathrm{MWh}$, between 02:00 and 08:00, probably due to the high contribution of must run renewable generation during that period and the simultaneous low consumption. This grid problem may become a market problem or an opportunity (Bundesnetzagentur, 2011) being one of the issues that both Demand Response and Distributed Storage aim to solve.

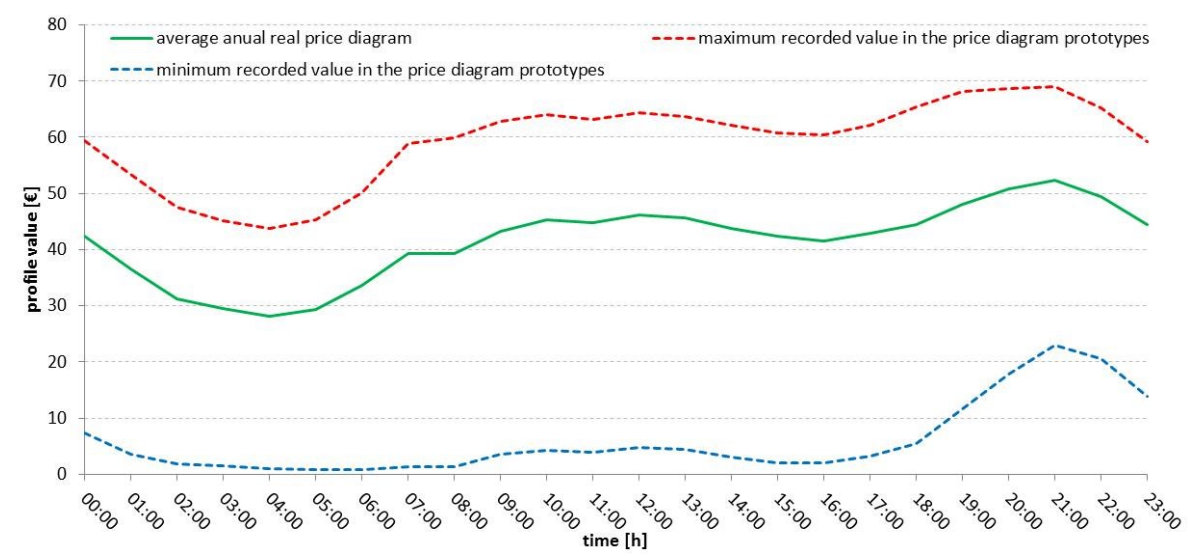

Figure 49 - Prototypes price range variation, from October 2012 to September 2013.

\subsection{Demand response results}

The present section partially reproduces the content of a paper published in the Electric Power Systems Research journal (Miguel, Neves, \& Martins, 2014). The analyses of results which are the outcome of the methodology are further developed, especially in sections 4.2.2 and 4.2.3.

${ }^{11}$ Source: http://www.pordata.pt/Portugal/Ambiente+de+Consulta/Tabela/5690459 


\subsubsection{Simulation based on the average 2012 day prices}

Table 26 presents the average residential aggregated consumption for the city of Coimbra, based on 100 simulation runs.

\begin{tabular}{|c|c|c|c|c|c|c|c|}
\hline \multirow{3}{*}{ scenario } & \multicolumn{7}{|c|}{ Energy [MWh]/day } \\
\hline & \multirow{2}{*}{ original } & \multirow{2}{*}{$\begin{array}{l}\text { original } \\
\text { simulated }\end{array}$} & \multicolumn{5}{|c|}{ Energy Box deployment [\%] } \\
\hline & & & $20 \%$ & $40 \%$ & $60 \%$ & $80 \%$ & $100 \%$ \\
\hline 1 & \multirow{3}{*}{$2,490.72$} & \multirow{3}{*}{$2,490.13$} & $2,491.16$ & $2,491.24$ & $2,492.67$ & $2,493.89$ & $2,495.42$ \\
\hline 2 & & & $2,490.64$ & $2,490.99$ & $2,491.22$ & $2,492.05$ & $2,491.98$ \\
\hline 3 & & & $2,490.97$ & $2,491.57$ & $2,492.20$ & $2,491.07$ & $2,493.30$ \\
\hline
\end{tabular}

Table 26 - Energy average day simulation results in MWh for the household sector in the City of Coimbra.

Departing from the original data regarding the energy consumption in the average day for the city of Coimbra, the original simulated values are the outcome of the matlab simulation using the aggregation of individual consumer models without any demand response intervention, as plotted in Figure 17. The intention of the developed routine is to reproduce the results in terms of the distribution of energy and power along the day at a city scale. The simulation of the Energy Box deployment provides the energy consumed for the average day in the city of Coimbra considering a defined consumer acceptance measured as a percentage.

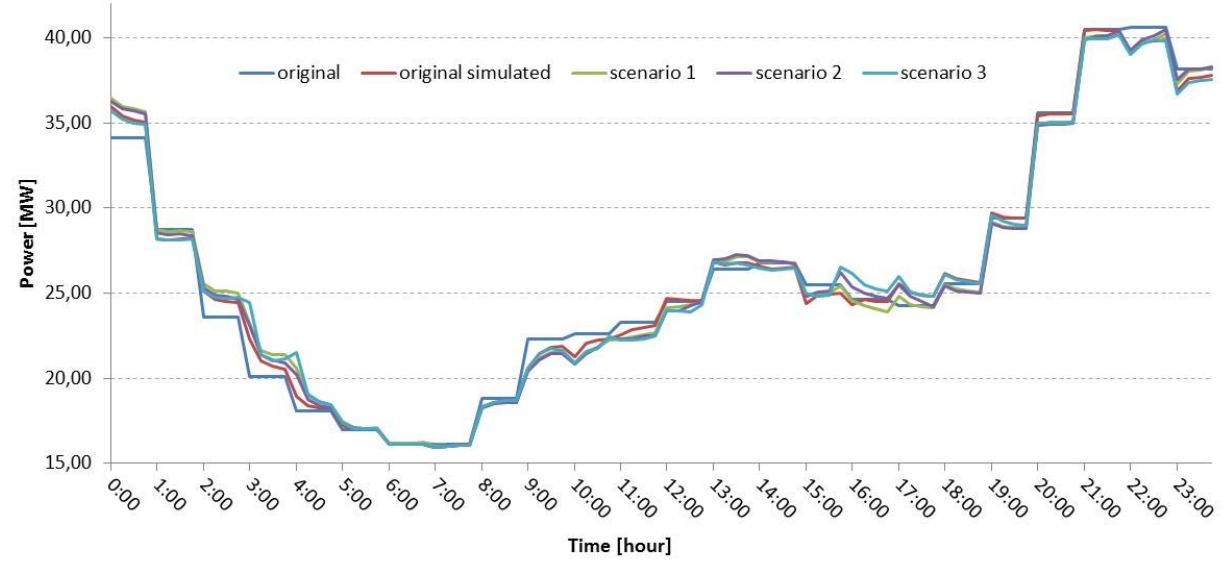

Figure 50 - City of Coimbra, simulation results for $20 \%$ deployment of the Energy Box (100 runs). 
Figure 50 represents the aggregated original and simulated diagrams of the household electricity consumers of the City of Coimbra and the resulting diagrams of three different scenarios of operation, for a $20 \%$ deployment of the Energy Box.

The power that the aggregated Energy Boxes may release in each quarter-hour may be assessed by the difference between the reference demand and the minimum demand obtained in the simulations. The rebound that can occur is also obtained by the difference between the maximum demand obtained in the simulations and the reference load diagram (Figure 51). The purpose of calculating these values is to estimate the possible range of the variation interval of both the rebound and of the power released (power delivery) as a function of the dissemination of an automatic load management system such as the Energy Box, as in Figure 51.

The results presented in Figure 51 show that the aggregated resource may deliver around $700 \mathrm{~kW}$ between 11:30-12:30 and between 17:30 and 21:30, to a maximum of circa $3 \%$ of the demand on that period. But the rebound may represent an additional load of $2.5 \mathrm{MW}$ at 4 a.m. or $1.8 \mathrm{MW}$ at 4 p.m. if the Energy Boxes are allowed to switch on all their interrupted loads immediately when possible.

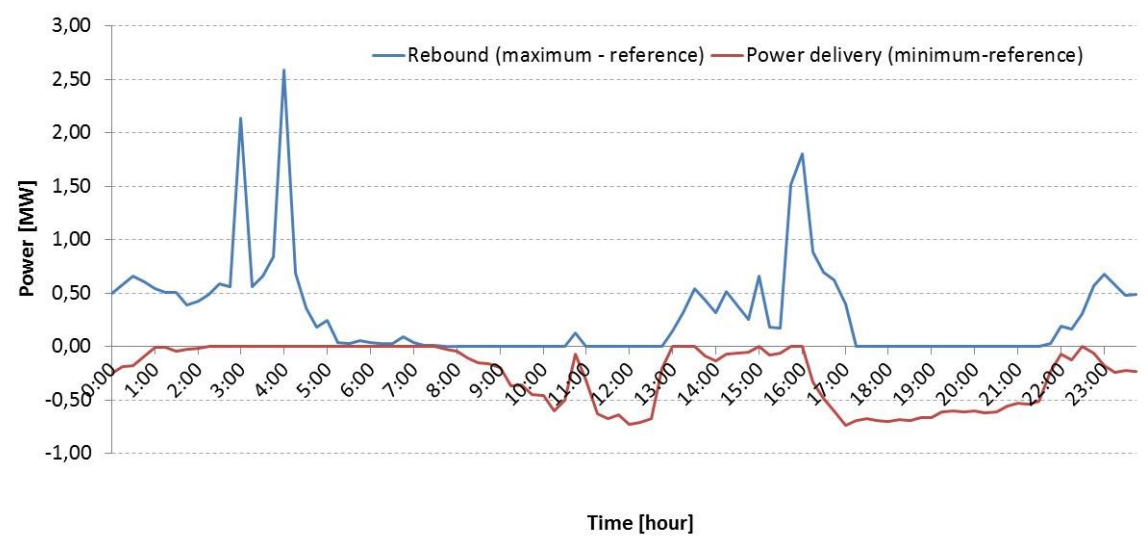

Figure 51 - Range of the power delivery and rebound for a $20 \%$ deployment of the Energy Box in the city of Coimbra.

From the selected scenarios a maximum power of $40.63 \mathrm{MW}$ was recorded as well as a minimum power of $15.92 \mathrm{MW}$, as can be confirmed through the reading of Table 27. 


\begin{tabular}{|c|c|c|c|c|c|c|}
\hline \multirow{3}{*}{$\begin{array}{c}\text { Maximum } \\
\text { diagram power }\end{array}$} & & original & $\begin{array}{c}\text { original } \\
\text { simulated }\end{array}$ & $\begin{array}{c}20 \% \text { EB } \\
\text { Scenario } 1\end{array}$ & $\begin{array}{l}20 \% \text { EB } \\
\text { Scenario }\end{array}$ & $\begin{array}{l}20 \% \text { EB } \\
\text { Scenario } 3\end{array}$ \\
\hline & Power [MW] & 40.63 & 40.50 & 40.32 & 40.47 & 40.18 \\
\hline & Occurred at : & $23 \mathrm{~h} 00 \mathrm{~m}$ & $22 \mathrm{~h} 15 \mathrm{~m}$ & $22 \mathrm{~h} 45 \mathrm{~m}$ & $23 \mathrm{~h} 45 \mathrm{~m}$ & $22 \mathrm{~h} 45 \mathrm{~m}$ \\
\hline \multirow{2}{*}{$\begin{array}{c}\text { Minimum } \\
\text { diagram power }\end{array}$} & Power [MW] & 16.09 & 15.92 & 15.96 & 15.92 & 15.92 \\
\hline & Occurred at: & & & $8 \mathrm{~h} 00 \mathrm{~m}$ & & \\
\hline
\end{tabular}

Table 27 - Maximum and minimum power verified in the load diagrams at a certain time.

\subsubsection{Simulation based on price clusters - $20 \%$ deployment of the Energy Box}

The present section considers the evaluation of the diversity provided by the data clustering exercise.

Table 28 displays the simulations results for a $20 \%$ deployment of the EB. From this table it is possible to verify that the conservation of total energy consumption is guaranteed for the central day of simulations, exhibiting a minimum value of 2,489.24 $\mathrm{MWh} /$ day, a maximum value of 2,491.20 $\mathrm{MWh} /$ day and an average energy value of $2,490.63 \mathrm{MWh} /$ day, among the three considered scenarios.

\begin{tabular}{|c|c|c|c|c|c|c|}
\hline \multirow{3}{*}{ scenario } & \multicolumn{6}{|c|}{ Energy [MWh]/day } \\
\hline & \multirow{2}{*}{ original } & \multirow{2}{*}{$\begin{array}{c}\text { original } \\
\text { simulated }\end{array}$} & \multicolumn{4}{|c|}{ Energy Box deployment [\%] } \\
\hline & & & $20 \%$ & $20 \% \min$ & $20 \% \max$ & $20 \%$ avg \\
\hline 1 & \multirow{3}{*}{$2,490.72$} & \multirow{3}{*}{$2,490.13$} & $2,491.16$ & $2,489.24$ & $2,491.20$ & $2,490,41$ \\
\hline 2 & & & $2,490.64$ & $2,490.33$ & $2,490.64$ & $2,490,50$ \\
\hline 3 & & & $2,490.97$ & $2,490.82$ & $2,491.20$ & $2,491.00$ \\
\hline All & - & - & - & $2,489.24$ & $2,491.20$ & $2,490.63$ \\
\hline
\end{tabular}

Table 28 - Energy day simulation results in MWh for the household sector in the City, for a $20 \%$ deployment of the Energy Box.

Figure 52, Figure 53 and Figure 54 present the range of rebound and power delivery from the set of simulations concerning scenario 1 , scenario 2 and scenario 3. 
Figure 52 showcases scenario 1 simulations, where it can be observed that the worst verified impact of rebound produces by far the lowest peak (1.74 MW), when compared to the remaining scenarios. The exhibited distribution is also the one that seems more linear and less peaky when compared to the other simulation scenarios, with the second highest peak presenting a $1.50 \mathrm{MW}$ power. The highest and longest power delivery occurs between around 16:00 (0.87 MW) and 23:00. Considering the usual constraints that may happen in distribution networks, when people arrive home at lunch and at night time, this simulation results may prove of appeal to the DSO, with zero or negligible rebound and a positive continuous power delivery.

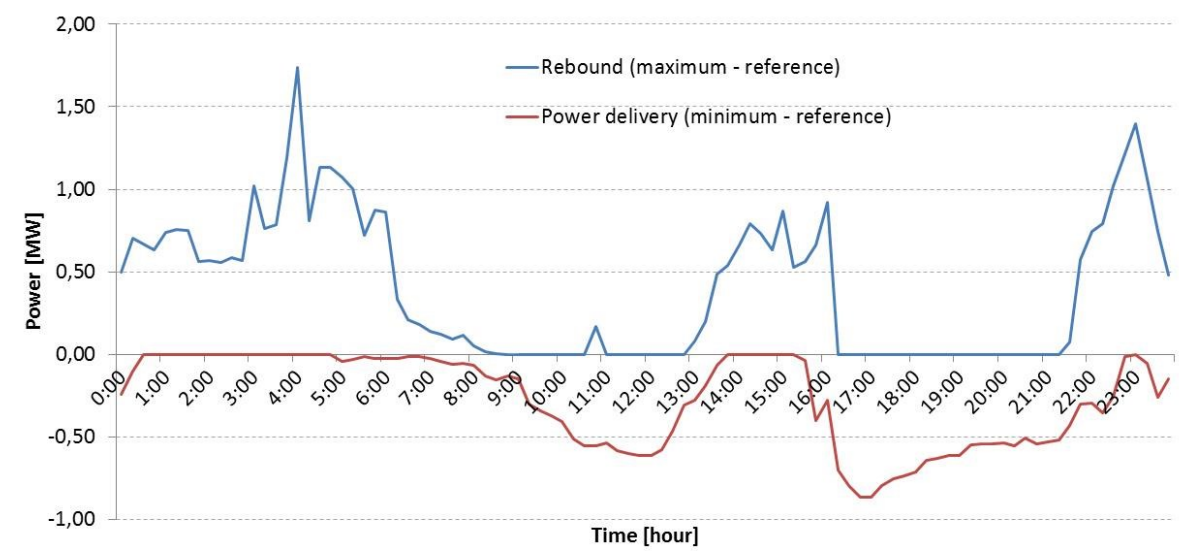

Figure 52 - Range of rebound and power delivery for all simulations concerning a $20 \%$ deployment, for scenario 1 .

In Figure 53, the range of rebound and power delivery for simulations that considered scenario 2 is displayed. The graphical representation of results places scenario 2, between scenario 1 (less peaky) and scenario 3 (more peaky). This set of simulations exhibit two groups of peaks, between 3 a.m. (2.14 MW) and 4 a.m. (2.58 MW), and the other one, comprising isolated peaks, at 16:00 and at 23:00, exhibiting 1.82 MW and 1.84 MW, respectively. Among scenarios, it is in this one, that the highest power delivery occurs in terms of magnitude, with $0.97 \mathrm{MW}$ at 17:00. 


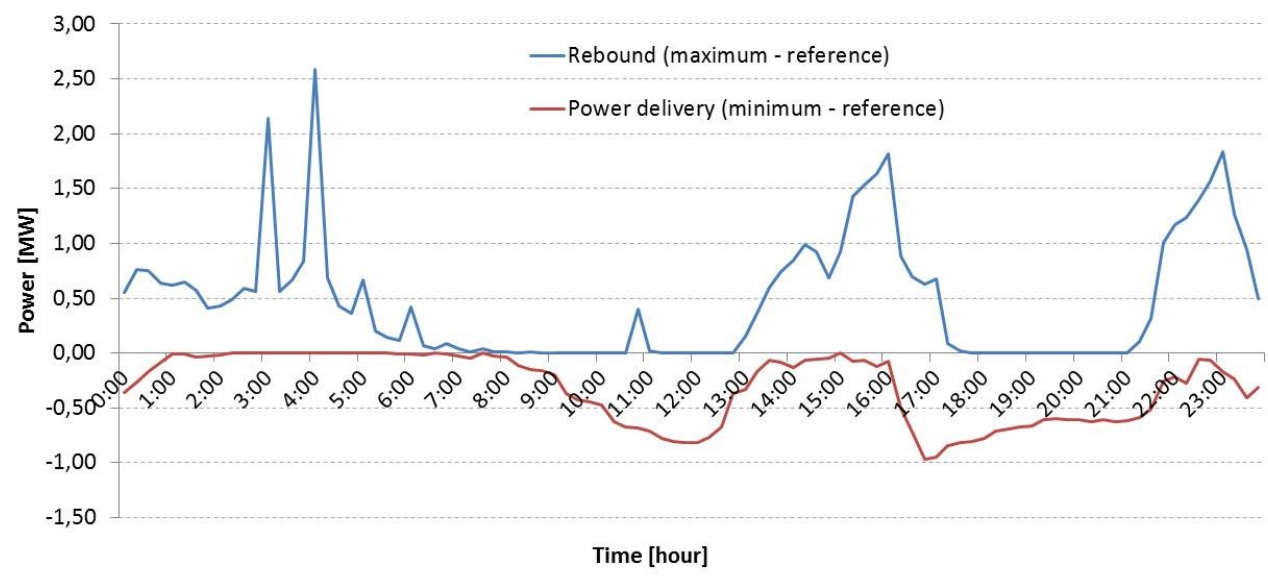

Figure 53 - Range of rebound and power delivery for all simulations concerning a $20 \%$ deployment, for scenario 2.

Figure 54, presents the range of values of power and energy for scenario 3. A graphical visualization of the range of rebounds presents six possible peaks (at least), with power varying from $1.57 \mathrm{MW}$ at $6: 00$ to $2.58 \mathrm{MW}$ (4:00). The highest recorded value for power delivery occurs at 12:00 with $0.74 \mathrm{MW}$. Regarding the DSO management, a possible peak at 10:45 with $0.57 \mathrm{MW}$ may prove to be a difficulty for managing constrained electrical infrastructures.

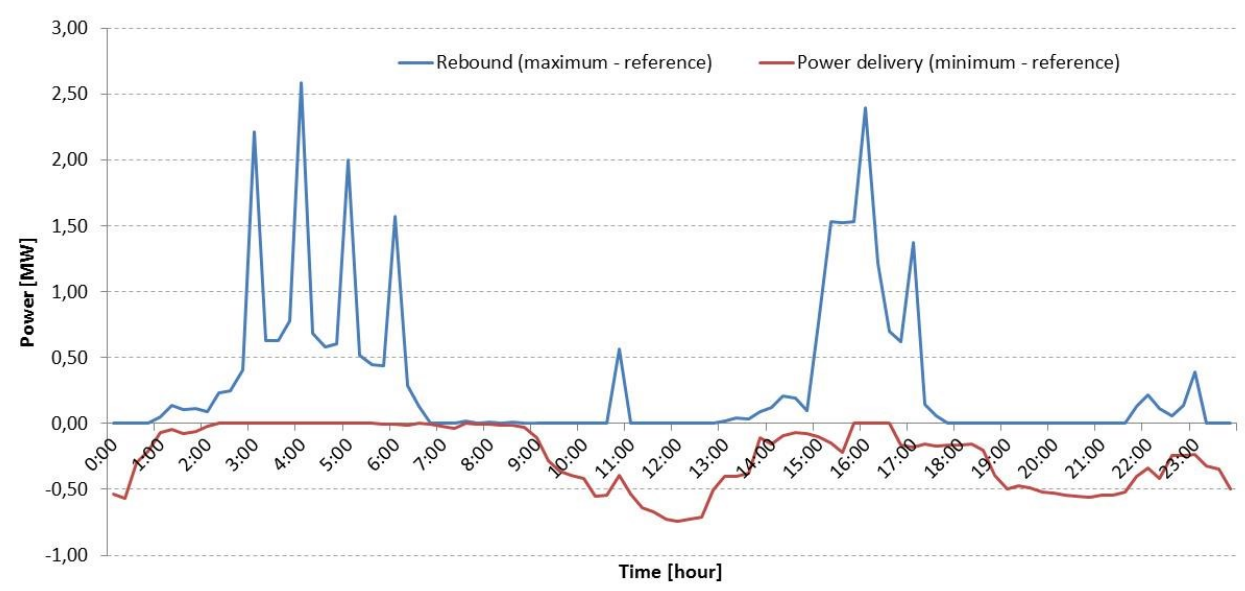

Figure 54 - Range of rebound and power delivery for all simulations concerning a $20 \%$ deployment, for scenario 3.

However and similarly to the analysis provided by (Miguel, Neves, \& Martins, 2014), these new peak demands that occur for a $20 \%$ deployment of the EB are not meaningful in an aggregated vision, as perceivable in Figure 55. 


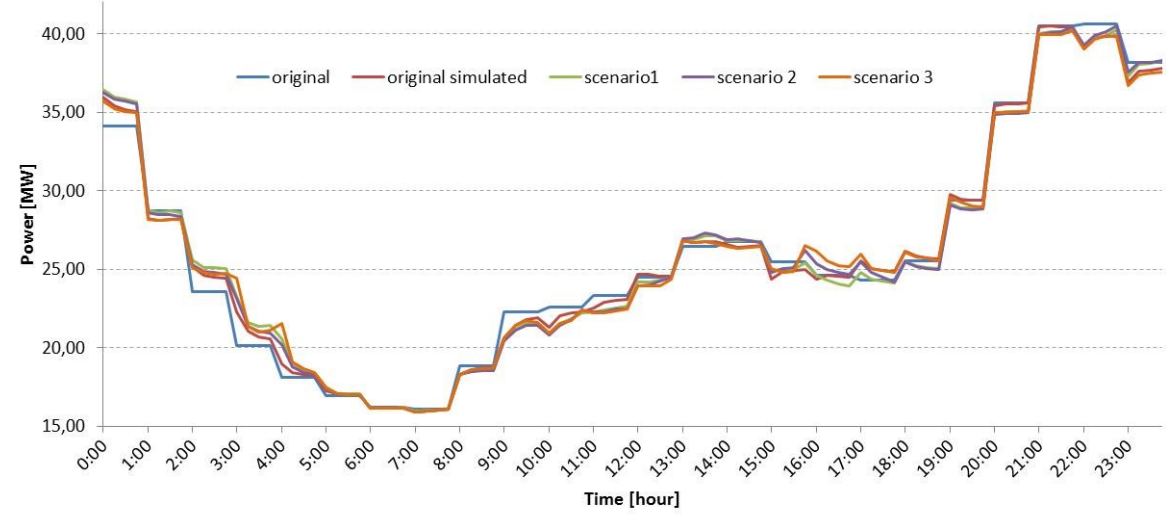

Figure 55 - Min and Max of all simulations concerning the deployment of the Energy Box, for a $20 \%$ deployment.

In Figure 56 it is possible to recognize the combined patterns of previously analyzed scenarios 1 to 3 .

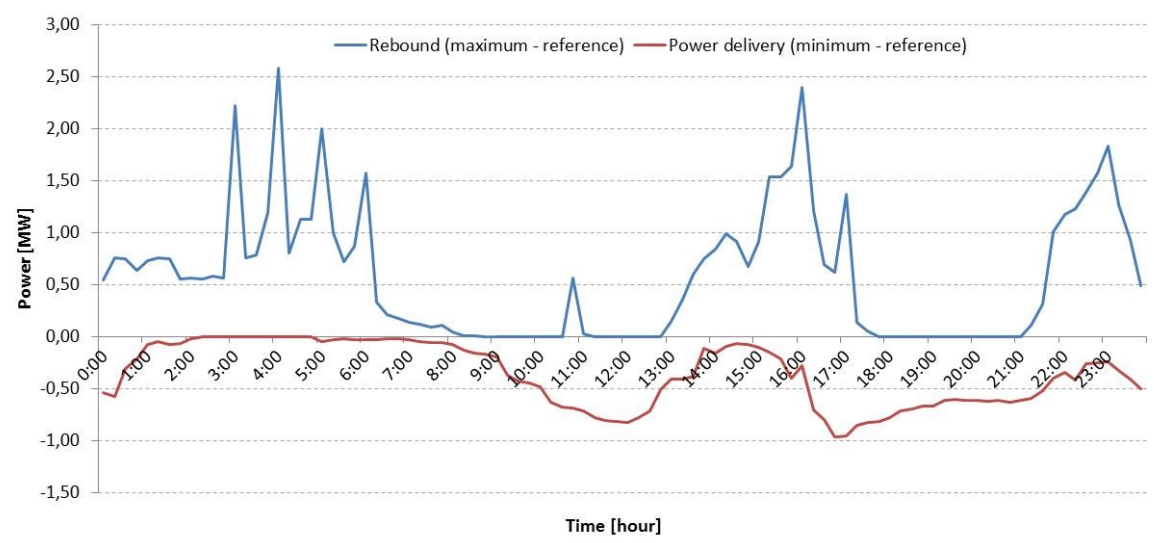

Figure 56 - Max. rebound and power delivery for all simulations concerning a $20 \%$ deployment.

In order to evaluate the possible electrical management impact of EB deployments for different DR strategies, the trends concerning physical changes in electricity demand due to the availability of consumers to postpone start were accounted.

For that matter, it was considered:

- Peak demand reduction, comprises decreasing the amplitude of the power from the maximum value of the original simulation;

- Valley power reduction, means that the smallest power demand in the original simulation was further decreased in the simulation that comprises DR actions; 
- Peak demand reduction and Valley power reduction, includes the combined effect of both actions;

- Valley power increase, refers to an increase in power demand when compared to the lowest value of the original simulation;

- Load shifting, encompasses increasing the lowest verified power demand of the original simulation and decreasing the power demand of the maximum value, also of the original simulation.

Such analysis is provided in Table 29.

\begin{tabular}{cccccc}
\hline Scenario & & & Number of simulations & & \\
& $\begin{array}{c}\text { Peak demand } \\
\text { reduction }\end{array}$ & $\begin{array}{c}\text { Valley power } \\
\text { reduction }\end{array}$ & $\begin{array}{c}\text { Peak demand reduction and } \\
\text { Valley power reduction }\end{array}$ & $\begin{array}{c}\text { Valley power } \\
\text { increase }\end{array}$ & $\begin{array}{c}\text { Load } \\
\text { shifting }\end{array}$ \\
\hline 1 & 7 out of 12 & 5 out of 12 & 0 out of 12 & 7 out of 12 & 7 out of 12 \\
\hline 3 & 7 out of 12 & 3 out of 12 & 3 out of 12 & 2 out of 12 \\
\hline Total & 25 out of 36 & 11 out of 36 & 3 out of 12 & out of 12 & 0 out of 12 \\
\hline
\end{tabular}

Table 29 - Demand Response actions verified for simulations of a $20 \%$ deployment of the Energy Box.

As for the analysis of the results of Table 29, it is possible to identify which trend or trends of strategies of Demand Response are attributable to each particular scenario.

Scenario 1 presents more than half of the simulations with positive DR features, like peak demand reduction, valley power increase and load shifting. However, in five simulations DR may have harmful results by lowering the minimum diagram power.

Scenario 2 seems particularly suited to reduce the maximum power demand (7 hits in 12) and in three simulations it was even possible to diminish the maximum power demand while lowering the minimum diagram power. Increasing load demand in Valleys and load shifting, accounted with two occurrences each. 
The highest number of occurrences of peak demand reduction was observable in scenario 3 , with 11 out of 12 simulations. In 3 simulations it was even possible to lower the minimum diagram power while reducing peak demand.

From the analysis of the overall results, it is visible that peak demand reduction $(25 / 36)$ represents the dominant outcome.

The existence of Valley power reduction phenomena, as observed in the simulations, corresponds to a possible non-desirable effect of DR for the management of the electricity grid, depending on the overall load demand. However, this phenomenon may be used for new applications, like charging the batteries of electric vehicles or storing energy in dedicated devices. This may prove justifiable given the advent of electric vehicles penetration and the arising of new peak demands that may increase the constraints in electricity networks.

\subsubsection{Simulation based on price clusters - comparing deployments}

The present section will present the differences between deployments of the EB that range from $20 \%$ to $100 \%$.

From the scope of results concerning all deployment rates, the minimum and maximum consumed energy values verified in simulations fluctuated between 2,485.86 MWh/day to 2,495.18 MWh/day, both from the 100\% EB deployment simulations.

Figure 57 presents the range of rebound and power delivery for all deployment shares of the EB under scenario 1 conditions. It is perceivable from the analysis of this figure that this scenario opens the possibility for new peak demand, at 4:00 with 1.62MW (20\% EB deployment) until $8.93 \mathrm{MW}$ (100\% EB deployment), at 16:00 with $0.92 \mathrm{MW}$ (20\% EB deployment) and 4.65 MW (100\% EB deployment) and at 23:00 with $1.40 \mathrm{MW}$ (20\% EB deployment) and $6.56 \mathrm{MW}$ (100\% EB deployment). Power delivery exhibits a trend for growth between 9:00 and 12:00 with a maximum of $3 \mathrm{MW}$. The reverse trend occurs between 17 p.m. and 23 p.m., with a maximum released power of $4.45 \mathrm{MW}$ at 17:00. 


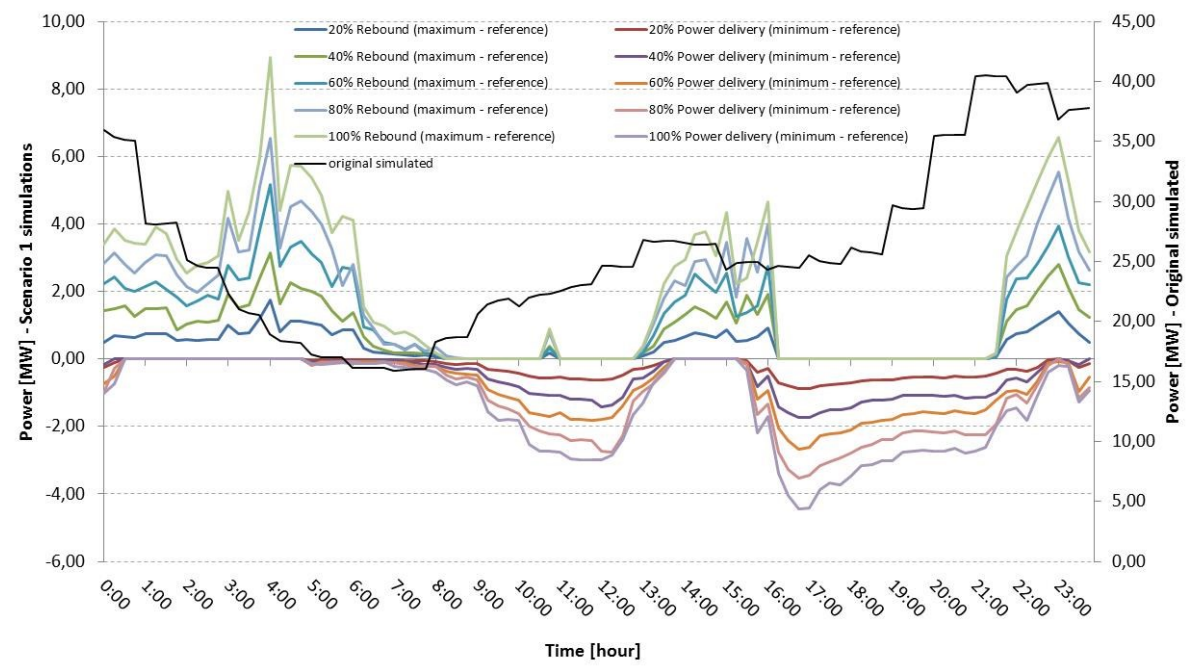

Figure 57 - Range of rebound and power delivery for scenario 1 simulations (100 runs each).

Figure 58 is the graphical representation of the range of rebound and power delivery verified in simulations using scenario 2 as a framework. Contrary to what was verified in scenario 1 , scenario 2 depicts the highest peak at 23:00 with 1.84 MW (20\% EB deployment) and 9.43 MW (100\% EB deployment). The second highest peak occurs previously than the already mentioned peak at 16:00 with 1.82 MW (20\% EB deployment) and 8.98 MW (100\% EB deployment).The introduction of new peak demand at 23:00 might represent a problem for the DSO to cope with, considering residential electricity demand in constrained grids. The range of rebound in scenario 2, due to the amplitude of its peaks, seems more problematic for the DSO to manage than in scenario 1. The behavior of power delivery in scenario 2 is similar to scenario 1 , but with slightly higher amplitudes, e.g. exhibiting a maximum of 4.85 MW at 17:00 (100\% EB deployment).

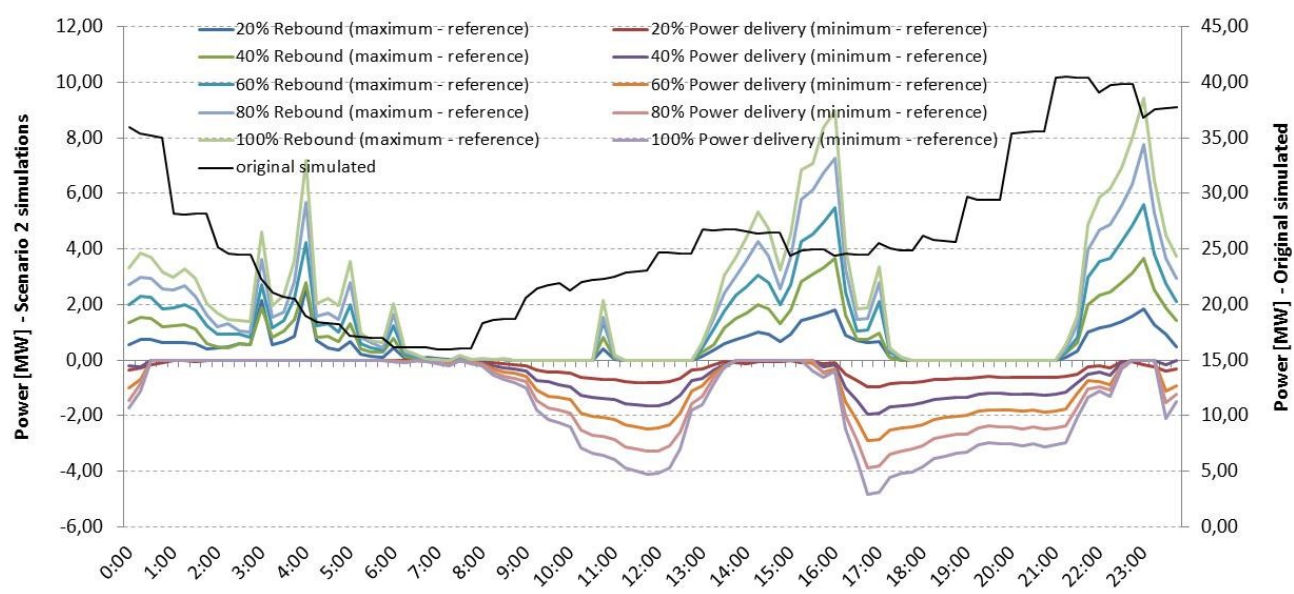

Figure 58 - Range of rebound and power delivery for scenario 2 simulations (100 runs each). 
Figure 59 exhibits the dynamics of demand response over the influence of scenario 3. From one perspective, scenario 3 presents the highest peaks among the three scenarios, with an impressive peak demand at 4:00 in the morning,13.08 MW (100\% EB deployment) and at 16:00 with $11.90 \mathrm{MW}$ (100\% EB deployment). From the other perspective, all peak demand appear in apparently non-critical periods from the aggregated view, while power delivery occurs in particularly important periods, especially at night, from 19:00 to 1:00 and 9:00 to 14:00.

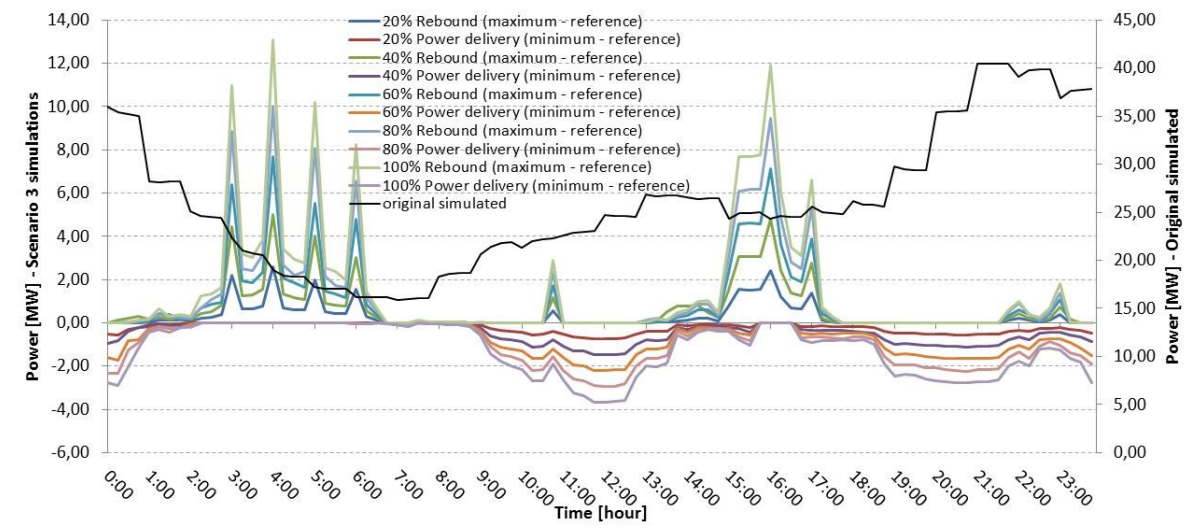

Figure 59 - Range of rebound and power delivery for scenario 3 simulations (100 runs each).

The following figures present a graphical representation of the number of hits for the actions which were previously framed, namely: peak demand reduction; valley power reduction; peak demand reduction and valley power reduction; valley power increase and load shifting. For the analysis and understanding of such results it needs to be stated that the elasticity expression according to this methodological approach (enabling consumers to postpone the start of their appliances) may lead to results, that from the DSM standpoint, are not all desired and that may not even be those envisaged by the network management. Some of these actions clearly correspond to DSM objectives, others do not. Hence, the analysis of such results will have to consider that these were selected as an example, not comprising all possible outcomes.

Figure 60 presents a graphical visualization, per deployment share, of the number of occurrences (hits) per each of the DR actions verified in scenario 1 which were here chosen to exemplify the effects of DR. 


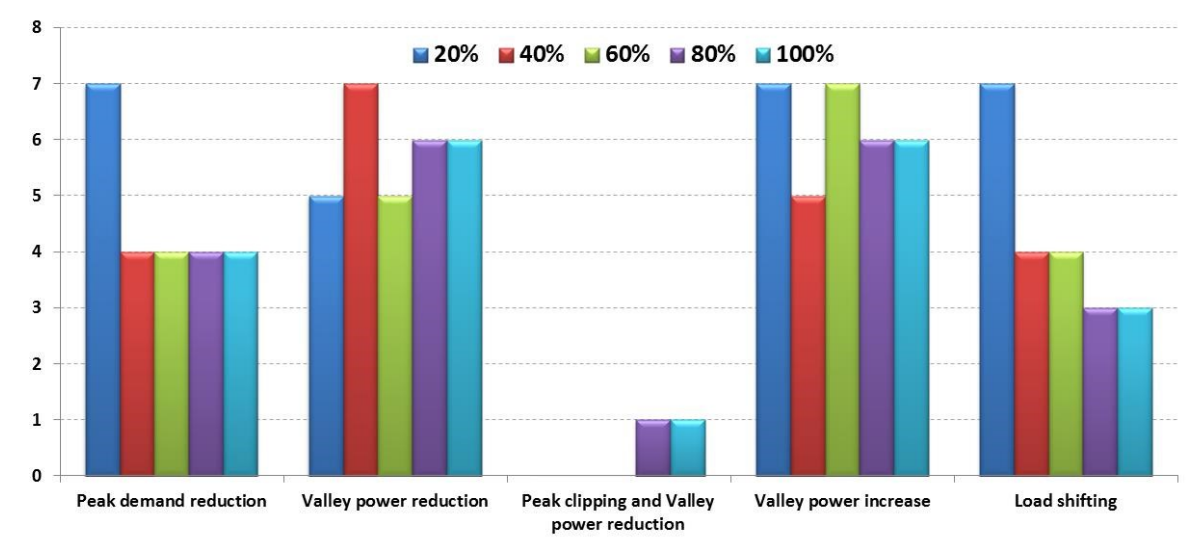

Figure 60 - Number of hits for actions of DR for Scenario 1, for all deployments.

Figure 61 presents the results regarding the 43 actions that were verified for scenario 2. Having a closer look to such results, for example, a $20 \%$ deployment of the EB, provides a reasonable higher number of hits when compared to other deployment shares in peak demand reduction, peak clipping and valley power reduction, valley power increase and load shifting.

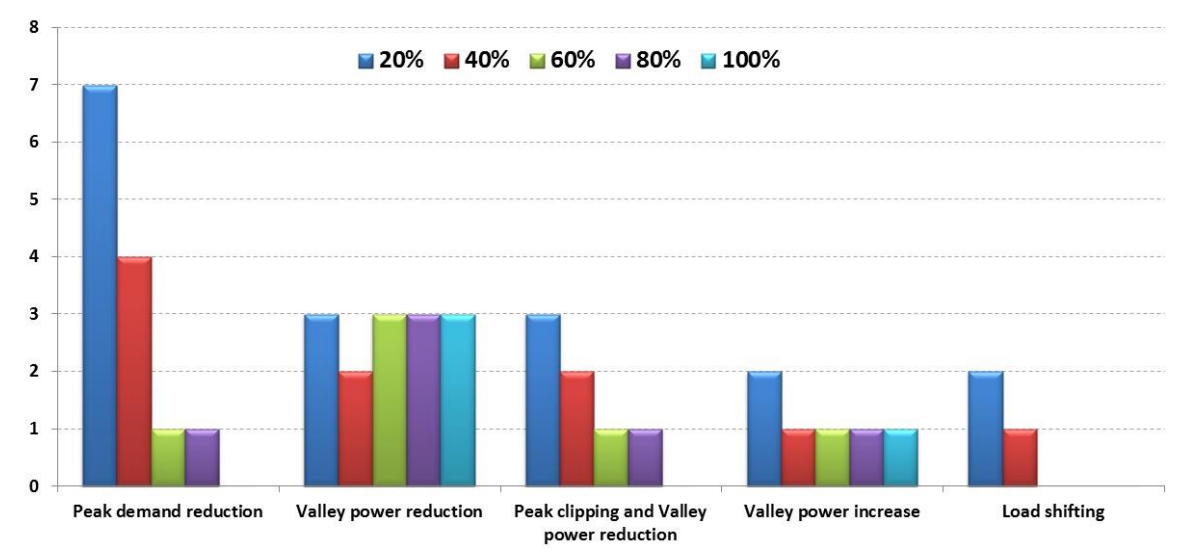

Figure 61 - Number of hits for actions of DR for Scenario 2, for all deployments.

Figure 62 presents the number of hits for the only three actions of DR that were provided by implementing scenario 3 . The conditions established for this scenario enabled for all deployment shares rather similar number of hits for peak demand reduction, except in the $20 \%$ deployment of the EB, for valley power reduction and for simultaneously peak clipping and valley power reduction. 


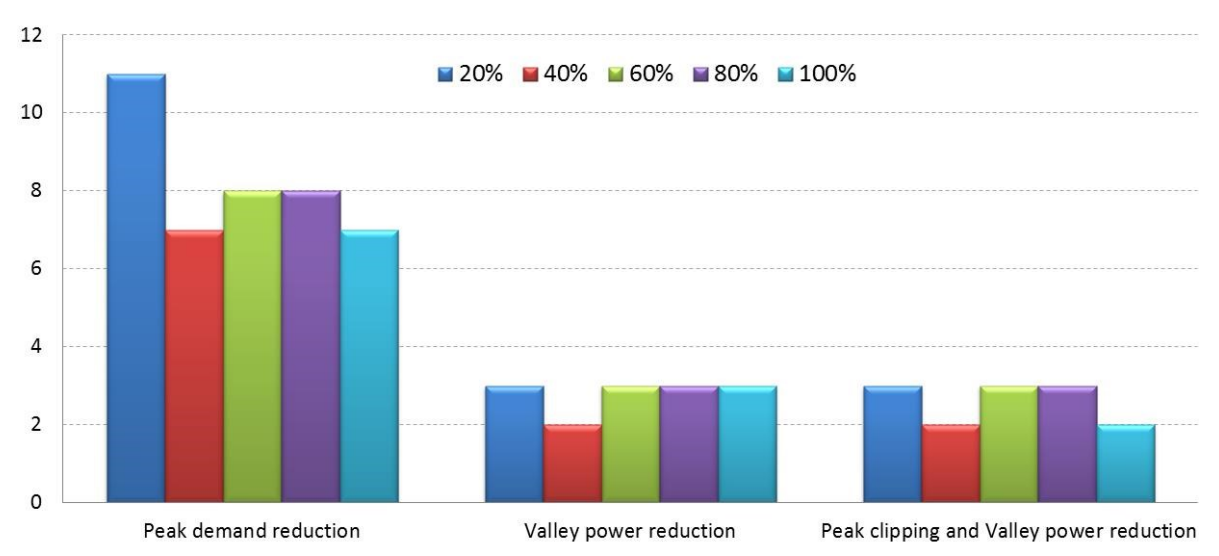

Figure 62 - Number of hits for actions of DR for Scenario 3, for all deployments.

\subsection{Environmental Results}

\subsubsection{Reference of the environmental impact of Demand Response}

The present section partially reproduces the content of a conference paper published by Miguel, Neves, \& Martins (2015).

Table 30 presents the contribution of each energy source for supplying electricity to the city of Coimbra for the average day.

\begin{tabular}{|c|c|c|c|c|c|c|c|c|c|c|}
\hline & \multicolumn{10}{|c|}{ Energy [GJ/day] } \\
\hline & $\begin{array}{l}\overline{\mathbb{\Omega}} \\
\mathcal{O}\end{array}$ & 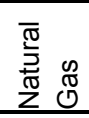 & 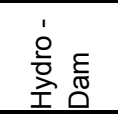 & 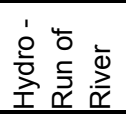 & $\begin{array}{l}\underline{t} \\
\text { 을 } \\
\underline{\underline{\xi}}\end{array}$ & 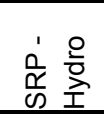 & 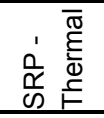 & $\begin{array}{l}\frac{0}{0} \\
\frac{c}{\infty} \\
\omega\end{array}$ & 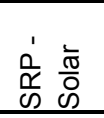 & 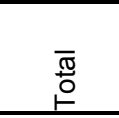 \\
\hline Original simulated & 461.35 & 65.12 & 266.26 & 294.72 & 223.58 & 55.76 & 358.74 & 499.55 & 16.38 & $2,241.45$ \\
\hline
\end{tabular}

Table 30 - Estimation of the contribution of each electricity generation technology for the average day of the city of Coimbra in the original simulated scenario (without DR) in [GJ/day].

In the average day of 2013, SRP Wind is the biggest contributor of the electricity generation system with $22.29 \%$. Coal thermal power plants are responsible for $20.58 \%$ of the energy supplied in the city of Coimbra. Above $10 \%$ share, electricity is provided through SRP - Thermal (16.00\%), Hydro - Run of River $(13.15 \%)$ and Hydro-Dam (11.88\%). Below 10\%, imported electricity $(9.97 \%)$, natural gas (2.91\%) and SRP-Hydro (2.49\%) and SRP - Solar with $0.73 \%$.

Table 31 presents the $\mathrm{CO}_{2}$ emissions for the original simulated scenario, based on (DRE, 2008) and considering a thermodynamic efficiency of $40 \%$ for generating electricity using coal and $55 \%$ for generating electricity using a CCGT (Eurelectric, 
2003) (World Energy Council, 2013). Such thermodynamic efficiencies mean that the calculated $\mathrm{CO}_{2}$ emissions per energy unit for coal is of $236.25 \mathrm{kgCO}_{2} \mathrm{e} / \mathrm{GJ}$ and for CCGT is $116.54 \mathrm{kgCO}_{2} \mathrm{e} / \mathrm{GJ}$.

\begin{tabular}{|c|c|c|c|}
\hline & \multicolumn{3}{|c|}{ Emissions $\left[\mathrm{tCO}_{2} \mathrm{e} /\right.$ day] } \\
\hline & $\begin{array}{l}\overline{\widetilde{\Omega}} \\
0\end{array}$ & 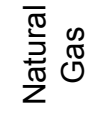 & $\begin{array}{l}\bar{\pi} \\
\stackrel{0}{0}\end{array}$ \\
\hline $\begin{array}{c}\text { Average } 2013 \\
\text { profile }\end{array}$ & 108.99 & 7.59 & 116.58 \\
\hline
\end{tabular}

Table $31-\mathrm{CO}_{2}$ emissions for the original simulated scenario.

\subsubsection{Case 1 - Using gas as the target for actions of the Energy Box}

In the present section the use of natural gas (CCGT) to compensate DR fluctuations is compared with other technologies. Table 32 presents the energy results.

\begin{tabular}{|c|c|c|c|c|c|c|}
\hline & \multicolumn{6}{|c|}{ Energy [GJ/day] } \\
\hline & \multicolumn{3}{|c|}{ Increase in load demand } & \multicolumn{3}{|c|}{ Decrease in load demand } \\
\hline & סू & 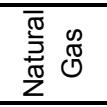 & $\begin{array}{l}\overline{\frac{\pi}{0}} \\
\stackrel{0}{\circ}\end{array}$ & סु & 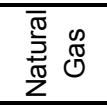 & $\begin{array}{l}\overline{\frac{\pi}{0}} \\
\stackrel{0}{\circ}\end{array}$ \\
\hline Mean & 442.61 & 85.21 & $2,242.80$ & 445.73 & 79.71 & $2,240.42$ \\
\hline Standard Error & 1.39 & 1.43 & 0.09 & 3.05 & 2.97 & 0.17 \\
\hline Median & 445.64 & 82.09 & $2,242.62$ & 456.73 & 69.6 & $2,240.69$ \\
\hline $\begin{array}{l}\text { Standard } \\
\text { Deviation }\end{array}$ & 16.68 & 17.17 & 1.03 & 18.06 & 17.58 & 1.01 \\
\hline Variance & 278.22 & 294.9 & 1.06 & 326.12 & 309.09 & 1.02 \\
\hline Minimum & 399.47 & 65.13 & $2,241.46$ & 409.52 & 63.98 & $2,237.27$ \\
\hline Maximum & 461.35 & 128.52 & $2,245.66$ & 461.35 & 114.47 & $2,241.43$ \\
\hline $\begin{array}{l}\text { Number of } \\
\text { simulations }\end{array}$ & & 145 & & & 35 & \\
\hline
\end{tabular}

Table 32 - Statistical results of energy supply contributions for simulations of Demand Response for the city of Coimbra with gas generation technology used to compensate power demand fluctuations.

In Table 33, it is perceivable that the standard deviation of simulations with energy decrease is higher than in simulations with energy increase, both in coal and in natural gas.

By using CCGT a significant number of simulations led to a reduction in the emissions, even if the total consumption was increased. This was due to the replacement of coal based electricity by CCGT based electricity as a result of DR. 


\begin{tabular}{|c|c|c|c|c|c|c|}
\hline & \multicolumn{6}{|c|}{ Emissions $\left[\mathrm{tCO}_{2} \mathrm{e} /\right.$ day] } \\
\hline & \multicolumn{3}{|c|}{ Emissions increase } & \multicolumn{3}{|c|}{ Emissions decrease } \\
\hline & סू & 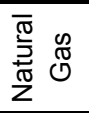 & 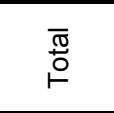 & $\begin{array}{l}\bar{\pi} \\
\text { O }\end{array}$ & 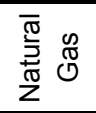 & $\begin{array}{l}\bar{\pi} \\
\text { Oீँ }\end{array}$ \\
\hline Mean & 108.99 & 7.64 & 116.62 & 103.99 & 10.17 & 114.16 \\
\hline Standard Error & 0 & 0.01 & 0 & 0.31 & 0.16 & 0.16 \\
\hline Median & 108.99 & 7.63 & 116.62 & 104.38 & 9.98 & 114.44 \\
\hline $\begin{array}{l}\text { Standard } \\
\text { Deviation }\end{array}$ & 0.02 & 0.04 & 0.02 & 3.89 & 1.96 & 1.94 \\
\hline Variance & 0 & 0 & 0 & 15.13 & 3.84 & 3.78 \\
\hline Minimum & 108.89 & 7.59 & 116.58 & 94.37 & 7.46 & 109.35 \\
\hline Maximum & 108.99 & 7.78 & 116.67 & 108.99 & 14.98 & 116.58 \\
\hline $\begin{array}{l}\text { Number of } \\
\text { simulations }\end{array}$ & & 26 & & & 154 & \\
\hline
\end{tabular}

Table 33 - Statistical results of equivalent $\mathrm{CO}_{2}$ emissions for simulations of Demand Response actions for the city of Coimbra, using gas generation technology to compensate power demand fluctuations.

These results are understandable as in larger deployments of the Energy Box there is a shift in the share of technologies, with coal reducing from $20.58 \%$ in the original simulated scenario to $18.65 \%$ in a $100 \%$ deployment scenario, while the share of natural gas rises from $2.91 \%$ to $4.90 \%$. In cases of load demand requiring a power reduction higher than the power provided by natural gas, the remaining value was subtracted to the coal generation technology in order to maintain the balance between supply and demand.

\begin{tabular}{ccc}
\cline { 2 - 3 } & \multicolumn{2}{c}{$\begin{array}{c}\text { Generation technology shares, } \\
\text { in \% }\end{array}$} \\
\hline EB deployment [\%] & Coal & Natural gas \\
\hline original simulated & 20.58 & 2.91 \\
\hline 20 & 20.58 & 2.91 \\
\hline 40 & 20.39 & 3.11 \\
\hline 60 & 19.91 & 3.61 \\
\hline 80 & 19.30 & 4.23 \\
\hline 100 & 18.65 & 4.90 \\
\hline
\end{tabular}

Table 34 - Case 1, generation technology shares, in \%.

Other findings:

- No simulation with a net energy consumption reduction resulted in increases in $\mathrm{CO}_{2}$ emissions; 
- In $82 \%$ of simulations with a consumption increase, a decrease in $\mathrm{CO}_{2}$ emissions was verified.

\subsubsection{Case 2 - Using coal and gas as the target of the Energy Box actions}

The present section presents the possibility of using coal and natural gas technologies in combination to compensate DR fluctuations. The new contribution of each of these two technologies will linearly reflect its share, considering the original contribution, thus maintaining percentage share while determining the new quarter-hour power contribution of the generation mix.

In Table 35 the simulations regarding the load demand of DR are presented, compensated by coal and natural gas generation technologies.

\begin{tabular}{|c|c|c|c|c|c|c|}
\hline & \multicolumn{6}{|c|}{ Energy [GJ/day] } \\
\hline & \multicolumn{3}{|c|}{ Increase in load demand } & \multicolumn{3}{|c|}{ Decrease in load demand } \\
\hline & סू & 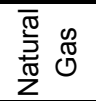 & $\begin{array}{l}\text { तू } \\
\stackrel{0}{\circ}\end{array}$ & ס্ণ & 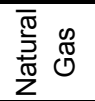 & 要 \\
\hline Mean & 465.25 & 62.60 & $2,242.80$ & 463.66 & 61.78 & $2,240.42$ \\
\hline Standard Error & 0.18 & 0.13 & 0.09 & 0.31 & 0.35 & 0.17 \\
\hline Median & 465.02 & 62.96 & $2,242.62$ & 462.98 & 62.39 & $2,240.69$ \\
\hline $\begin{array}{l}\text { Standard } \\
\text { Deviation }\end{array}$ & 2.16 & 1.53 & 1.03 & 1.81 & 2.10 & 1.01 \\
\hline Variance & 4.68 & 2.35 & 1.06 & 3.27 & 4.42 & 1.02 \\
\hline Minimum & 462.13 & 58.36 & $2,241.46$ & 461.56 & 57.56 & $2,237.27$ \\
\hline Maximum & 472.35 & 64.73 & $2,245.67$ & 468.65 & 64.38 & $2,241.43$ \\
\hline $\begin{array}{l}\text { Number of } \\
\text { simulations }\end{array}$ & & 145 & & & 35 & \\
\hline
\end{tabular}

Table 35 - Statistical results of energy supply contributions of Demand Response for the city of Coimbra, with coal and gas generation technologies used to compensate power demand fluctuations.

Table 36 presents the results of the simulations regarding the emissions of $\mathrm{CO}_{2}$. Considering the difference of scale between the shares of coal and natural gas, there is a natural trend towards the increase of $\mathrm{CO}_{2}$ emissions in simulations, especially, due to the increase of the contribution of coal: 172 simulations had an increase in $\mathrm{CO}_{2}$ emissions, while only 8 simulations showed a $\mathrm{CO}_{2}$ emissions decrease. 


\begin{tabular}{|c|c|c|c|c|c|c|}
\hline & \multicolumn{6}{|c|}{ Emissions $\left[\mathrm{tCO}_{2} \mathrm{e} /\right.$ day] } \\
\hline & \multicolumn{3}{|c|}{ Emissions increase } & \multicolumn{3}{|c|}{ Emissions decrease } \\
\hline & סू & 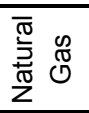 & $\begin{array}{l}\bar{\pi} \\
\text { 음 }\end{array}$ & $\begin{array}{l}\overline{\widetilde{\pi}} \\
\text { Oे }\end{array}$ & 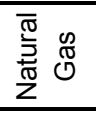 & $\begin{array}{l}\bar{\pi} \\
\text { 0 }\end{array}$ \\
\hline Mean & 109.87 & 7.28 & 117.15 & 109.22 & 7.24 & 116.47 \\
\hline Standard Error & 0.04 & 0.01 & 0.03 & 0.06 & 0.07 & 0.02 \\
\hline Median & 109.84 & 7.32 & 117.10 & 109.13 & 7.27 & 116.47 \\
\hline $\begin{array}{l}\text { Standard } \\
\text { Deviation }\end{array}$ & 0.51 & 0.2 & 0.38 & 0.17 & 0.21 & 0.07 \\
\hline Variance & 0.26 & 0.04 & 0.15 & 0.03 & 0.04 & 0 \\
\hline Minimum & 109.13 & 6.71 & 116.61 & 109.04 & 6.83 & 116.38 \\
\hline Maximum & 111.59 & 7.54 & 119.03 & 109.55 & 7.44 & 116.56 \\
\hline $\begin{array}{l}\text { Number of } \\
\text { simulations }\end{array}$ & & 172 & & & 8 & \\
\hline
\end{tabular}

Table 36 - Statistical results of equivalent $\mathrm{CO}_{2}$ emissions simulations of Demand Response actions for the city of Coimbra, with coal and gas generation technologies used to compensate power demand fluctuations.

Table 37, confirms what was claimed earlier, namely the slight increase of $\mathrm{CO}_{2}$ emissions due to the increase of the contribution of coal and the decrease of the contribution of natural gas, for larger deployments of the Energy Box.

\begin{tabular}{ccc}
\cline { 2 - 3 } & \multicolumn{2}{c}{$\begin{array}{c}\text { Generation technology } \\
\text { shares, in \% }\end{array}$} \\
\hline EB deployment [\%] & Coal & Natural gas \\
\hline original simulated & 20.58 & 2.91 \\
\hline 20 & 20.63 & 2.86 \\
\hline 40 & 20.68 & 2.82 \\
\hline 60 & 20.73 & 2.78 \\
\hline 80 & 20.79 & 2.75 \\
\hline 100 & 20.84 & 2.70 \\
\hline
\end{tabular}

Table 37 - Case 2, generation technology shares, in \%.

Other findings:

- In $77 \%$ of simulations with a decrease of energy consumption, an increase in $\mathrm{CO}_{2}$ emissions is verified;

- In $16 \%$ of simulations with an increase in $\mathrm{CO}_{2}$ emissions, a decrease in energy consumption occurs;

- In all simulations with an energy consumption increase, an increase in $\mathrm{CO}_{2}$ emissions occurs. 


\subsubsection{Case 3 - Using hydro-dam as the target of the Energy Box actions}

In the following section, the results regarding the possibility of using hydroelectricity from dams to compensate load demand fluctuations due to actions of DR are represented.

Table 38 show results regarding the energy distribution of coal and hydro-dam technologies. It is possible to verify that while in the energy increase scenario, the standard deviation of hydro-dam is higher than for coal, the standard deviation of hydro-dam in the situations where energy consumption increase occurs is lower than for coal generation technologies. Similarly, to what happened in the case where natural gas was used to compensate load demand, in certain simulations, maintaining supply and demand balance required a reduction of the coal based generation output.

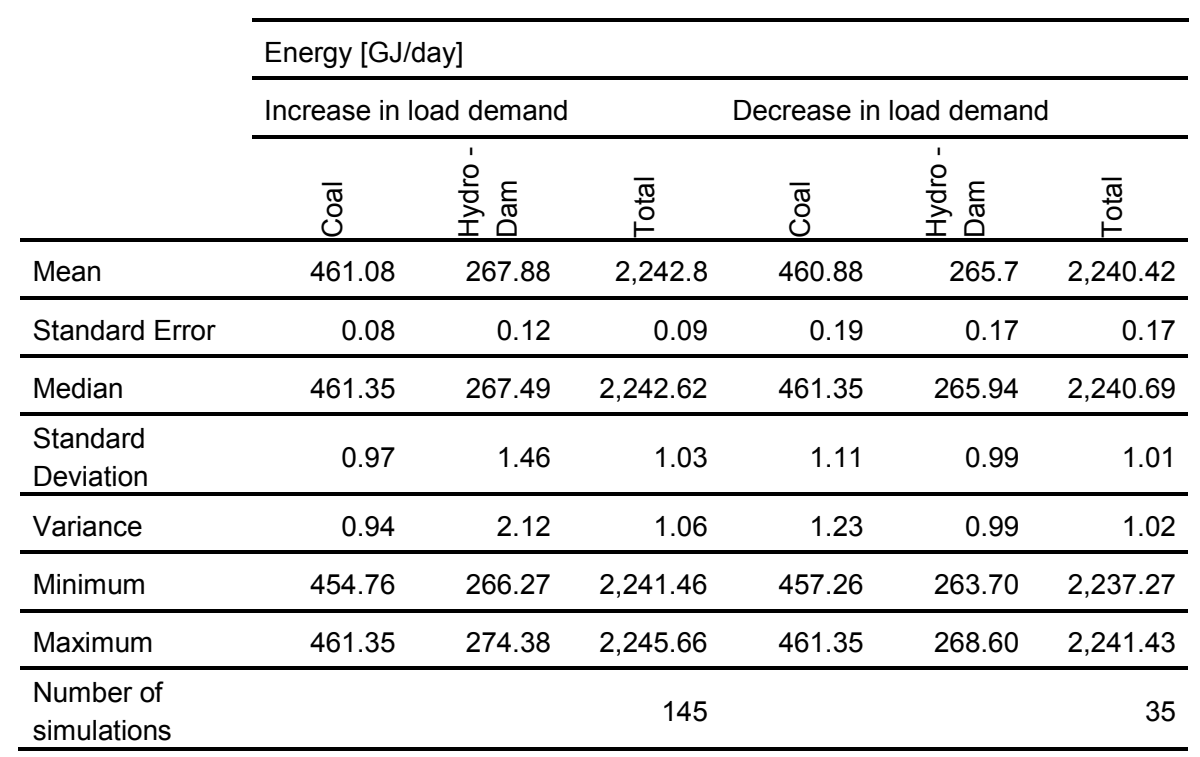

Table 38 - Statistical results of energy supply contributions for simulations of Demand

Response for the city of Coimbra, with hydro-dam generation technology used to compensate power demand fluctuations.

The use of an emissions-free source as hydro-dam to compensate the actions of the EB results in a neutral output, maintaining the level of emissions of the original supply to the city. The results are shown in Table 39. 


\begin{tabular}{|c|c|c|c|c|}
\hline & \multicolumn{4}{|c|}{ Emissions [tCO2e/day] } \\
\hline & \multicolumn{2}{|c|}{$\begin{array}{l}\text { Emissions lowered to the } \\
\text { level of the average day }\end{array}$} & \multicolumn{2}{|c|}{ Emissions decrease } \\
\hline & बृ & 产 & $\overline{\mathscr{O}}$ & $\begin{array}{l}\bar{\pi} \\
0 \\
\end{array}$ \\
\hline Mean & 108.99 & 116.58 & 108.67 & 116.26 \\
\hline Standard Error & 0 & 0 & 0.07 & 0.07 \\
\hline Median & 108.99 & 116.58 & 108.86 & 116.45 \\
\hline $\begin{array}{l}\text { Standard } \\
\text { Deviation }\end{array}$ & \multirow[t]{2}{*}{0} & \multirow[t]{2}{*}{0} & 0.41 & 0.41 \\
\hline Variance & & & 0.17 & 0.17 \\
\hline Minimum & \multirow{2}{*}{108.99} & \multirow{2}{*}{116.58} & 107.44 & 115.03 \\
\hline Maximum & & & 108.98 & 116.57 \\
\hline $\begin{array}{l}\text { Number of } \\
\text { simulations }\end{array}$ & & 140 & & 40 \\
\hline
\end{tabular}

Table 39 - Statistical results of equivalent $\mathrm{CO}_{2}$ emissions of Demand Response actions for the city of Coimbra, with hydro-dam generation technology used to compensate power demand fluctuations.

Despite the number of simulations with lower $\mathrm{CO}_{2}$ emissions (below the average value) being not meaningful, it is perceivable from Table 40 that the impact of coal and natural gas technologies is slightly lower, while the impact of hydro-dam is slightly higher.

\begin{tabular}{cccc}
\hline & \multicolumn{3}{c}{ Generation technology shares, in \% } \\
\hline $\begin{array}{c}\text { EB deployment } \\
{[\%]}\end{array}$ & Coal & Natural gas & Hydro - Dam \\
\hline original simulated & 20.58 & 2,91 & $11.88 \%$ \\
\hline 20 & 20.58 & 2.90 & $12.02 \%$ \\
\hline 40 & 20.58 & 2.90 & $12.04 \%$ \\
\hline 60 & 20.57 & 2.90 & $12.05 \%$ \\
\hline 80 & 20.56 & 2.90 & $12.07 \%$ \\
\hline 100 & 20.51 & 2.90 & $12.12 \%$ \\
\hline
\end{tabular}

Table 40 - Case 3, generation technology shares, in \%.

Other findings:

- In $71 \%$ of simulations with energy decrease, $\mathrm{CO}_{2}$ emissions did not surpass the average emissions from the original simulated scenario;

- In $81 \%$ of simulations with an increase in energy consumption, emissions were lowered to the level of the average day. 
THIS PAGE INTENTIONALLY LEFT BLANK 


\section{Conclusions}

This work deals with the characterization of the dynamic response of demand through the use of advanced smart meters with load management capabilities. Throughout this work, such device has been designated as Energy Box, an original designation by Livengood \& Larson (2009). Inspired by the original concept of the Energy Box this work tried to answer the following four research questions:

1. What potential for demand flexibility is available in a defined household area?

2. What is the reasonable expected potential of the Energy Box?

3. What are the consequences of a wide integration of the Energy Box in Portuguese households for the DSO management operations?

4. Are the results expected to be attractive enough for the DSO to demand/suggest the launch of this type of equipment or stimulate its use?

The answers to the first three research questions are presented in subsection 5.1 Potential for Demand response.

Subsection 5.2 encompasses the conclusions regarding the environmental analysis due to the possible impact of DR actions. This work was not originally planned, however during the course of the thesis development it was thought to be an added value to make such assessment. This subsection will help answering the fourth research question by combining the main conclusions of the answer to the second research question with the environmental results due to actions of DR.

An analysis to the selected methodology, focusing on price clusters, is the core subject of subsection 5.3 entitled Analysis of the electricity price profiles obtained through clustering.

Overall advantages and disadvantages of the selected model are pointed out in subsection 5.4 - Advantages and disadvantages of the developed methodology Subsection 5.5 - Future work, presents possible clues for future research to be conducted. 


\subsection{Potential for Demand response}

This work presented a possible methodological approach for evaluating the impact at grid level of the deployment of a demand response technology. To attain this objective it is a requirement to know the acceptance of consumers regarding the participation in a demand response setting, and their particular willingness to accept the automatic control of certain loads within a predefined set of constraints, being this requirement the focus of the first research question. The demand flexibility that was later used to simulate the actions of DR was defined through 3 test scenarios of consumer's willingness to postpone the start of the selected appliances. The first two scenarios use the data published by Mert (2008), scenario 1 depicting the entire set of hourly tolerances to smart operation (from $0.5 \mathrm{~h}$ to $24 \mathrm{~h}$ ), while in scenario 2 a $24 \mathrm{~h}$ postponement is not possible. Scenario 3 makes use of the hourly tolerances that were published by Jamasb \& Pollitt (2011). The use of these data allowed the test of the proposed methodology, since carrying out the necessary surveys to directly obtain relevant data for the specific case study would surpass the time and funding available.

The purpose of the developed work consisted of identifying the size of the aggregated Energy Box resource, as an equivalent to a generation resource, considering the possible postponement of the operation of available loads that usually contribute to peak and partial peak hours demand. From that perspective, this work considered particularly important to identify the period where energy consumption may be reduced, but also the periods when the rebound resulting from the switching-on of the shifted appliances will occur, as observable in section 4.2. An aggregated response of the results of the EB's operation was obtained through a Monte Carlo simulation.

Regarding the reasonable expected potential of the Energy Box, the results show that scenario 1 is less prone to the introduction of new peak demand while scenario 3 leads to highest peak demands. In what concerns power delivery, results show periods of continuous capacity release, two in the case of scenario 3 and three in the remaining scenarios. The combined effect of the rebound and capacity relief needs to be considered by the DSO, namely with regard to the time period when they arise: e.g. the range of rebound in scenario 2 at 23:00, that may 
present some difficulties to the grid management, but in scenario 3 new peak demand appears during apparently non-critical periods from the aggregated view while power delivery occurs in particularly important periods.

The possible introduction of new peak demand periods in the diagram implies the need to take into consideration management strategies. This is strongly related with the willingness and the time availability of consumers for the DR actions that are considered. One possible management hypothesis would be the introduction of a random delay in the firmware of each EB when defining the re-start of the various end-use loads. Peak coincidence would thus be minimized and the resulting aggregated diagram would be smoother. A different possibility may imply the DSO to have some degree of control, imposing a queue in order to only enable the switching-on of controlled appliances by the connected Energy Boxes, on an established maximum rate.

\subsection{Environmental conclusions}

Demand response is not per se a tool for reducing $\mathrm{CO}_{2}$ emissions. It strongly depends of the generation technologies that support the electricity system (energy matrix), and of which generation technologies and strategies will be used to compensate load demand fluctuations caused by DR actions.

In the case of using gas-based electricity generation as the target of the EB actions it can be highlighted that a $20 \%$ deployment of the EB does not create a significant impact on the energy supply mix, gas and coal-based generation keeping their "original" values. However, in $82 \%$ of simulations with higher energy consumption than in the average day it was possible to reduce the level of $\mathrm{CO}_{2}$ emissions from the original value of $116.58 \mathrm{tCO}_{2} \mathrm{e} /$ day to a minimum of 109.35 $\mathrm{tCO}_{2} \mathrm{e} /$ day (approximately $6 \%$ reduction in $\mathrm{CO}_{2}$ emissions).

By using coal and gas as the target of the EB actions and maintaining their original quarter-hour shares, a constant increase in the share of coal was verified, as well as a constant decrease of the share of gas for compensating the actions of the EB. Thus, maintaining the current quarter-hour shares of such generation technologies, to compensate DR actions, implies a generalized increase in $\mathrm{CO}_{2}$ emissions. This is easily verifiable because an increase of $\mathrm{CO}_{2}$ emissions was 
obtained in $77 \%$ of simulations with lower energy consumption compared to an average day.

An effective way not to allow the increase of $\mathrm{CO}_{2}$ emissions is to make the usage of potential energy stored in hydroelectric plants the target of EB actions. In fact, on $81 \%$ of simulations with energy consumption increase the emissions were leveled to the emissions of the average day. However, effectively lowering emissions may not be possible. In the simulation cases were a $\mathrm{CO}_{2}$ reduction occurred, the emissions were lowered from $116.57 \mathrm{tCO} 2 \mathrm{e} / \mathrm{day}$ to 115.03 $\mathrm{tCO}_{2} \mathrm{e} /$ day, a maximum possible reduction of $1.32 \%$ in $\mathrm{CO}_{2}$ emissions.

The differences in the maximum possible reduction in $\mathrm{CO}_{2}$ emissions between using gas (109.35 $\mathrm{tCO}_{2} \mathrm{e} /$ day) and hydro-dam (115.03 $\mathrm{tCO}_{2} \mathrm{e} /$ day) as targets for the DR actions are only explainable by the share of other energy sources in the mix, namely coal. In fact, when gas is the target, the weight of coal in the mix becomes $18.65 \%$ and gas $4.90 \%$ (there is a remarkable shift, with environmental benefit). When hydro is the target, the weight of coal remains high $(20.51 \%)$, not allowing a big decrease in emissions.

From the environmental standpoint, using the simulation framework, for DR to effectively decrease emissions, lower or zero emission generation technologies will have to replace traditional generation. However, this increases the challenges of integrating such energy in the grid and into the market.

\subsection{Analysis of the electricity price profiles obtained through clustering}

This work was triggered due to the need for reliable data to assess the deployment of new technologies in the smart grid, namely of those based on demand response and distributed energy storage systems.

The use of two clustering methods enabled the comparison of results. This methodology shows that both methods return similar data, which is useful for prototype development.

The prototypes obtained from the average annual real prices clustering revealed a more competitive market between October, $1^{\text {st }}, 2012$, and September, $30^{\text {th }}, 2013$, 
than in the entire year of 2008. The average gross energy prices have been decreasing since 2008 , possibly due to the market liberalization introduced with the Iberian electricity market settlement (MIBEL) and the corresponding operational agreements of January 2008, and also to the increased integration of electricity from renewable generation combined with a lower demand.

A clear identification of the clusters with the weekday type (workday, Saturday, Sunday and holiday) was obtained for the demand profiles, while this was not the case with electricity prices. Such lack of correspondence in weekday type for price prototypes was verified despite the current market situation intending to create conditions for this to happen, which suggests that the natural consumption variation is not influencing prices.

The proposed methodology can be used for developing plausible scenarios, using real and up-to-date data, thus enabling the development of prototypes for simulating the smart grid environment. The classification process enabled the perception of how market prices, and also consumption and renewable generation profiles may be grouped, in one year time.

It is thus possible to study innovative technologies under the smart grid paradigm, such as, the use of energy management systems or of distributed electrical energy storage systems.

\subsection{Advantages and disadvantages of the developed methodology}

An advantage that can be pointed out is the possibility to attain and discriminate the smart grid value per Municipality or per region. The basic requirements to perform such assessment are enabled by easy updatable information using data regarding the electrical energy consumption, the existence of regulated consumption profiles, the hourly information regarding the average energy usage of households and a matrix of hourly prices of electricity.

As for the disadvantages, the methodology is dependent on the availability and quality of data about equipment/appliances regional shares and consumer behavior, prompting the need for further studies. Another need consists in having a detailed study on how appliances are used outside the average day. Such limitation doesn't allow an evaluation to be made for the different seasons of the 
year. This problem can eventually be minimized by providing 4 average consumption load diagrams, each per season of the year (winter, spring, summer and autumn).

In Portugal, energy tariff schemes use block rates for the contracted power. This means that there is a possible benefit in combining/managing the operation of appliances. However, most users are not willing to change their habits just for economic reasons, as described in 3.3, particularly in the studies of Mert (2008) and Lopes, Peixoto, Antunes, \& Martins (2014). In summary, such restrictions are related with influences on the wellbeing and comfort of the energy consumer, as well as the possible impact that such actions may cause due to the delay or the interruption of the required energy service. As an example, consumers fear possible damages in the clothes being washed or disturbing noise during the sleeping period.

\subsection{Future work}

Future results of appliance-focused testbed projects aiming at the identification of price elasticity related behavior of electricity demand will hopefully lead to a deeper understanding of the impact that demand response may have on optimizing the power system management and increasing the share of renewable energy. Such understanding may provide the basis to evaluate DR under different circumstances, crossing demand and generation capacity and their respective variations during the year.

The original question that prompted this work consisted in finding how an investment in an infrastructure, necessary to support a device such as the Energy Box, can be justified without knowing what could be its outcome. This equipment is supposed to provide the network operator with a set of standard flexible loads. Currently, this work is dealing with delays to the operation of appliances. Other additional possibilities include interrupting the operation of appliances, considering more types of loads, e.g. appliances dealing with thermal energy or the electric vehicle, and considering local renewable generation. This extended view could provide a wider image of the increasing potential of energy management systems such as the Energy Box. 


\section{References}

Prabhudesai , P., Hazare, A., Patil , D., Parab , R., \& Tawade, M. (2011). Smart Grid: Advantages \& Economics. India: World Trade Institute and Maharashtra Electricity Regulatory Commission.

ADENE.

(2009).

CASA+

Feasibility Analysis for energy efficiency technologies in residential building $s$ of Portugal . Final Report.

Akkermans, H., \& Ygge, F. (1996). Power load management as a computational market. Proceedings of the Second International Conference on Multi-Agent Systems, (pp. 393-400). Kyoto, Japan.

Albadi, M., \& El-Saadany, E. (2007). Demand Response in Electricity Markets: An Overview . Power Engineering Society General Meeting (pp. 1-5). Tampa, FL : IEEE.

Albadi, M., \& El-Saadany, E. (2008). "A summary of demand response in electricity markets". Electric Power Systems Research, 78, 1986-1996.

Borenstein, S., Jaske, M., \& Rosenfeld, A. (2002). Dynamic pricing, advanced metering, and demand response in electricity markets. University of California, Paper CSEMWP-105.

Bundesnetzagentur. (2011). Smart Grid und Smart Market. Bonn, Germany: Bundesnetzagentur.

Chardon, A., Almén, O., Lewis, P., Stromback, J., \& Château, B. (2008). Demand Response: a decisive breakthrough for Europe. Capgemini.

Charles River Associates. (2005). Primer on demand-side management with an emphasis on price-responsive programs. Retrieved September 3, 2015, from Report Prepared for The World Bank, Washington: http://siteresources.worldbank.org/INTENERGY/Resources/PrimeronDema ndSideManagement.pdf

Conte, G., Scaradozzi, D., Perdon , A., Cesaretti, M., \& Morganti, G. (2007). A simulation environment for the analysis of home automation systems. Mediterranean Conference on Control and Automation. Athens, Greece. 
D.O.E, U. S. (March 2002). Final Report of the US Department of Energy's Power outage study.

DGGE/IP-3E. (2004). Eficiência Energética em Equipamentos e Sistemas Eléctricos no Sector Residencial. ISBN 972-8268-31-9: DGGE/IP-3E.

DRE. (2008). Despacho n. ${ }^{\circ} 17313 / 2008$ (Legal Order 17313/2008) - Energy and

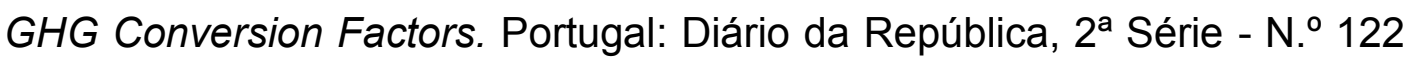
- 26 de Junho de 2008 (Diary of the Portuguese Republic).

Energaia, Factor Social, TerraSystemics. (2011). EnergyProfiler - Transformar Atitudes em Ação:Perfil Energético do Setor Residencial. Final Report.

EPRI. (2006). Turning on Energy Efficiency. Palo Alto, CA, USA: EPRI.

EPRI. (2008). The Green Grid - Energy Savings and Carbon Emissions Reductions Enabled by a Smart Grid. California, USA: EPRI.

ERSE. (2005). Despacho n. ${ }^{\circ} 18$ 993-A de 31 Agosto - Revisão: do Regulamento de Relações Comerciais, do Regulamento Tarifário e do Regulamento do Acesso às Redes. ERSE.

ERSE. (2007). Despacho n. ${ }^{\circ} 4$ 591-A- Guia de Medição, Leitura e Disponibilização de Dados. ERSE.

ERSE. (2009). Nota explicativa da informação sobre a produção em regime especial - explanatory note of the information on special regime producers. Lisbon: Entidade Reguladora dos Serviços Energéticos.

ERSE. (2011). Regulamento n. ${ }^{\circ} 496 / 2011$ - Aprovação dos novos regulamentos: Regulamento de Relações Comerciais, Regulamento Tarifário e Regulamento do acesso às Redes e Interligações. Diário da República, 2. ${ }^{a}$ série - n. ${ }^{\circ} 159$ - 19 de agosto, 34035-34322.

ERSE. (2012). Caracterização da procura de energia elétrica em 2013. Lisboa: ERSE.

EurActiv. (21 de June de 2012). EurActiv. Obtido em 30 de June de 2012, de http://www.euractiv.com/specialreport-access-energy/consumers-weaksmart-meter-roll-news-513445 
EURECO. (2002). End-use metering campaign in 400 households of the European Community. Save Programme Contract n. ${ }^{\circ}$ 4.1031/Z/98-267.

Eurelectric. (2003). Efficiency in Electricity Generation. Brussels: EURELECTRIC Union of the Electricity Industry.

European Council. (2014). European Council (23 and 24 October 2014) and Conclusions on 2030 Climate and Energy Policy Framework. Brussels: European Council (SN 79/14).

European Parliament and European Council. (2009). Directive 2009/28/EC. Official Journal of the European Union.

European Union Advisory Council. (2010). Smartgrids - Strategic Deployment Document for Europe's Electricity Networks of the Future. EU: EUAC.

Eurostat. (2014). Greenhouse gas emissions by sector. (European Commission) $\begin{array}{llll}\text { Retrieved } & \text { October } & 19, & 2014,\end{array}$ http://epp.eurostat.ec.europa.eu/tgm/table.do?tab=table\&init=1\&plugin=1\&l anguage $=$ en $\&$ pcode $=$ tsdcc 210

Eurostat. (2014). Greenhouse gas emissions, base year 1990. Obtido em 19 de October de 2014, de http://epp.eurostat.ec.europa.eu/tgm/table.do?tab=table\&init=1\&plugin=0\&l anguage $=$ en $\&$ pcode $=\mathbf{t} 2020 \_30$

Eurostat. (2014). The EU in the world 2014. Luxembourg: Luxemburg: Publications Office of the European Union.

Everitt, B. S., Landau, S., Leese, M., \& Stalh, D. (2011). Cluster Analysis 5th Edition. Wiley - A John Wiley and Sons, Ltd., Publication.

Faria, P. (2010). DemSi A Demand Response Simulator in the context of intensive use of Distributed Generation. IEEE International Conference on Systems Man and Cybernetics (SMC). Istanbul.

Faruqui, A., \& Sergici, S. (August, 2010). Household Response to dynamic pricing of electricity: a survey of 15 experiments. Regul. Economics, 193-225. 
Figueiredo, V., Rodrigues, D., \& Vale, Z. (2005). "Simulating DSM Impact in the New Liberalized Electricity Market". Porto, Portugal: Polytechnic Institute of Porto.

Franco, E., \& Neves, L. (2011). User defined dynamic electric load in ATPDraw. EEEG. Ohrid, Macedonia.

Gardner, E. (1995). Load management DSM: past, present and future . Rural Electric Power Conference (pp. A2/1 - A213). Nashville, TN: IEEE.

Gellings, C. (1996). Then and now - The perspective of the man who coined the term "DSM". Energy Policy, 285-288.

Gellings, C., \& Chamberlin, J. (1993). Demand-side management: Concepts \& Methods. The Fairmont Press, Inc.

Gillingham, K., Newell, R., \& Palmer, K. (2004). Retrospective Examination of Demand-Side Energy Efficiency Policies. Resources for the Future, Discussion Paper 04-19. Washington, DC.

Gonçalves, A. (2015). EDP Disputa em Novembro financiamento para novos contadores. Retrieved August 28, 2015, from economico: http://economico.sapo.pt/noticias/edp-disputa-em-novembro-financiamentopara-novos-contadores_219896.html

Gonçalves, J. A., Vitorino, R. M., Neves, L. M., \& Martins, A. G. (2013). Assessment of best location of distribution storage using improved genetic algorithms. Energy for Sustainability 2013 - Sustainable Cities: Designing for People and the Planet panel.

Gonçalves, J., Neves, L., \& Martins, A. (2015). Multiobjective assessment of distributed energy storage location in electricity networks. International Journal of Sustainable Energy.

Gorria, C., Jimeno, J., Laresgoiti, I., Lezaun, M., \& Ruiz, N. (2013). Forecasting flexibility in electricity demand with price/consumption volume signals. Electric Power Systems Research 95, 200-205. 
Gottwalt, S., Ketter, W., Block, C., Collins, J., \& Weinhardt, C. (2011). Demand side management-A simulation of household behavior under variable prices. Energy Policy 39, 8163-8174.

Grandjean, A., Adnot, J., \& Binet, G. (2012). A review and an analysis of the residential electric load curve models. Renewable and Sustainable Energy Reviews 16, 6539-6565.

Gudi, N., Wang, L., Devabhaktuni, V., \& Depuru, S. S. (2010). Demand response simulation implementing heuristic optimization for home energy management. Design, 3390.

Guo, Y., Li, J., \& James, G. (2005). Evolutionary optimization of distributed energy resources. Advances in Artificial Intelligence. 18th Australian Joint Conference on Artificial Intelligence.

Guo, Y., Zeman, A., \& Li, R. (2009). Utility Simulation Tool For Automated Energy Demand Side Management. Energy Network, 37-44.

Gyamfi, S., \& Krumdieck, S. (2012). Scenario analysis of residential demand response at network peak periods. Electric Power Systems Research 93, 32-38.

Hippert, H. S., Pedreira, C. E., \& Souza, C. R. (February, 2001). Neural Networls for Short-Term Load Forecasting: A Review and Evaluation. IEEE Transactions on Power Systems, 1, 44-55.

IEA. (2011). Smart Grids - Technology Roadmap. Paris, France: OECD/IEA.

Imprensa Nacional da Casa da Moeda. (2005). Revisão do: Regulamento de Relações Comerciais, do Regulamento Tarifário e do Regulamento do Acesso às Redes e às Interligações do sector elétrico. Diário da República, Il série, n. $^{\circ} 167$ de 31 agosto, 12756-(2) to 12756-(154).

Imprensa Nacional da Casa da Moeda. (2012). Diretiva (extrato) n. ${ }^{\circ}$ 2/2012 - Guia de medição, Leitura e Disponibilização de dados para Portugal Continental. Diário da República, $2^{a}$ série, $n .^{\circ} 5$ - 6 janeiro, Parte E, 544-546.

INE. (2001). Inquérito à ocupação do tempo (IOT) - Principais Resultados 1999. ISSN 1645-1961: INE. 
INE, I.P., \& DGEG. (2011). Inquérito ao consumo de energia no sector doméstico. Lisbon, Portugal: INE.

Jamasb, T., \& Pollitt, M. (2011). The Future of Electricity Demand- Customers, Citizens and Loads. Cambridge University Press.

Karnouskos, S., \& de Holanda, T. N. (2009). Simulation of a smart grid city with software agents. Third UKSim European Symposium on Computer Modeling and Simulation EMS '09 . 25-27 Nov. 2009.

Kempton, W., \& Tomic, J. (2005). Vehicle-to-grid power implementation: From stabilizing the grid to supporting large-scale renewable energy. Journal of Power Sources, 144, 280-294.

Kockar, I., Davidson, E., Ault, G., \& Dolan, M. (2010). Distributed Generation access and power flow management. Minneapolis, MN: General Meeting IEEE.

Kohonen, T. (1998). The self-organizing map. Neurocomputing, 21, 1-6.

Kostková, K., Omelina, L., Kyčina, P., \& Jamrich, P. (2013). An introduction to load management. Electric Power Systems Research (95), 184-191.

Livengood, D. J. (2011). The Energy Box: Comparing Locally Automated Control Strategies of Residential Electricity Consumption under Uncertainty. Massachussets, USA: Massachussets Institute of Technology.

Livengood, D., \& Larson, R. (2009). The Energy Box: Locally Automated Optimal Control of Residential Electricity Usage. Engineering Systems Division, Massachusetts Institute of Technology, pp. pp. 1-16.

Lopes, M., Antunes, C., \& Martins, N. (2012). Energy behaviours as promoters of energy efficiency: A 21st century review. Elsevier, Renewable and Sustainable Energy Reviews 16, 4095-4104.

Lopes, M., Peixoto, P., Antunes, C., \& Martins, N. (2014). Facilitanting energy behaviours transistion to more sustainable patterns: findings from a case study. Proc. of BEHAVE2014 - Behaviour and Energy Efficiency Conference. Oxford, UK. 
McKinsey \& Company. (2009). Unlocking Energy Efficiency in the US Economy. USA: McKinsey \& Company.

Mert, W. (2008). Consumer acceptance of smart appliances - D5.5 of WP5 report from Smart-A project. Report prespared as part of the EIE project "Smart Domestic Appliances in Sustainable Energy Systems (Smart-A)".

Miguel, P., Neves, L., \& Martins, A. (2014). Methodology to simulate the impact of a large deployment of a residential energy management system in the electricity grid. (Elsevier, Ed.) Electric Power Systems Research, 116, 399407.

Miguel, P., Neves, L., \& Martins, A. (2015). Demand response: a buzzword or a sustainability driver? European Council for an energy efficient economy Summer Study on energy efficiency, (pp. 727-738). Toulon/Hyères, France.

Miguel, P., Neves, L., Martins, A., \& Sousa, J. (2013). Review of load research studies applied to the Portuguese household sector. 7th International Conference on Energy Efficiency in Domestic Appliances and Lighting. (EEDAL'13). Coimbra.

Molderink, A., Bakker, V., Bosman, M. G., Hurink, J. L., \& Smit, G. J. (2010). Management and control of domestic smart grid technology. IEEE Transactions on Smart Grid, 1, Issue 2, 109-119.

Monteiro, P. L. (2013). Energy Efficiency in Inovcity Évora. 7th International Conference on Energy Efficiency in Domestic Appliances and Lighting (EEDAL2013). Coimbra.

Mooi, E., \& Sarstedt, M. (2011). A Concise Guide to Market Research. Berlin, Heidelberg, Alemanha: Springer Berlin Heidelberg.

Nadel, S., \& Geuer, H. (1996). Utility DSM what have we learned? Where are we going? Energy Policy 24 (4), 289-302.

Nunes, P. d. (October-December de 2011). Automatic Meter Reading Systems as a Precondition for Enhancing Energy Efficiency and Increasing Competion in the Energy Sector. Energia e Futuro, pp. 43-50. 
OMIP. (2013). The Iberian Energy Derivatives Exchange. Retrieved June 16, 2013, from http://www.omip.pt/Downloads/tabid/104/language/ptPT/Default.aspx

Park, S., Kim, H., Moon, H., Heo, J., \& Yoon, S. (August, 2010). Concurrent simulation platform for energy-aware smart metering systems. IEEE Transactions on Consumer Electronics, 56, 1918-1926.

PNNL. (2010). The Smart Grid: An Estimation of the Energy and CO2 Benefits. Washington, USA: PNNL.

PORDATA. (2013). Base de Dados Portugal Contemporâneo. Retrieved July 16, 2013, from http://www.pordata.pt/

Quercus - Associação Nacional de Conservação da Natureza. (2007). Programa Ecofamilias - Relatório Final. Quercus.

REMODECE. (2008). Residential Monitoring to decrease Energy Use and Carbon Emission in Europe. Intelligent Energy Europe and FCT POCI/V.5/B106/2005.

Renner, S., Albu, M., van Elburg, H., Heinemann, C., Laziki, C., Pentinen, L., et al. (2011). Smart Regions Delicerable 2.1 European Smart Metering Landscape Report. Vienna: Smart Regions.

Ribeiro, M. G. (2012). Redes Inteligentes e o Conceito Energy Box - Simulação do impacto do deslocamento de cargas no sector residencial, em Portugal. University of Coimbra: MSc Thesis.

Roe, C., Meliopoulos, S., Entriken, R., \& Chhaya, S. (2011). Simulated demand response of a residential energy management system. Energytech. Cleveland, USA.

Roscoe, A. J., \& Ault, G. (2010). Supporting high penetrations of renewable generation via implementation of real-time electricity pricing and demand response. IET Renewable Power Generation, 4, 369-382.

Sá, J. L. (December de 2011). Um périplo pelos roteiros alternativos nas Smartgrids. Energia e Futuro. 
Salvador, S., \& Chan, P. (Nov. 2004). Determining the number of Clusters/Segments in Hierarchical Clustering/Segmentation Algorithms. Tools with Artificial Intelligence, 2004. ICTAI 2004. 16th IEEE International Conference, (pp. 576 - 584).

Santos, P., Martins, A., Pires, A., Martins, J., \& Mendes, R. (2006). Short-term load forecast using trend information and process reconstruction. International Journal of Energy Research, 30(10), 811-822.

Schweppe, F., Daryanian, B., \& Tabors, R. (1989). Algorithms for a Spot Price Responding Residential Load Controller. IEEE Transactions on Power Systems, 507-516.

Schweppe, F., Tabors, R., Kirtley, J., Outhred, H., Pickel, F., \& Cox, A. (1980). Homeostatic Utility Control. IEEE Transactions on Power Apparatus and Systems, 1151-1159.

SELINA. (2010). Standby and Off-Mode Energy Losses in New Appliances Measured in Shops. IEE/07/563/S12.499206: ISBN 978-972-8822-21-7.

Seryak, J., \& Kissock, K. (2003). Occupancy and behavioral affects on residential energy. Solar Conference. Austin, Texas.

Siano, P. (2014). Demand response and smart grids-A survey. Renewable and Sustainable Energy Reviews 30, 461-478.

Sidler, O. (1998). ECODROME - Rapport Final - Etude Expérimentale des Appareils électroménagers à haute efficacité énergétique placés en situation réelle. Programme Save Contrat n. ${ }^{\circ} 4.1031 / \mathrm{s} / 94-093$ : Enertech.

Simchak, T., \& Ungar, L. (2011). Realizing the Energy Efficiency Potential of Smart Grid. USA: Alliance to Save Energy - Creating an Energy-Efficient World.

Simões, J. B. (2008). A telecontagem como elemento catalisador de uma maior eficiência energética. Colégio de Engenharia Eletrotécnica - Ordem dos Engenheiros (Região Centro). Coimbra. 
Smart Grid Australia. (2010). Smart Grid Australia - Submission to Prime Minister's Task Group on Energy Efficiency. Australia: www.smartgridaustralia.com.au.

smartgridnews.com. (18 de January de 2010). www.smartgridnews.com. Obtido em 17 de April de 2012, de http://www.smartgridnews.com/artman/publish/Business_Smart_Grid_101/T he-Barriers-to-a-Smart-Grid-1770.html

Soares, A. R. (2011). Dissertação de Mestrado em Energia Para a Sustentabilidade, Gestão Integrada de Recursos Energéticos Contextualização e Análise. Universidade de Coimbra.

Sousa, J. C., Jorge, H. M., \& Neves, L. M. (2011). Forecasting the next day load profile using load profiling information and meteorological variables. Proceedings of the 2011 3rd International Youth Conference on Energetics (IYCE). Leiria, Portugal.

Sousa, J. C., Jorge, H. M., \& Neves, L. P. (2013). Short-Therm Load Forecasting Based on Support Vector Regression and Load Profiling. International Journal of Energy Research, doi:10.1002/er.3048.

Sousa, J. C., Neves, L. M., \& Jorge, H. M. (2009). Integrating information available from load profiling in electric load forecasting. Coimbra: No.17, INESCCoimbra.

Sousa, J. C., Neves, L. M., \& Jorge, H. M. (2009). Short-term load forecasting using information obtained from low voltage load profiles. International Conference on Power Engineering, Energy and Electrical Drives. Lisbon.

Sousa, J. M. (2006). Metodologia para determinação de perfis de consumidores de Baixa Tensão. Coimbra: Faculdade de Ciências e Tecnologia da Universidade de Coimbra.

Stamminger, R. (2008). Synergy Potential of Smart Appliances (D2.3 of WP2 from the Smart-A project). Report prepared as part of the EIE project, "Smart Domestic Appliances in Sustainable Energy Systems (Smart-A)". 
Stromback, J., Dromacque, C., \& Yassin, M. (2011). The potential of smart meter enabled programs to increase energy and systems efficiency: a mass pilot comparisson. Helsinki, Finland: Vaasaaett.

Swan, L. G., \& Ugursal, V. I. (2009). Modeling of end-use energy consumption in the residential sector: A review of modeling techniques. Elsevier Renewable and Sustainable Energy Reviews, 1819-1835.

Teng, R., \& Yamazaki, T. (2010). Bit-Watt Home System with Power Supply. National Institute of Information and Communication Technology. Kyoto, Japan.

The Comission of the European Communities. (2008). Commission Regulation no 1275/2008, implementing Directive 2005/32/EC of the EU Parliament and of the Council with regard to ecodesign requirements for standby and off mode electric consumption of electrical and electronic household and office equipment. Official Journal of the European Union, L339/45-L339/52 (EN).

UCTE. (2007). Final Report - System Disturbance on 4 November 2006.

Wilson, B., Rassenti, S. J., \& Smith, V. L. (2003). Controlling market power and price spikes in electricity networks, demand-side bidding. Proceedings of the National Academy of Sciences.

WMO. (2014). WMO - Greenhouse Gas Bulletin - The State of Greenhouse Gases in the Atmosphere Based on Global Observations through 2013. World Meteorological Organization.

World Energy Council. (2013). World Energy Resources - 2013 Survey. England and Wales: World Energy Council.

Zeilinger, F. (2011). Simulation of the Effect of Demand Side Management to the Power Consumption of Households. 3rd International Youth Conference on Energetics 2011. Leiria. 
